ERNEST

BERKELEY NATIONAL LABURATURY $2 \because \because$

\title{
Guidelines for the Monitoring, Evaluation, Reporting, Verification, and Certification of Forestry Projects for Climate Change Mitigation
}

Edward Vine, Jayant Sathaye, and Willy Makundi

Environmental Energy Technologies Division

March 1999

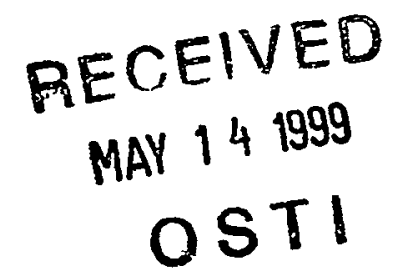




\section{DISCLAIMER}

This document was prepared as an account of work sponsored by the United States Government. While this document is believed to contain correct information, neither the United States Government nor any agency thereof, nor The Regents of the University of California, nor any of their employees, makes any warranty, express or implied, or assumes any legal responsibility for the accuracy, completeness, or usefulness of any information, apparatus, product, or process disclosed, or represents that its use would not infringe privately owned rights. Reference herein to any specific commercial product, process, or service by its trade name, trademark, manufacturer, or otherwise, does not necessarily constitute or imply its endorsement, recommendation, or favoring by the United States Government or any agency thereof, or The Regents of the University of California. The views and opinions of authors expressed herein do not necessarily state or reflect those of the United States Government or any agency thereof, or The Regents of the University of California.

This report has been reproduced directly from the best available copy.

Available to DOE and DOE Contractors

from the Office of Scientific and Technical Information

P.O. Box 62, Oak Ridge, TN 37831

Prices available from (615) 576-8401

Available to the public from the National Technical Information Service

U.S. Department of Commerce

5285 Port Royal Road, Springfield, VA 22161

Ernest Orlando Lawrence Berkeley National Laboratory is an equal opportunity employer. 


\section{DISCLAIMER}

Portions of this document may be illegible in electronic image products. Images are produced from the best available original document. 
LBNL-41877

\title{
GUIDELINES FOR
}

\section{THE MONITORING, EVALUATION, REPORTING, VERIFICATION, AND CERTIFICATION OF FORESTRY PROJECTS FOR CLIMATE CHANGE MITIGATION}

\author{
Edward Vine, Jayant Sathaye, and Willy Makundi \\ Energy Analysis Department \\ Environmental Energy Technologies Division \\ Lawrence Berkeley National Laboratory \\ Berkeley, CA 94720 USA
}

\begin{abstract}
March 1999
Prepared for the U.S. Environmental Protection Agency

Climate Policy and Program Division

Office of Economics and Environment

Office of Policy, Planning and Evaluation
\end{abstract}

Maurice LeFranc, Project Manager

This work was supported by the U.S. Environmental Protection Agency through the U.S. Department of Energy under Contract No. DE-AC03-76SF00098 


\section{PREFACE}

To combat the growing threat of global climate change from increasing concentrations of greenhouse gases in the atmosphere, the Kyoto Protocol includes project-based mitigation efforts to achieve large-scale and cost-effective emissions reductions. The Protocol requires real and measurable reductions in emissions that are additional to any that would occur in the absence of a certified project activity. Monitoring, evaluation, reporting, verification and certification of these projects are activities that the U.S. Environmental Protection Agency (EPA) sees as important.

EPA has initiated a three-phase process in developing usable guidelines on monitoring, evaluation, reporting, verification and certification (MERVC). In the first phase, an overview of MERVC issues was prepared (E. Vine and J. Sathaye. 1997. The Monitoring, Evaluation, Reporting, and Verification of Climate Change Mitigation Projects: Discussion of Issues and Methodologies and Review of Existing Protocols and Guidelines. LBNL-40316. Berkeley, CA: Lawrence Berkeley National Laboratory). The guidelines presented in this report constitute the second phase of work. The third phase will be a procedural handbook that describes the information and requirements for specific measurement and evaluation methods that can be employed for measuring carbon sequestration.

The intent of these reports is to provide initial methodologies that will support the measurement of greenhouse gas removals from project-level activities. These methodologies will also assist project developers in preparing and implementing monitoring, evaluation, and verification plans that can lead to better estimates of carbon stock as well as improve the projects themselves, making them more attractive to investors, the private sector, and local communities.

These guidelines have been reviewed by project developers (working on projects in Russia, Eastern Europe, Africa and Latin America) as well as experts in the monitoring and evaluation of forestry projects. The practitioners reviewed the report for accuracy and assessed whether data were available for completing the forms presented at the end of this report. Based on their feedback, we believe these guidelines and related forms can be used by project developers, evaluators, and verifiers.

These guidelines can also be used by anyone involved with the design and development of joint implementation and Clean Development Mechanism projects, such as: forest management companies, development banks, finance firms, consultants, government agency employees and contractors, city and municipal managers, researchers, and nonprofit organizations. National and international entities can also use these guidelines and forms as a model for developing official MERVC-type guidelines.

Maurice LeFranc

U.S. Environmental Protection Agency 
This page is intentionally left blank. 


\begin{abstract}
Because of concerns with the growing threat of global climate change from increasing concentrations of greenhouse gases in the atmosphere, the United States and other countries are implementing, by themselves or in cooperation with one or more other nations, climate change mitigation projects. These projects will reduce greenhouse gas (GHG) emissions or sequester carbon, and may also result in non-GHG benefits and costs (i.e., other environmental and socioeconomic benefits and costs).

Monitoring, evaluating, reporting, verifying, and certifying (MERVC) guidelines are needed for these projects in order to accurately determine their impact on GHG and other attributes. Implementation of standardized guidelines is also intended to: (1) increase the reliability of data for estimating GHG benefits; (2) provide real-time data so that programs and plans can be revised mid-course; (3) introduce consistency and transparency across project types and reporters; (4) enhance the credibility of the projects with stakeholders; (5) reduce costs by providing an international, industry consensus approach and methodologies; and (6) reduce financing costs, allowing project bundling and pooled project financing.
\end{abstract}

These guidelines cover the following items: (1) a description of three methods (modeling, remote sensing, and field/site measurement) for evaluating changes in the carbon stock; (2) an explanation of key issues influencing the establishment of a credible baseline (free riders) and the calculation of changes to the carbon stock (project leakage, positive project spillover, and market transformation); (3) a process for verifying and certifying project impacts, based on an interpretation of the Kyoto Protocol; (4) a discussion of the importance and value of including environmental and socioeconomic impacts in the evaluation of forestry projects; (5) reporting forms for estimation of changes in carbon stock (Appendix A), for monitoring and evaluation of these changes (Appendix B), and for verification (Appendix C); and (6) Quality Assurance Guidelines that require evaluators and verifiers to indicate specifically how key methodological issues are addressed.

The next phase of this work will be to develop a procedural handbook providing information on how one can complete the monitoring, evaluation and verification forms contained in this report. Next, we plan to test the usefulness of these guidelines in the real world. 
This page is intentionally left blank. 


\section{TABLE OF CONTENTS}

List of Tables and Figures................................................................................................. vii

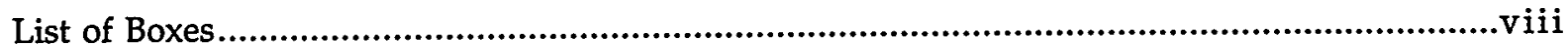

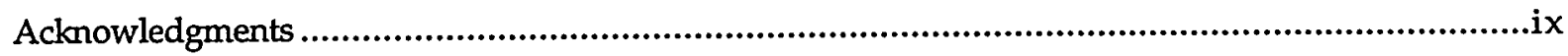

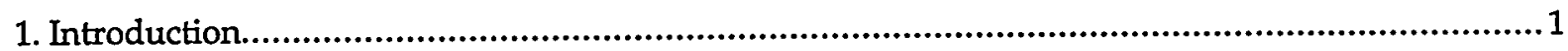

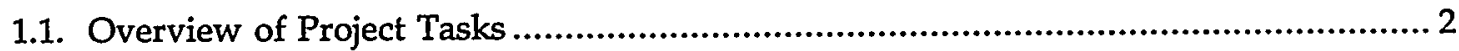

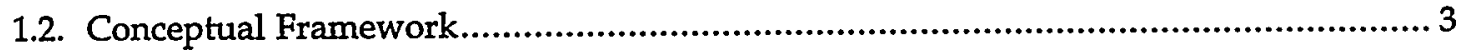

1.3. Purpose of MERVC Guidelines........................................................................ 5

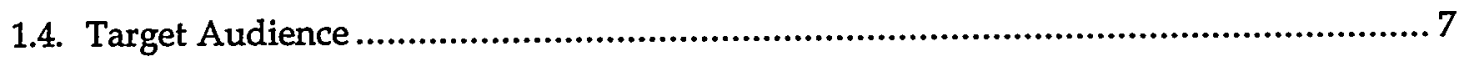

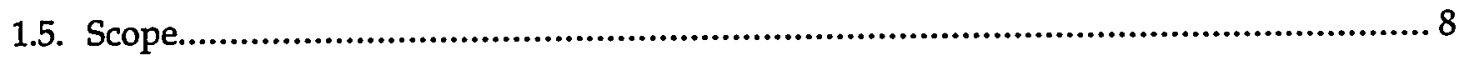

1.6. Relationship to Other Programs/Documents......................................................9

1.6.1. World Bank's monitoring and evaluation guidelines....................................9

1.6.2. Winrock's carbon monitoring guidelines.......................................................10

1.6.3. SGS Forestry's Carbon Offset Verification Service......................................10

1.6.4. USIJI's Project Proposal Guidelines ............................................................10

1.6.5. DOE's Voluntary Reporting of Greenhouse Gases .........................................11

1.6.6. Face Foundation.................................................................................11

1.6.7. Forest Stewardship Council's Principles and Criteria for Forest Management.11

1.6.8. University of Edinburgh's provisional guidelines and standards....................11

2. Carbon Pools and Forestry Projects...................................................................................13

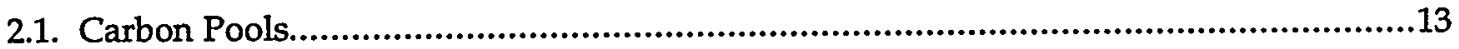

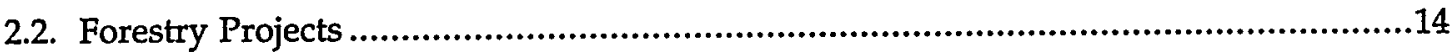

2.3. Biomass Energy Plantations...............................................................................16

2.4. Unique Features of Carbon Pools and Forestry Projects .........................................16

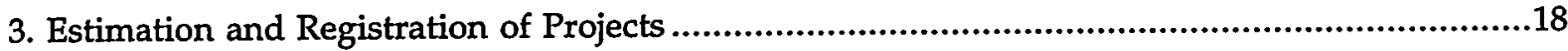

3.1. Estimating Gross Changes in Carbon Stock .......................................................19

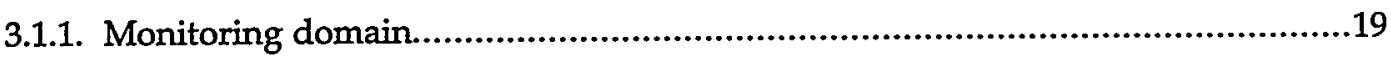

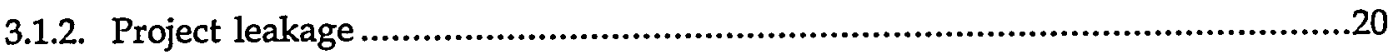

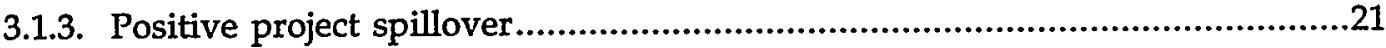

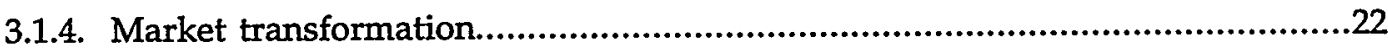

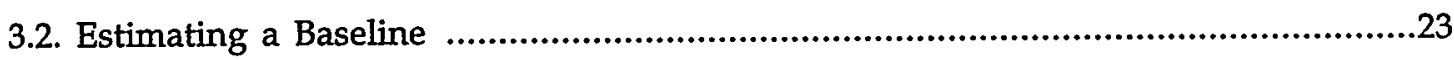

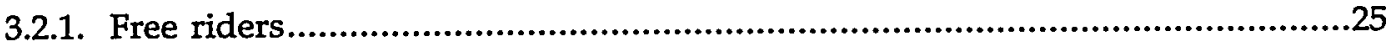

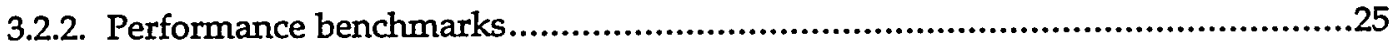


4. Monitoring and Evaluation of Changes in Carbon Stock................................................27

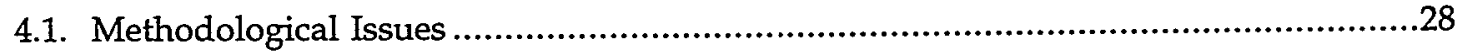

4.1.1. Measurement uncertainty .....................................................................29

4.1.2. Frequency and duration of monitoring and evaluation .................................30

4.2. Measurement of Gross Changes in Carbon Stock .................................................32

4.2.1. Establishing the monitoring domain .......................................................33

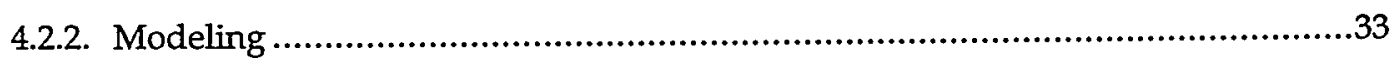

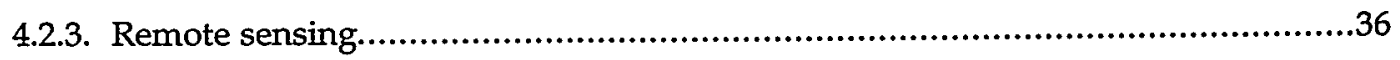

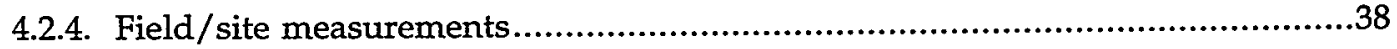

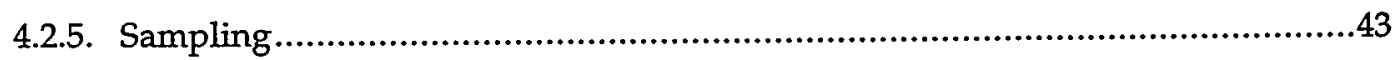

4.2.6. Application of forestry monitoring methods.............................................44

4.2.7. Quality assurance guidelines ...............................................................47

4.2.8. Project leakage and positive project spillover............................................50

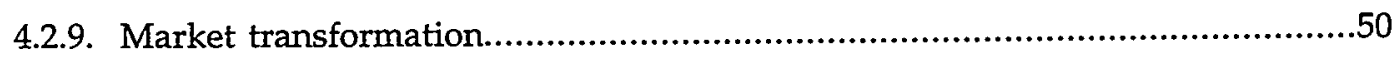

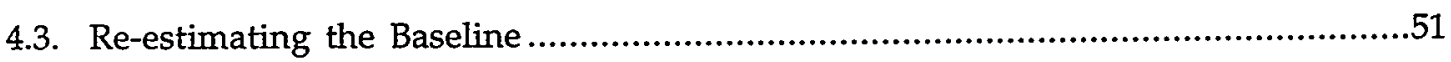

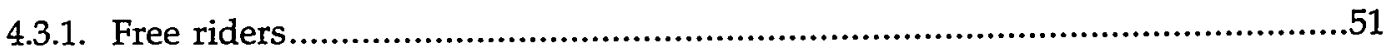

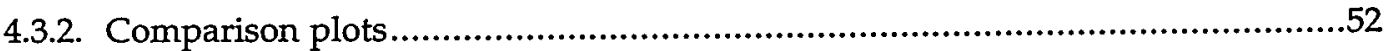

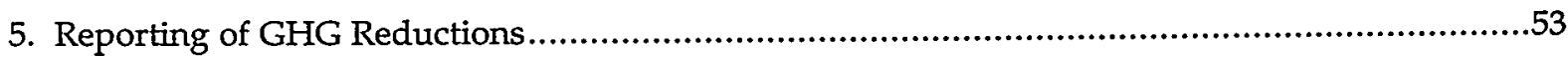

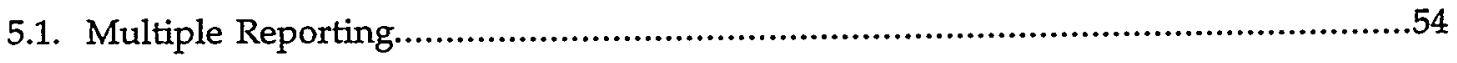

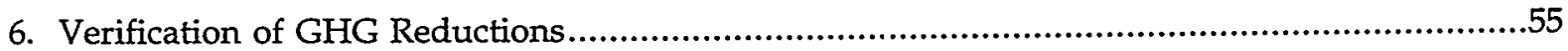

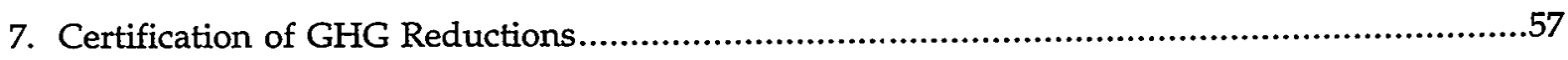

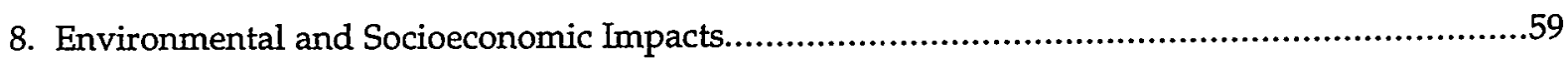

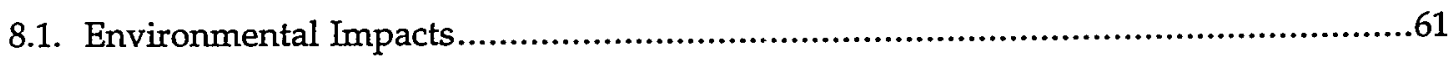

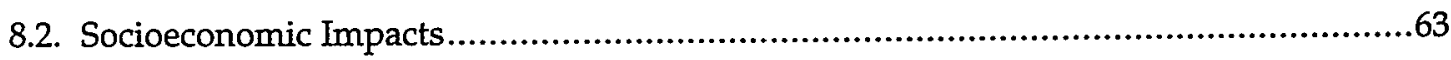

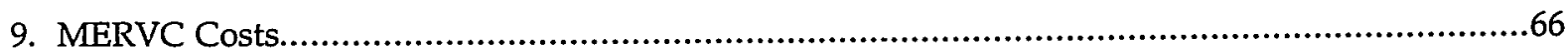

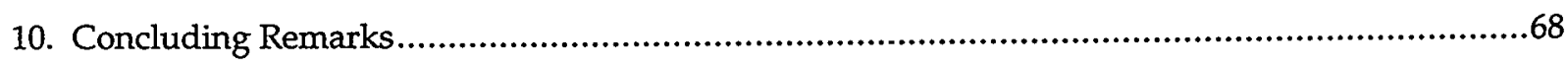

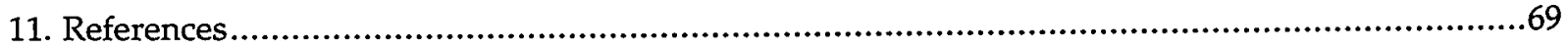

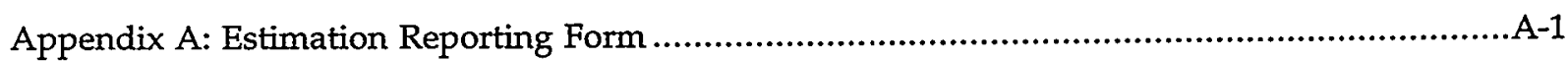

Appendix B: Monitoring and Evaluation Reporting Form ....................................................

Appendix C: Verification Reporting Form ................................................................... 


\section{LIST OF TABLES AND FIGURES}

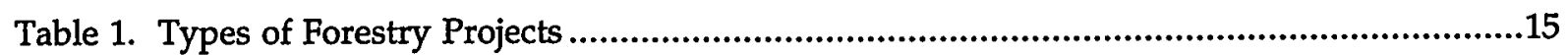

Table 2. Advantages and Disadvantages of Forestry Monitoring Techniques ............................46

Table 3. Forestry Monitoring Methods by Forestry Project Type.............................................47

Table 4. Quality Assurance Issues for Data Collection and Analysis Methods..........................49

Table 5. Potential Environmental Impacts.................................................................62

Table 6. Potential Socioeconomic Impacts..................................................................65

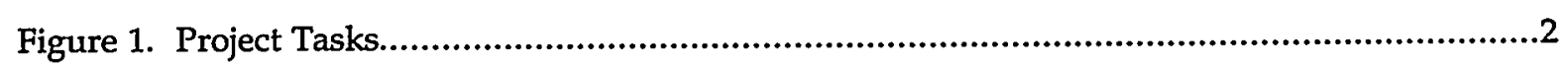

Figure 2. Example of Carbon Storage Over Time ...............................................................4

Figure 3. Forest System Carbon Cycle...................................................................... 13

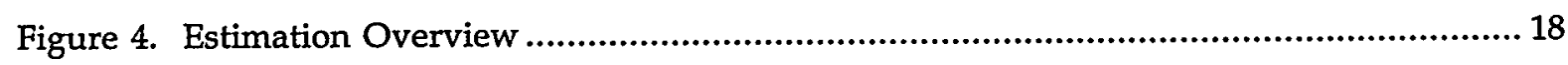

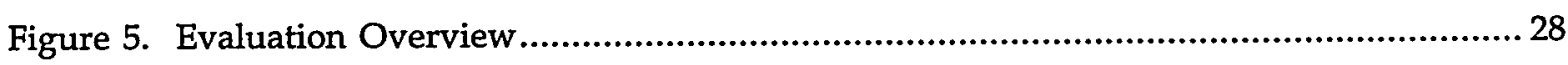




\section{LIST OF BOXES}

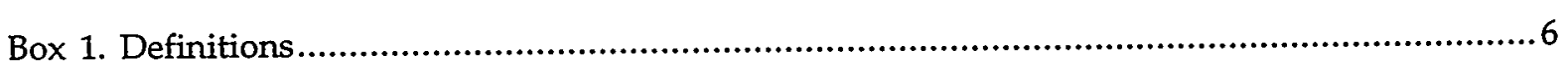

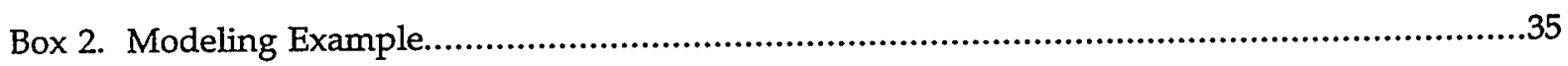

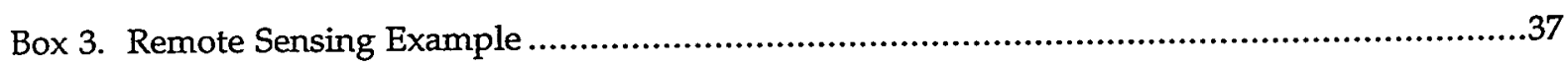

Box 4. Field/Site Measurement Example........................................................................39

Box 5. Items to Monitor under the Biodiversity Convention................................................60

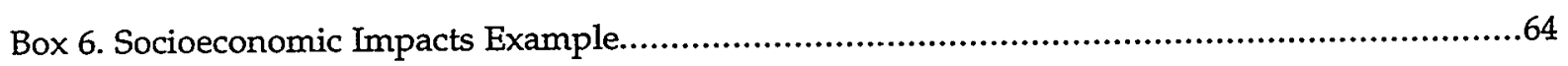




\section{Acknowledgments}

We would like to thank Maurice N. LeFranc, Jr. of the U.S. Environmental Protection Agency, Climate Policy and Program Division, Office of Economics and Environment, Office of Policy, Planning and Evaluation for their assistance. We also appreciate the comments by reviewers of an earlier draft of this report: Neil Bird, Paige Brown, Sandra Brown, Margo Burnham, Johannes Heister, Robert Hrubes, Axel Michaelowa, Pedro Moura-Costa, Neil Samson, Bill Stanley, Marc Stuart, Richard Tipper, and Ted Vinson. This work was supported by the U.S. Environmental Protection Agency through the U.S. Department of Energy under Contract No. DE-AC03-76SF00098. 
This page is intentionally left blank. 


\section{Introduction}

Because of concerns with the growing threat of global climate change from increasing concentrations of greenhouse gases in the atmosphere, more than 176 countries (as of Oct. 7, 1998) have become Parties to the U.N. Framework Convention on Climate Change (FCCC) (UNEP/WMO 1992). The FCCC was entered into force on March 21, 1994, and the Parties to the FCCC adopted the Kyoto Protocol for continuing the implementation of the FCCC in December 1997 (UNFCCC 1997). The Protocol requires developed countries to reduce their aggregate emissions by at least $5.2 \%$ below 1990 levels by the 2008-2012 time period.

The Kyoto Protocol requires Annex I (developed) countries to report anthropogenic emissions by sources, and removals by sinks, of greenhouse gases at the national level (Article 5). ${ }^{1}$ For example, countries would have to set national systems for estimating emissions accurately, achieving compliance with emissions targets, and ensuring enforcement for meeting emissions targets. Annual reports on measurement, compliance and enforcement efforts at the national level would be required and made available to the public.

The Kyoto Protocol includes two project-based mechanisms for activities across countries. Article 6 of the Protocol allows for joint implementation projects between Annex I countries: i.e., project-level trading of emissions reductions ("transferable emission reduction units") can occur among countries with GHG emission reduction commitments under the Protocol. Article 12 of the Protocol provides for a "Clean Development Mechanism" (CDM) that allows legal entities in the developed world to enter into cooperative projects to reduce emissions in the developing world for the benefit of both parties. Developed countries will be able to use "certified emissions reductions" from project activities in developing countries to contribute to their compliance with GHG targets. Projects undertaken by developed countries will not only reduce greenhouse gas (GHG) emissions or sequester carbon, but may also result in non-GHG benefits and costs (i.e., other environmental and socioeconomic benefits and costs). The key provisions of the Kyoto Protocol remain to be developed in more detail as negotiations clarify the existing text of the Protocol. ${ }^{2}$

1 GHG sources include emissions from fossil fuel combustion, industry, decomposing and oxidized biomass, soil carbon loss, and methane from agricultural activities, livestock, landfills and anaerobic decomposition of phytomass. GHG sinks include storage in the atmosphere, ocean uptake, and uptake by growing vegetation (IPCC 1996; Andrasko et al. 1996).

2 While this report focuses on the Kyoto Protocol, it should also be useful for projects undertaken before the Protocol goes into effect: e.g., in the U.S., the President's Climate Change Proposal contains a program that rewards organizations, by providing credits or incentives (e.g., a credit against a company's emissions or a tax credit), for taking early actions to reduce greenhouse gases 


\subsection{Overview of Project Tasks}

Forestry projects to be undertaken within the Clean Development Mechanism or under joint implementation will likely involve several tasks (Fig. 1.). The guidelines contained in this report are primarily targeted to the tasks that occur during the implementation of a project (see section numbers in Fig. 1). The project design and development phase will incorporate many of the information needs required for completing the later tasks (see Section 3). We expect that there will be different types of arrangements for implementing these projects: e.g., (1) a project developer might implement the project with his/her own money; (2) a developer might borrow money from a financial institution to implement the project; (3) a developer might work with a third party who would be responsible for many project activities; etc. While the flow of funds might change as a result of these different arrangements, the guidelines presented in this report should be relevant to all parties, independent of the arrangement.

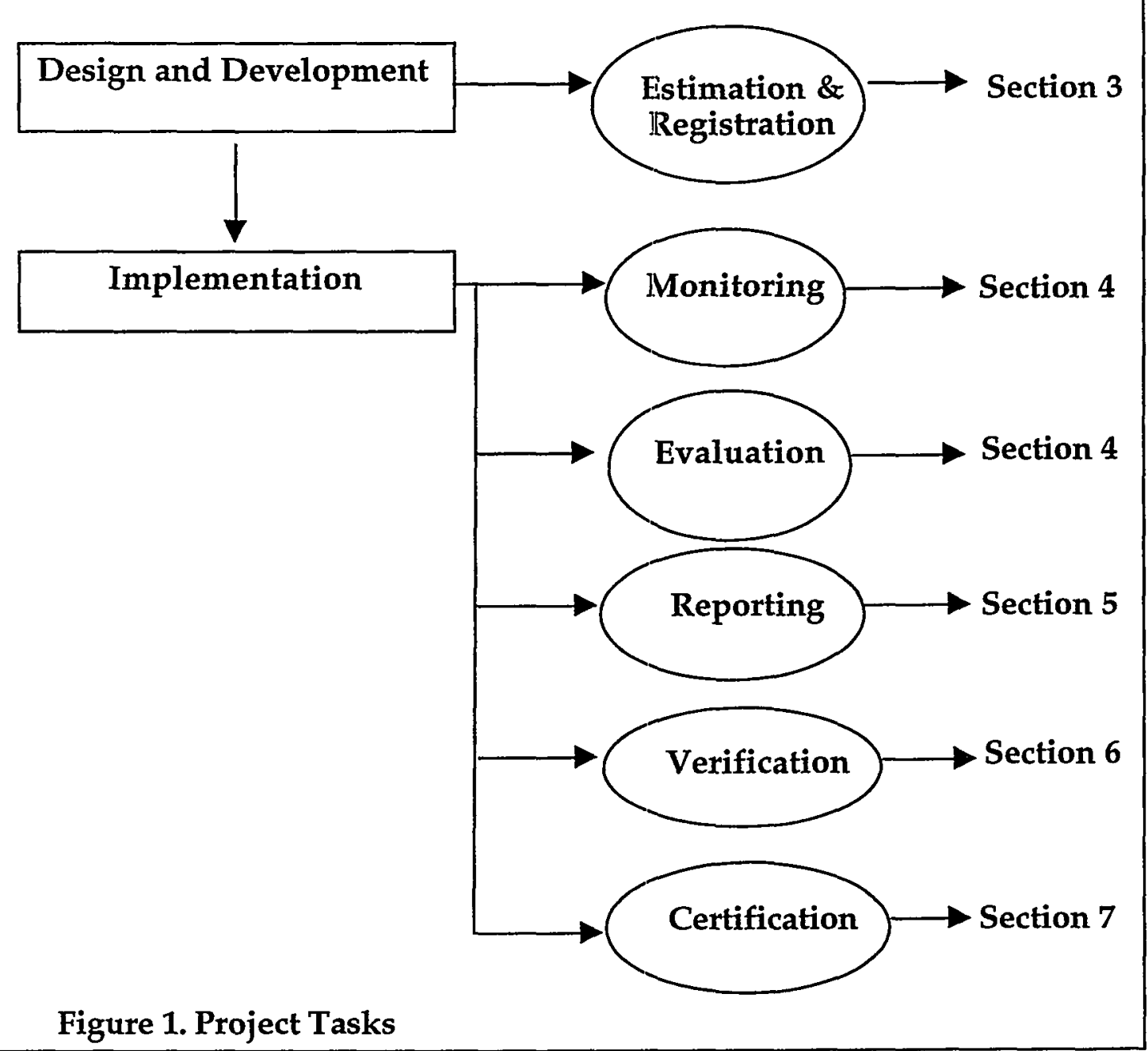

before the international agreements from the Kyoto Protocol would take effect. The proposal is now commonly referred to as a "credit for early action" program (USGAO 1998). 
In Figure 1, we differentiate "registration" from "certification" (see Section 7). Certification refers to certifying whether the measured GHG reductions actually occurred. This definition reflects the language in the Kyoto Protocol regarding the Clean Development Mechanism and "certified emission reductions." In contrast, when a host country approves a project for implementation, the project is "registered" (see UNFCCC 1998b). ${ }^{1}$ For a project to be approved, each country will rely on project approval criteria that they developed: e.g., (1) the project funding sources must be additional to traditional project development funding source; (2) the project must be consistent with the host country's national priorities (including sustainable development); (3) confirmation of local stakeholder involvement; (4) confirmation that adequate local capacity exists or will be developed; (5) potential for long-term climate change mitigation; (6) baseline and project scenarios; and (7) the inclusion of a monitoring protocol (see Watt et al. 1995).

A country may also use different administrative or legal requirements for registering projects. For example, the project proposal (containing construction and operation plans, proposed monitoring and evaluation of carbon sequestration, and estimated carbon sequestration) might have to be reviewed and assessed by independent reviewers (see Section 3). ${ }^{2}$ After this initial review, the project participants would have an opportunity to make adjustments to the project design and make appropriate adjustments to the expected carbon sequestration. The reviewers would then approve the project, and the project would be registered. ${ }^{3}$ Individuals or organizations voicing concerns about the project would have an opportunity to appeal the approval of the project, if desired.

\subsection{Conceptual Framework}

The analysis of changes in carbon stock occurs when a project is being designed and during the implementation of a forestry project. In the design stage, the first step is estimating the baseline (i.e., what would have happened to the carbon stock if the project had not been implemented) (see Section 3.2) and the project impacts. Once these have been estimated, then the net change in carbon stock is simply the difference between the estimated project impacts and the baseline ( $\mathrm{P}-\mathrm{B}$, in Fig.

1 In contrast to our interpretation, others believe certification occurs at the project approval stage, prior to implementation. We disagree, since certification can only occur after carbon sequestration has been measured.

2 The term carbon sequestration describes the process of carbon uptake and storage. This refers to carbon dioxide uptake through photosynthesis and storage of carbon in vegetation, soils, and wood products.

3 Under this approach, the independent reviewers could be the same people who verify the project during project implementation (personal communication from Johannes Heister, The World Bank, Jan. 12, 1999). 
2). After a project has started to be implemented, the baseline can be re-estimated and the project impacts will be calculated based on monitoring and evaluation methods (Section 4). The net changes will be the difference between the measured project impacts and the re-estimated baseline $\left(\mathrm{P}^{\wedge}-\mathrm{B}^{\wedge}\right.$, in Fig. 2). The example in Fig. 2 illustrates a case where measured carbon storage is greater than estimated as a result of a forestry project. On the other hand, carbon storage in the re-estimated baseline is lower than what had been estimated at the project design stage. In this case, the calculated net change in carbon storage is larger than what was first estimated. It is also possible that either $\mathrm{P}^{\wedge}$ may be less than $\mathrm{P}$ and $\mathrm{B}^{\wedge}$ may be more than $\mathrm{B}$, or both might occur, making the net carbon storage less than estimated.

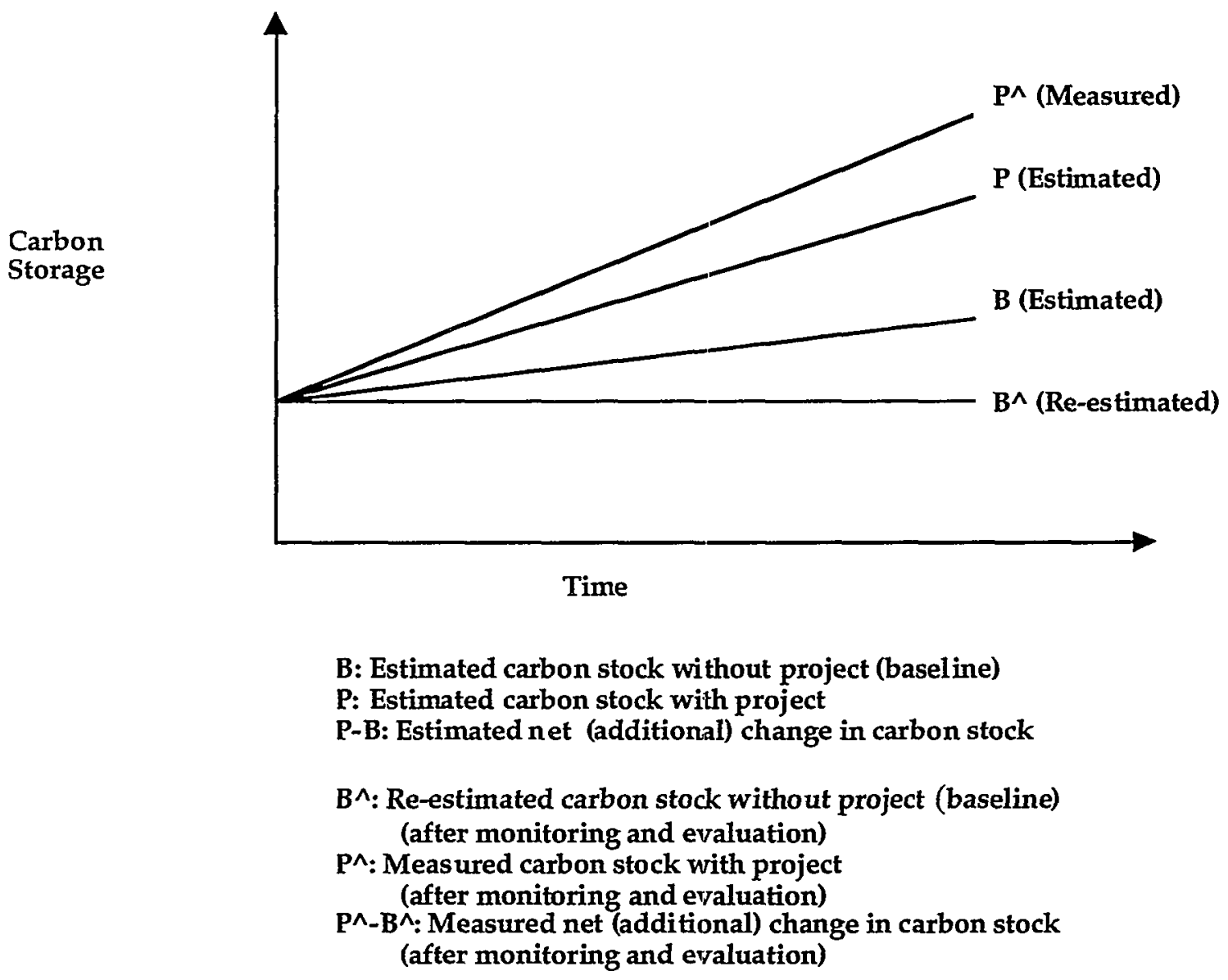

Figure 2. Example of Carbon Storage Over Time 


\subsection{Purpose of MERVC Guidelines}

Monitoring, evaluating, reporting, verifying, and certifying (MERVC) guidelines are needed for joint implementation and CDM projects in order to accurately determine their impact on GHG and other attributes (see Box 1) (Vine and Sathaye 1997). The estimation of project impacts is not the focus of the guidelines in this report; however, these guidelines do discuss many of the issues involved in estimation, since they are of utmost concern in the activities that occur after a project is implemented. Furthermore, the findings based on measurement and evaluation are often compared with the estimated impacts of a project.

Under joint implementation, the reduction in emissions by sources, or an enhancement of removals by sinks, must be "additional" to any that would otherwise occur, entailing project evaluation (Article 6) (see Section 3). And the "emission reduction units" from these projects can be used to meet Annex I Party's commitment under Article 3 of the Kyoto Protocol, necessitating all MERVC activities to be conducted. Similarly, under the Clean Development Mechanism, emission reductions must not only be additional, but certified, real and measurable, again requiring the performance of all MERVC activities (Article 12).

Implementation of standardized guidelines is intended to: (1) increase the reliability of data for estimating GHG impacts; (2) provide real-time data so programs and plans can be revised midcourse; (3) introduce consistency and transparency across project types, sectors, and reporters; (4) enhance the credibility of the projects with stakeholders; (5) reduce costs by providing an international, industry consensus approach and methodologies; and (6) reduce financing costs, allowing project bundling and pooled project financing.

These guidelines are important management tools for all parties involved in carbon mitigation in land-use sectors. There will be different approaches ("models") in how the monitoring, evaluation, reporting, verification, and certification of forestry projects will be conducted: e.g., a project developer might decide to conduct monitoring and evaluation, or might decide to contract out one or more of these functions. Verification and certification must be implemented by third parties (Article 12). Similarly, some projects might include a portfolio of projects. Despite the diversity of responsibilities and project types, the Lawrence Berkeley National Laboratory's (LBNL's) MERVC guidelines are designed to be relevant for all models and project approaches. 


\section{Box 1}

\section{Definitions}

Estimation: refers to making a judgement on the likely or approximate stock of carbon, GHG emissions, and socioeconomic and environmental benefits and costs in the with- and without-project (baseline) scenarios. Estimation can occur throughout the lifetime of the project, but plays a central role during the project design stage when the project proposal is being developed.

Monitoring: refers to the measurement of carbon stocks, GHG emissions, and socioeconomic and environmental benefits and costs that occur as a result of a project. Monitoring does not involve the calculation of GHG reductions nor does it involve comparisons with previous baseline measurements. For example, monitoring could involve the number of hectares preserved by a forestry project. The objectives of monitoring are to inform interested parties about the performance of a project, to adjust project development, to identify measures that can improve project quality, to make the project more cost-effective, to improve planning and measuring processes, and to be part of a learning process for all participants (De Jong et al. 1997). Monitoring is often conducted internally, by the project developers.

Evaluation: refers to both impact and process evaluations of a particular project, typically entailing a more in-depth and rigorous analysis of a project compared to monitoring emissions. Project evaluation usually involves comparisons requiring information from outside the project in time, area, or population (De Jong et al. 1997). The calculation of GHG reductions is conducted at this stage. Project evaluation would include GHG impacts and non-GHG impacts (i.e., environmental, economic, and social impacts), and the re-estimation of the baseline, leakage, positive project spillover, etc., which were estimated during the project design stage (see Section 3 ). Evaluation organizes and analyzes the information collected by the monitoring procedures, compares this information with information collected in other ways, and presents the resulting analysis of the overall performance of a project. Project evaluations will be used to determine the official level of GHG emissions reductions that should be assigned to the project. The focus of evaluation is on projects that have been implemented for a period of time, not on proposals (i.e., project development and assessment). While it is true that similar activities may be conducted during the project design stage (e.g., estimating a baseline, leakage, or spillover), this type of analysis is estimation and not the type of evaluation that is described in this report and which is based on the collection of data.

Reporting refers to measured GHG and non-GHG impacts of a project (in some cases, organizations may report on their estimated impacts, prior to project implementation, but this is not the focus of this paper). Reporting occurs throughout the MERVC process (e.g., periodic reporting of monitored results and a final report once the project has ended).

Verification refers to establishing whether the measured GHG reductions actually occurred, similar to an accounting audit performed by an objective, accredited party not directly involved with the project. Verification can occur without certification.

Certification refers to certifying whether the measured GHG reductions actually occurred. Certification is expected to be the outcome of a verification process. The value-added function of certification is in the transfer of liability/responsibility to the certifier. 
LBNL's MERVC guidelines will help project participants determine how effective their project has been in curbing GHG emissions, and they will help planners and policy makers in determining the potential impacts for different types of projects, and for improvements in project design and implementation. Finally, by providing a basis for more reliable sequestered carbon and a common approach to the measurement and evaluation of forestry projects, widespread adoption of the MERVC guidelines will make these projects more reliable and profitable.

In the longer term, MERVC guidelines will be a necessary element of any international carbon trading system, as proposed in the Kyoto Protocol. A country could generate carbon credits by implementing projects that result in a net reduction in emissions. The validation of such projects will require MERVC guidelines that are acceptable to all parties. These guidelines will lead to verified findings, conducted on an ex-post facto basis (i.e., actual as opposed to predicted (ex-ante) project performance).

LBNL's MERVC guidelines have been reviewed by project developers (working on projects in Russia, Eastern Europe, Africa and Latin America) as well as experts in the monitoring and evaluation of forestry projects. The practitioners reviewed the report for accuracy and assessed whether data were available for completing the forms presented at the end of this report. Based on their feedback, we believe LBNL's MERVC guidelines can be used by project developers, evaluators, and verifiers. We hope that international entities can also use our guidelines as a model for developing official MERVC-type guidelines.

\subsection{Target Audience}

These guidelines are primarily for developers, evaluators, verifiers, and certifiers of forestry projects. This document can also be used by anyone involved with the design and development of joint implementation and Clean Development Mechanism projects, such as: forest management companies, development banks, finance firms, consultants, government agency employees and contractors, city and municipal managers, researchers, and nonprofit organizations. 


\subsection{Scope}

LBNL's MERVC guidelines are targeted to forestry projects. ${ }^{1}$ The guidelines can be used for assessing the impacts for a single project, or for a group of projects (e.g., in a program, where there are many participants). These guidelines occupy an intermediate position between a previous report that provided an overview of MERVC issues (Vine and Sathaye 1997) and a procedural handbook that describes the information and requirements for specific measurement and evaluation methods that may be employed for measuring carbon sequestration.

LBNL's MERVC guidelines address several key issues, such as: (1) uncertainty and risk; (2) the frequency and duration of monitoring and evaluation; (3) methods for estimating gross and net changes in the carbon stock; and (4) verification and certification of changes in the carbon stock (Vine and Sathaye 1997). We provide a Monitoring and Evaluation Reporting Form and a Verification Reporting Form at the end of this report to facilitate the review of forestry projects.

LBNL's MERVC guidelines also:

- Address the needs of participants in forestry projects, including financiers, investors, developers, and technical consultants.

- Discuss procedures, with varying levels of accuracy and cost, for evaluating and verifying (1) baseline and project installation conditions, and (2) long-term change in carbon stock.

- Apply MERVC procedures to a variety of projects.

- Provide procedures that (1) are consistently applicable to similar projects throughout all geographic regions, and (2) are internationally accepted, impartial and reliable.

These guidelines reflect the following principles: MERVC activities should be consistent, technically sound, readily verifiable, objective, simple, relevant, transparent, and cost-effective. Sometimes, tradeoffs need to be made for some of these criteria: e.g., simplicity versus technical soundness. Because of concerns about high costs in responding to MERVC guidelines, these guidelines are designed to be not too burdensome. Nevertheless, adequate funding and expertise are necessary for carrying out these activities.

While we have provided checklists for evaluating environmental and socioeconomic impacts, we believe that other existing guidelines are better suited for addressing these impacts (Section 8 ). The

1 A similar set of guidelines has been prepared for energy-efficiency projects (Vine and Sathaye 1999). 
checklists are included to remind project developers and evaluators about the importance of these impacts and the need to examine them during the evaluation of forestry projects.

We assume that the monitoring, evaluation and reporting activities will be undertaken by project implementors, but that verification and certification will be conducted by an outside third party experienced in verification (see Sections 6 and 7). We do not address which organization is the primary recipient of the information collected in MERVC activities: e.g., a national government, the FCCC Secretariat, or the CDM Executive Board. Nor do we address how this information will be used by these entities: e.g., granting full carbon credits, partial credits, or zero credits, based on the evaluation and verification reports. We expect these issues to be addressed by international bodies in the coming years.

Finally, the Kyoto Protocol contains emission targets, differentiated by country, for an aggregate of six major greenhouse gases (measured in carbon equivalents): carbon dioxide $\left(\mathrm{CO}_{2}\right)$, methane $\left(\mathrm{CH}_{4}\right)$, nitrous oxide $\left(\mathrm{N}_{2} \mathrm{O}\right)$, hydrofluorocarbons (HFCs), perfluorocarbons (PFCs), and sulfur hexafluoride (SF6). LBNL's MERVC guidelines only examine issues dealing with $\mathrm{CO}_{2}$.

\subsection{Relationship to Other Programs/Documents}

In a previous paper, we reviewed existing guidelines and protocols related to GHG reductions (Vine and Sathaye 1997). We concluded that while one or more of these documents addressed many of the issues that need to be covered in MERVC guidelines, none of them provided the type of detailed, standardized guidelines needed for addressing all of the issues in this report. Nevertheless, as noted below, LBNL's MERVC guidelines are indebted to the information and guidance contained in these documents.

1.6.1. World Bank's monitoring and evaluation guidelines. The World Bank prepared monitoring and evaluation guidelines for the Global Environment Facility (GEF), a multilateral funding program created to support projects that yield global environmental benefits but would not otherwise be implemented because of inadequate economic or financial returns to project investors (World Bank 1994a). The GEF supports four types of projects: biodiversity preservation, pollution reduction of international waters, GHG emission reduction and, to a limited extent, the control of ozone-depleting substances. LBNL's MERVC guidelines have incorporated several aspects of the World Bank guidelines. 
1.6.2. Winrock's carbon monitoring guidelines. The Winrock International Institute for Agricultural Development published a guide to monitoring carbon sequestration in forestry and agroforestry projects (MacDicken 1998). The guide describes a system of cost-effective methods for monitoring and verifying, on a commercial basis, the accumulation of carbon in forest plantations, managed natural forests and agroforestry land uses. This system is based on accepted principles and practices of forest inventory, soil science and ecological surveys. Winrock's monitoring system assesses changes in four main carbon pools: above-ground biomass, below-ground biomass, soils, and standing litter crop. It aims to assess the net difference in each pool for project and non-project (or pre-project) areas over a specified period of time. LBNL's MERVC guidelines have extensively used Winrock's guidelines for carbon monitoring in forestry projects.

\subsubsection{SGS Forestry's Carbon Offset Verification Service. SGS Forestry's Carbon Offset Verification} Service is the first international third-party verification service of forestry-based carbon offset projects (EcoSecurities 1998). The service consists of a formal analysis of project concept and design, and an independent quantification and verification of projected and achieved savings in carbon stock derived from the project. SGS Forestry's methodology covers the following components: (1) suitability assessment of project design, to determine whether the project fulfills SGS Forestry's carbon offset project eligibility criteria; (2) assessment of the project's scientific methodology, focusing on data quality and statistical analysis; (3) verification of projections of net carbon flows derived from the project by quantifying carbon flows of with- and without-project (baseline) scenarios, using SGS Forestry's Carbon Quantification Model; and (4) a surveillance program for assessment of project development and verification of achieved offsets. The SGS service is designed to provide a greater confidence for carbon offset projects, regulation and transactions, by being an impartial third-party with a uniform evaluation methodology. LBNL's MERVC guidelines have extensively used SGS Forestry's guidelines for carbon monitoring in forestry projects.

1.6.4. USIJI's Project Proposal Guidelines. The U.S. Initiative on Joint Implementation (USIJI) prepared project proposal guidelines for organizations seeking funding from investors to reduce GHG emissions (USIJI 1996). The guidelines request information on the proposed project, including the identification of all GHG sources and sinks included in the emissions baseline as well as those affected by the proposed project, and net impacts. The guidelines also ask for additional information, such as the estimates of GHG emissions and sequestration, including methodologies, type of data used, calculations, assumptions, references and key uncertainties affecting the emissions estimates. The estimates include the baseline estimate of emissions or sequestration of GHG without measures and the estimate of emissions or sequestration of GHG with measures. LBNL's MERVC guidelines have incorporated many aspects of the USIII's guidelines. 
1.6.5. DOE's Voluntary Reporting of Greenhouse Gases. The U.S. Department of Energy (DOE) prepared guidelines and forms for the voluntary reporting of greenhouse gases (USDOE 1994a and 1994b). The guidelines and forms can be used by corporations, government agencies, households and voluntary organizations to report to the DOE's Energy Information Administration on actions taken that have reduced or avoided emissions of greenhouse gases. The documents offer guidance on recording historic and current GHG emissions, emissions reductions, and carbon sequestration. The supporting documents (USDOE 1994b) contain limited examples of project analysis for the following sectors: electricity supply, residential and commercial buildings, industrial, transportation, forestry, and agriculture. Companies are allowed discretion in determining the basis from which their emissions reductions are estimated and can self-certify that their claims are accurate. LBNL's MERVC guidelines have incorporated aspects of DOE's guidelines.

1.6.6. Face Foundation. The Face Foundation in the Netherlands has worked on joint implementation projects in the forestry sector for many years and has used satellite imagery for evaluating these projects (Face Foundation 1997). The Face Foundation was set up by Sep (the Dutch Electricity Generating Board) to fund projects to sequester some of the carbon dioxide emitted into the atmosphere by the burning of fossil fuels when generating electricity in the Netherlands. Face stands for Forests Absorbing Carbon dioxide Emissions. Remote sensing is one of the monitoring methods used in LBNL's MERVC guidelines.

1.6.7. Forest Stewardship Council's Principles and Criteria for Forest Management. The Forest Stewardship Council (FSC) is an international body that accredits certification organizations in order to guarantee the authenticity of their claims (Forest Stewardship Council 1996). In all cases, the process of certification is initiated voluntarily by forest owners and managers who request the services of a certification organization. The FSC's "Principles and Criteria for Forest Management" apply to all tropical, temperate and boreal forests, and more detailed standards may be prepared at national and local levels. The Principles and Criteria are to be incorporated into the evaluation systems and standards of all certification organizations seeking accreditation by the FSC. LBNL's MERVC guidelines have incorporated many of the basic principles of the FSC's Principles and Criteria (including Principle \#8: Monitoring and Assessment).

1.6.8. University of Edinburgh's provisional guidelines and standards. The University of Edinburgh's Institute of Ecology and Resource Management has developed provisional guidelines and standards for assessing carbon offset projects (University of Edinburgh 1998). These guidelines are based on the experience of a community forestry and carbon sequestration project in Chiapas, Mexico, and overlap with the forestry standards of the Forest Stewardship Council (see Section 1.6.7). LBNL's MERVC 
guidelines reflect the basic principles of these guidelines: verifiable, viable, and socially and environmentally responsible. 


\section{Carbon Pools and Forestry Projects}

\subsection{Carbon Pools}

Forest ecosystems can be compartmentalized into three main carbon pools: live biomass, detritus and soils (Fig. 3) (Apps and Price 1996). The exchanges of carbon among these pools and between them and the atmosphere form the basis of the forest carbon cycle. This type of typology is useful for monitoring and evaluation purposes because forestry projects have different carbon stocks: some store carbon in standing natural forest or new vegetation grown in the project (biomass), some of which may end up as detritus or in the soil (soil and peat); some accumulate carbon in harvested products (products) that enter long-term storage, some of which may end up in landfills; and some biomass energy farms and plantations and natural vegetation and wood waste store additional net carbon in unburned fossil fuel by preventing carbon emissions from fossil fuel use and wood grown unsustainably. The use of fossil energy in management, harvesting and wood processing results in the release of additional carbon from the fossil fuel pool. The carbon dynamics of the products, landfills, and fossil fuel pools are determined largely by socioeconomic and technological factors (the right side of the figure), as distinguished from the forest ecosystem (the left side of the figure).

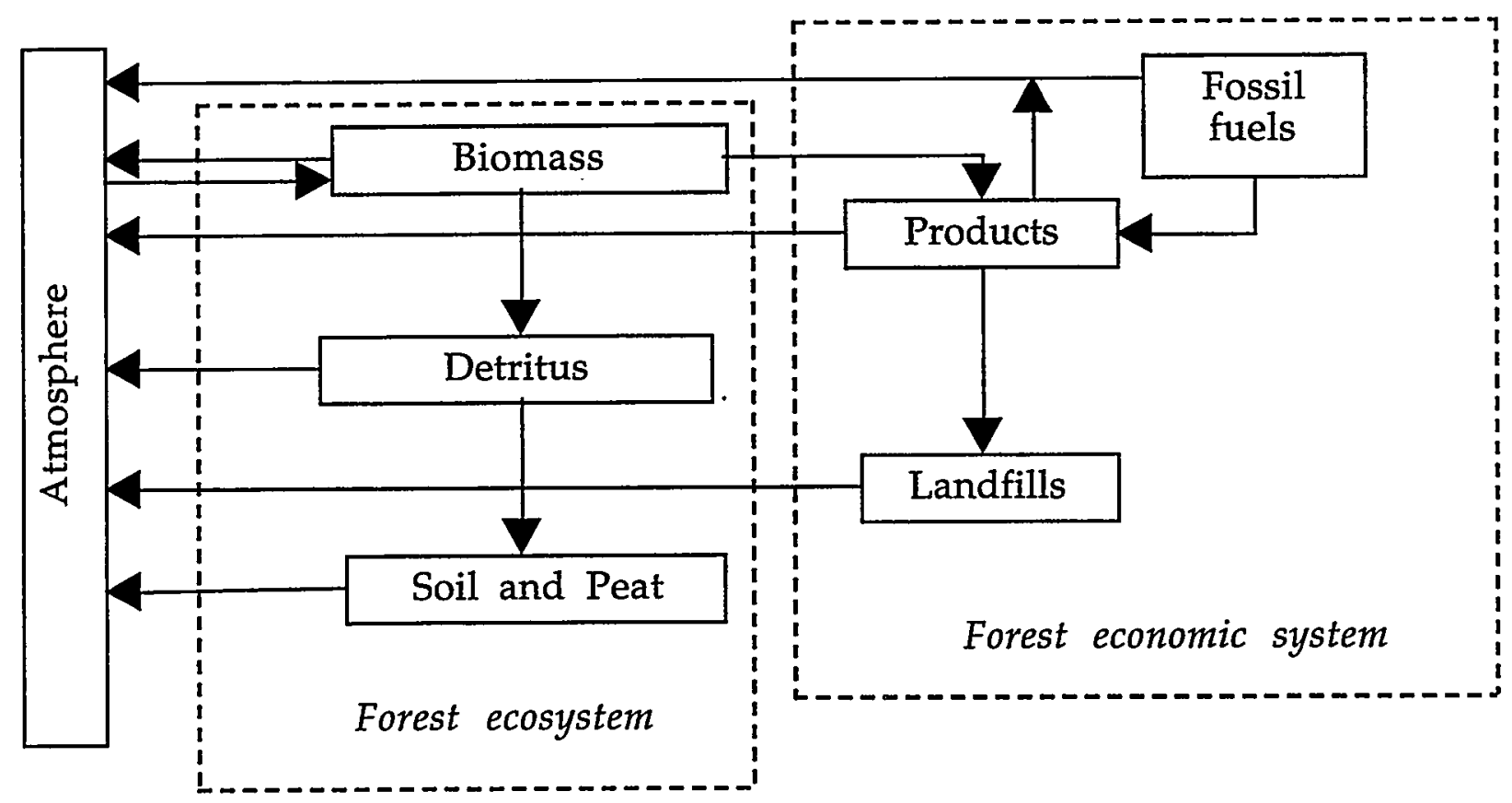

Figure 3. Forest System Carbon Cycle

Source: Apps and Price (1996) 
The relative size of the carbon pools, and potential changes in the carbon pools from forestry projects, will determine the type of monitoring and evaluation that will be needed for a specific project. If the carbon pools are small, or if the potential changes to the carbon pool from a project are minor, then less resources will be needed for MERVC activities. Thus, one of the key monitoring and evaluation issues is determining which of the carbon pools are significant. The significance of a carbon pool may be defined by its relative size:

"For example, in a forest preservation project, the carbon stored in trees may represent $70-80 \%$ of the total carbon stored on site, and consequently is a relatively significant pool. Leaf litter may contain as little as $1 \%$ of the carbon contained in the trees and, therefore, does not represent a significant pool in terms of relative size. Changes in pools that are directly attributed to project activities should be the focus of the monitoring program, but changes in all pools need to be evaluated for their relative significance to the project's carbon balance." (EcoSecurities 1998)

In addition to relative size, we believe it is useful to rank the carbon pools according to their vulnerability (rate of change) and direction of change (positive or negative). Pools that are relatively large and that are likely to change rapidly are very important to monitor. Pools that are relatively small and unlikely to change are not so important to monitor. A monitoring and evaluation program should adopt a conservative approach when deciding upon which pools to monitor and evaluate. Only pools that are monitored and evaluated should be considered in the calculation of GHG impacts. Some small pools may not justify the expense required to acquire reasonably reliable estimates of carbon contents (e.g., fine roots or fine litter); default values for carbon storage may be used in these cases (IPCC 1996; World Bank 1997). Nevertheless, it is important to ensure that the remaining pools are not depleted due to the activities being pursued. To avoid inaccurate accounting, it is important to conduct some evaluation to report on the increase and depletion of carbon stocks, or at a minimum, to demonstrate that carbon is not lost from pools for which no improvement is being made (UNFCCC 1998a).

\subsection{Forestry Projects}

The forestry sector affects a broad range of potential GHG sources, emissions reduction activities, and carbon sequestration activities. There are basically three categories of forest management practices that can be employed to curb the rate of increase in carbon dioxide in the atmosphere (Brown et al. 1996; Watson et al. 1996). These categories are: (1) management for carbon conservation, (2) management for carbon sequestration and storage, and (3) management for carbon substitution (Table 1). 


\begin{tabular}{|c|c|}
\hline Carbon conservation management & $\begin{array}{l}\text { Carbon sequestration and storage } \\
\text { management }\end{array}$ \\
\hline Forest reserves / reduced deforestation & Afforestation \\
\hline Modified forest management & Reforestation \\
\hline $\begin{array}{l}\text { Reduced degradation (e.g., from fires and } \\
\text { pests) }\end{array}$ & Urban forestry \\
\hline Carbon substitution management & Agroforestry \\
\hline Biomass for energy generation & Natural regeneration \\
\hline \multirow[t]{2}{*}{ Substitution for fossil-fuel based products } & Biomass enrichment \\
\hline & Forest product management \\
\hline
\end{tabular}

Source: Adapted from Watson et al. (1996)

The goal of carbon conservation management is primarily to conserve existing carbon pools in forests as much as possible through options such as controlling deforestation, protecting forests (forest preservation), modified forest management (e.g., reduced impact logging, hardwood control, sound silvicultural practices, firewood harvests, more efficient use of wood, and fertilization), and controlling other anthropogenic disturbances such as fire and pest outbreaks ("reduced degradation").

The goal of carbon sequestration and storage management is to expand the storage of carbon in forest ecosystems by increasing the area or carbon density of natural and plantation forests and increasing storage in durable wood products. Thus, this includes afforestation (i.e., the planting of trees in areas absent of trees in recent times), reforestation (i.e., the planting of trees where trees had recently been before, but currently are absent), urban forestry (i.e., the planting of trees in urban or suburban settings), and agroforestry (i.e., planting and managing trees in conjunction with agricultural crops). Other activities include natural regeneration, biomass enrichment, and forest product management.

Finally, carbon substitution management aims at increasing the transfer of forest biomass carbon into products (e.g., construction materials and biofuels) that can replace fossil-fuel-based energy and products, cement-based products, and other building materials. This type of management includes short-rotation woody biomass energy plantations (Section 2.3). 


\subsection{Biomass Energy Plantations}

The conventional view of forest management assumes that initial forest establishment is followed by a relatively extensive period of growth (and carbon accumulation). With short-rotation forests for bioenergy, harvesting occurs approximately every 5-12 years, and regeneration is accomplished through replanting or coppicing (USDOE 1994). Longer rotation plantations and natural forests can also be used for producing biomass for power generation (Carpentieri et al. 1993; Hall 1997; McLain 1998; Perlack et al. 1991; Russell et al. 1992; Swisher 1994; Swisher and Renner 1996). Thus, the cultivation of bioenergy resources, such as short-rotation forestry, can mitigate climate change, not only by replacing fossil fuels in the energy system, but also by storing additional terrestrial carbon in trees. Furthermore, to the extent that harvests are sustainable, the biomass fuel supplied from the same land can continue to prevent carbon emissions indefinitely in the future.

In the analysis of these projects, associated carbon sequestration in soils, detritus and growing vegetation has to be accounted (Swisher 1992). The carbon capture resulting from woody biomass plantations can be analyzed in conventional forestry sector terms (Sathaye and Meyers 1995). Analysis of these projects also depends upon information regarding how energy would have been supplied in the absence of the project (McLain 1998; Swisher and Renner 1996). The release of carbon from the combustion of biomass fuel and the displacement of emissions from fossil fuels relates more closely to activities in the energy supply sector. Thus, the monitoring and evaluation of the impacts of biomass energy projects will rely on the methods described in this report as well as methods used in monitoring and evaluating energy-efficiency projects (Vine and Sathaye 1999). The MERVC of the two components of biomass projects is important because the use of biomass on a renewable basis as a substitute for fossil fuels typically yields greater GHG abatement benefits than sequestration alone (World Bank 1994a).

\subsection{Unique Features of Carbon Pools and Forestry Projects}

Several unique features of carbon pools and forestry projects make the MERVC of forestry projects challenging. First, temporal changes in the carbon pools of forested ecosystems are driven mainly by the dynamics of the living biomass: accumulations of organic carbon in litter and soil reservoirs change significantly as forest stands develop or decay, and whenever disturbances to the ecosystem occur (Apps and Price 1996). Some of these changes do occur relatively more quickly in some carbon pools than others (see Section 4.1.2). Keeping track of ecosystem processes is a necessary part of forest carbon assessment. 
Second, although carbon storage in forest products typically represents a very small fraction of the total forest stores, these products can play an important role in the net forest-atmosphere exchange over the short term by delaying the return of photosynthetically fixed carbon to the atmosphere (Apps and Price 1996). Of the carbon that reaches wood products, some remains only for a short time (1-5 years), but a significant amount remains stored in the wood products for long periods (on the order of decades) before returning to the atmosphere (Winjum et al. 1998; USDOE 1994).

Third, the monitoring domain (see Section 3.1.1) of the carbon pool will be different, depending on the carbon pool: e.g., a larger monitoring domain is needed for tracking the fate of wood products. Fourth, the fate of some of these products is difficult to track and, therefore, adds to the level of uncertainty in impact measurement. The most conservative approach is to treat carbon destined for wood products as if it is released immediately after the harvest (IPCC 1996; USDOE 1994). Fifth, forestry activities can have a wide range of effects: e.g., reforestation may increase fertilizer use in forests, which can increase nitrous oxide emissions, and fossil fuel use in harvesting and transporting timber. And sixth, forestry activities may have indirect impacts on GHG emissions (e.g., urban tree planting can decrease the extent and severity of urban heat islands (Rosenfeld et al. 1998), potentially reducing the consumption of electricity to cool buildings, thereby reducing GHG emissions). 


\section{Estimation and Registration of Projects}

As part of the project proposal (design) stage, project developers describe the project activities intended to generate carbon sequestration, establish a project baseline, estimate the project's carbon and monetary returns, and design a monitoring and evaluation plan (see Andrasko et al. 1996). In Figure 4, we present an overview of the approach used in this report in estimating gross and net changes in carbon stock. In this section, we focus on the issues involved in estimating the baseline and gross changes in the carbon stock, since the net change is simply the difference between the gross change and the baseline.

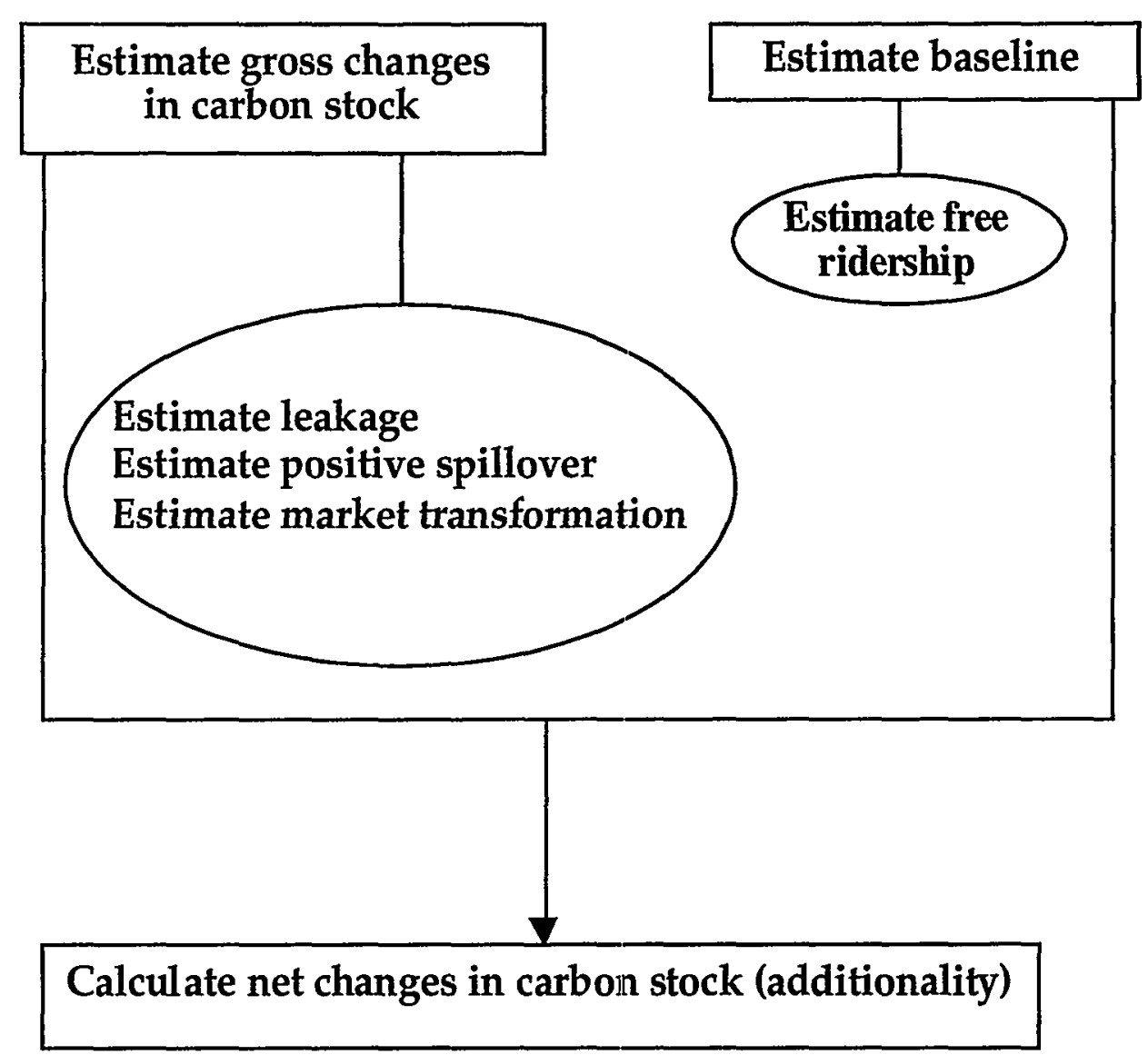

Fig. 4. Estimation Overview

The monitoring and evaluation plan describes the type of data to be collected, the data collection activities (procedures and methods) to be undertaken, and how the data will be evaluated. The plan also specifies the equipment and organizational requirements for monitoring and evaluation. 
The monitoring and evaluation plan is an integral part of the implementation of the project and should produce more accurate estimates of impacts at a lower cost. The results from the monitoring will later be used to re-estimate the baseline. In Appendix A, we provide an Estimation Reporting Form for project developers to use when designing a forestry project. The intent of this form is to provide guidance to developers on issues that evaluators and verifiers will examine after a project is implemented.

\subsection{Estimating Gross Changes in Carbon Stock}

At the project design stage, changes in the carbon stock will be estimated by using one or more techniques: (1) modeling, (2) review and analysis of the literature on similar projects (content analysis), (3) review and analysis of data from similar projects recently undertaken; and (4) expert judgement. The estimation methodology can be either simple or complex, depending on the resources available for conducting the estimation and the concern for reliable results (Watt et al. 1995). Since many assumptions need to be made, project estimates are later compared with measured data to determine the accuracy and precision of the estimated changes in carbon stock. The key issues that need to be addressed in estimating gross changes are: (1) determining the appropriate monitoring domain, and (2) accounting for project leakage, positive project spillover, and market transformation.

\subsubsection{Monitoring domain}

The domain that needs to be monitored (i.e., the monitoring domain, see Andrasko 1997 and MacDicken 1997) is typically viewed as larger than the geographic and temporal boundaries of the project. In order to compare GHG reductions across projects, a monitoring domain needs to be defined. Consideration of the domain needs to address the following issues: (1) the temporal and geographic extent of a project's direct impacts; and (2) coverage of project leakage and positive project spillover.

The first monitoring domain issue concerns the appropriate geographic boundary for evaluating and reporting impacts. A forestry project might have local (project-specific) impacts that are directly related to the project in question, or the project might have more widespread (e.g., regional) impacts. Thus, one must decide the appropriate geographic boundary for evaluating and reporting impacts. Similarly, the MERVC of changes in the carbon stock of forestry projects can be conducted at the point of extraction (e.g., when trees are logged) or point of use (e.g., when trees are made into furniture), and when forests are later transformed to other uses (e.g., agriculture, grassland, or 
range). Thus, depending on the project developer's claims, one may decide to focus solely on the changes in the carbon stock from the logging of trees at the project site, monitor the changes over time from the new land use type, or account for the wood products produced and traded outside project boundaries.

The second issue concerns coverage of project leakage and positive project spillover, and they are discussed in the next two sections. It is important to note that not all secondary impacts can be predicted. In fact, many secondary impacts occur unexpectedly and cannot be foreseen. And when secondary impacts are recognized, a commitment needs to be made to ensure that resources are available to evaluate these impacts.

One could broaden the monitoring domain to inclucle, for example, project leakage and off-site baseline changes (which are normally perceived as occurring outside the monitoring domain). Widening the system boundary, however, will most likely entail greater MERVC costs (see Section 9) and could bring in tertiary and even less direct effects that could overwhelm any attempt at project-specific calculations (Trexler and Kosloff 1998). Consequently, project developers should devote most of their resources to the immediate monitoring domain, but include all carbon pools (e.g., forest products). During the monitoring and evaluation stage, the monitoring domain can be expanded if warranted.

\subsubsection{Project leakage}

Leakage occurs because the project boundary within which a project's benefits are calculated may not be able to encompass all potential indirect project effects. In this report, negative indirect effects are referred to as "project leakage" while positive indirect effects are referred to as "positive project spillover" (Section 3.1.3). For example, projects affecting the supply of timber products can affect price signals for the rest of the market, potentially counteracting a portion of the calculated benefits of the project: the establishment of forestry plantations could lead to a decrease in timber prices, leading to a higher incentive to convert forests to agricultural purposes. Another example of leakage occurs when a forest preservation project involves protecting land that was previously harvested by the local population for their personal consumption as fuel wood (MacDicken 1998; Watt et al. 1995). Although this area is now protected from harvesting, people from the surrounding communities still require wood for fuel and construction. Preserving this forest area has shifted their demand for fuel wood to a nearby site, leading to increased deforestation. This off-site deforestation will at least partially offset the carbon sequestration at the project site. Furthermore, some projects may involve international leakage: e.g., in 1989, when all commercial logging in Thailand was 
banned, the logging shifted to neighboring countries such as Burma, Cambodia and Laos as well as to Brazil (Watt et al. 1995).

Leakage may occur not only after a project has been completed but also during project development. For example, in the Rio Bravo Carbon Sequestration Pilot Project, a local timber company used the money from the sale of the land to project participants for upgrading their equipment, allowing for the possibility of an increase in output of plywood (Programme for Belize 1997). However, this increase in output did not occur. Similarly, the land purchases for the Rio Bravo project could also motivate competitors that had wanted to purchase that land to intensify clearance of the land already in their possession, or intensify production from the land, increasing emissions from agricultural inputs and machinery. However, this also has not occurred (Programme for Belize 1997).

Leakage needs to be accounted for if off-site GHG emissions are to be accounted for, rather than those at a particular site. However, leakage can be difficult to identify and even more difficult to estimate and quantify. Nevertheless, because the developer's project is responsible for leakage and a project's estimate of carbon storage may be later reduced due to project leakage, it is the developer's responsibility to monitor leakage and assume responsibility for the carbon lost.

\subsubsection{Positive project spillover}

When measuring changes in carbon stock, it is possible that the actual reductions in carbon are greater than measured because of changes in participant behavior not directly related to the project, as well as to changes in the behavior of other individuals not participating in the project (i.e., nonparticipants). These secondary impacts stemming from a forestry project are commonly referred to as "positive project spillover." Project spillover may be regarded as an unintended consequence of a forestry project; however, as noted below, increasing project spillover may also be perceived as a strategic, intended mechanism for reducing GHG emissions.

The intent of some forestry projects is often not only to induce project developers to adopt certain forestry measures, but more broadly to transform neighboring areas for implementing similar measures. For example, in the Rio Bravo Carbon Sequestration Pilot Project, other projects have been implemented to preserve forests, catalyzed by the successful launch of the Rio Bravo project (Programme for Belize 1997). In the CARE/Guatemala project, which increased fuelwood availability and agricultural productivity by providing trees through CARE-sponsored tree nurseries, the project's techniques have been adopted in other areas beyond the project's boundaries by participants setting up their own tree nurseries (Brown et al. 1997). 
Positive project spillover effects can occur through a variety of channels including: (1) an individual hearing about a project measure from a participant and deciding to pursue it on his or her own ("free drivers"); (2) project participants that undertake additional, but unaided, forestry measures based on positive experience with the project; (3) wood product manufacturers changing the nature of their products, to reflect the demand for more wood products created through the project; (4) governments adopting new forestry policies and legislation because of the results from one or more forestry projects; (5) technology transfer efforts by project participants which help reduce market barriers throughout a region or country; or (6) the emergence of ecotourism.

Because of the multiple actors that may be involved in causing positive project spillover, it is unclear on how much of these changes should be attributed to the project developer. Since spillover is an unintended consequence, and the project developer is a passive recipient of the benefits of spillover, it should not be his responsibility for expending resources for an assessment of project spillover. Project spillover still needs to be evaluated, but not assessed in the estimation stage.

\subsubsection{Market transformation}

Positive project spillover is related to the more general concept of "market transformation," defined as: "the reduction in market barriers due to a market intervention, as evidenced by a set of market effects, that lasts after the intervention has been withdrawn, reduced or changed" (Eto et al. 1996). The concept of market transformation has been used in many fields, most recently in the energy sector. Increasing market transformation is expected to be a strategic mechanism (i.e., an intended consequence) for reducing carbon emissions in the forestry sector for the following reasons:

- To increase the effectiveness of forestry projects: e.g., by examining market structures more closely, looking for ways to intervene in markets more broadly, and investigating alternative points of intervention.

- To reduce reliance on incentive mechanisms: e.g., by strategic interventions in the market place with other market actors.

- To take advantage of regional and national efforts and markets.

- To increase focus on key market barriers other than cost.

- To create permanent changes in the market.

As a hypothetical example, consider a bioenergy project that grows trees on a rotational basis and harvests the trees as an energy resource for a community hospital. The developer of the project needs to make sure there are no technical, financial, administrative, or policy barriers to the 
implementation of this project, and to determine if there are other large, energy-intensive end users who could take advantage of this resource (e.g., industrial customers?). The project developer could also examine what partnering opportunities exist for promoting the bioenergy project (e.g., developing a voluntary labeling program that labels customers as "green energy users"). Once the labeling program is in place, additional projects might emerge, creating an expanded market for bioenergy projects. Finally, the developer could try to extend the proposed labeling program to other regions, in order to enlarge the market for the project's trees.

Two examples in the forestry sector show the beginnings of market transformation: (1) the availability of improved biomass cook stoves, an important technology for reducing deforestation, has influenced many nonparticipants to purchase cook stoves as these programs develop (Bialy 1991); and (2) the reduced impact logging project in Malaysia (Box 3) is being replicated in Brazil and other parts of Indonesia (personal communication from Pedro Moura-Costa, EcoSecurities, Ltd., Sept. 15, 1998; Jepma 1997).

In the case of market transformation, the project developer is one of the responsible parties for engendering change in the carbon stock and, therefore, should be responsible for estimating the amount of market transformation. However, because of the multiple actors involved in causing market transformation, the developer should not be solely responsible for assessing and later monitoring and evaluating market transformation. ${ }^{1}$ The amount of resources devoted to assessing market transformation, therefore, will depend on how much carbon storage can be attributed to this project which may be reflected in contracts among parties involved in transforming markets.

\subsection{Estimating a Baseline}

For joint implementation (Article 6) and Clean Development Mechanism (Article 12) projects implemented under the Kyoto Protocol, the emissions reductions from each project activity must be "additional to any that would otherwise occur," also referred to as "additionality criteria"

1 Other challenges in proving attribution include the following: (1) multiple interventions occur (e.g., changes in standards, products offerings and prices and activities of other market actors (e.g., regulators and regulatory intervenors)); (2) programs and underlying change factors interact with one another; (3) the effects of different programs are likely to have different lag times; (4) changes in different technologies are likely to proceed along different time paths; (5) changes are likely to differ among different target segments; (6) the lack of an effective external comparison group; (7) data availability; and (8) large, complex interconnected sociotechnical systems are involved, with different sectors changing at different rates and under different influences. 
(Articles $6.1 \mathrm{~b}$ and $12.5 \mathrm{c}$ ). ${ }^{1}$ Determining additionality requires a baseline for the calculation of carbon sequestered, i.e., a description of what would have happened to the carbon stock had the project not been implemented (see Violette et al. 1998). Additionality and baselines are inextricably linked and are a major source of debate (Trexler and Kosloff 1998). Determining additionality is inherently problematic because it requires resolving a counter-factual question: What would have happened in the absence of the specific project?

Because investors and hosts of forestry projects have the same interest in a forestry project (i.e., they want to get maximum carbon sequestration through the project), they are likely to overstate and over-report the amount of carbon sequestered by the project (e.g., by overstating business-as-usual changes to the carbon stock). Cheating may be widespread if there is no strong monitoring and verification of the projects. Even if projects are well monitored, it is still possible that the real amount of carbon sequestered is less than estimated values. Hence, there is a critical need for the establishment of realistic and credible baselines.

Future changes in carbon stock may differ from past levels, even in the absence of the project, due to growth, technological changes, input and product prices, policy or regulatory shifts, social and population pressure, market barriers, and other exogenous factors. Consequently, the calculation of the baseline needs to account for likely changes in relevant regulations and laws, changes in key variables (e.g., population growth or decline, economic growth or decline, deforestation, development of markets for wood products, and how future land use patterns (e.g., gradual deforestation) affect the carbon cycle) (Andrasko et al. 1996; Michaelowa 1998). For example, for a forest protection project, a simple baseline would try to account for how many hectares might be lost in a year, how the loss would occur (e.g., through burning or timber harvest), what biomass would replace the forest, and whether the forest would return after the land has been abandoned. Ideally, the baseline would track this information annually.

Forward-looking benchmarks might be based on national forestry policy or land use simulation models. Mitigation scenarios can evaluate the carbon sequestration potential of various policies such as afforestation, reforestation, or forest management practices (e.g., fire suppression). However, results at the end of long planning or modeling horizons can be very imprecise. One could define a

I In this report, the criterion of additionality refers only to carbon emissions. The related criterion of "financial additionality" is not described in LBNL's MERVC guidelines. Financial additionality refers to the financial flows of a project (Andrasko et al. 1996): would the expenditures involved been made without the carbon offset project? This question addresses: (1) the sources of funding for the project, (2) the alternative uses of that funding, and (3) the motivation for choosing the carbon offset projects (Swisher 1998). We expect financial additionality to be addressed when the proposed project is registered (see Section 1.1). 
median baseline or a set of baselines with different assumptions, which are weighted according to their probability (Andrasko et al. 1996).

Ideally, when first establishing the baseline, carbon stocks should be measured for at least a full year before the date of the initiation of the project. The baseline will be re-estimated based on monitoring and evaluation data collected during project implementation. ${ }^{1}$ Finally, in order to be credible, project-specific baselines need to account for free riders.

\subsubsection{Free riders}

It is possible that forestry projects are undertaken by participants who would have conducted the same activities if there had been no project and, therefore, the carbon sequestered by these "free riders" would not be perceived as "additional" to what would otherwise have occurred (Vine 1994). Although free riders may be regarded as an unintended consequence of a forestry project, free ridership should still be estimated, if possible, during the estimation of the baseline. The project developer is responsible for monitoring and evaluating free riders after the project is implemented, for re-estimating the baseline (Section 4.3). While free riders can also cause leakage and spillover, these impacts are typically considered to be insignificant compared to the impacts from other participants.

\subsubsection{Performance benchmarks}

Concerned about an arduous project-by-project review that might impose prohibitive costs, some researchers have proposed an alternate approach, based on a combination of performance benchmarks and procedural guidelines that are tied to appropriate measures of output (e.g., Lashof 1998; Michaelowa 1998; Swisher 1998; Trexler and Kosloff 1998). In all cases, measurement and verification of the actual performance of the project is required. The performance benchmarks for new projects could be chosen to represent the high performance end of the spectrum of current commercial practice (e.g., representing roughly the top $25^{\text {th }}$ percentile of best performance). In this

1 In some cases, allometric equations for estimating carbon emissions may be used, but only under special conditions: e.g., when environmental conditions are not variable, in managed forests (e.g., plantations), and in areas of increased homogeneity (see Box 2). In forestry, an allometric equation characterizes the predictable form of a tree by relating one or two easy-to-measure variables (e.g., diameter at breast height and/or height) to other more difficult-to-measure variables (e.g., biomass and tree volume) (personal communication from Steve Hamburg, Brown University, Feb. 9, 1999). 
case, the benchmark serves as a goal to be achieved. In contrast, others might want to use benchmarks as a reference or default baseline: an extension of existing technology, and not representing the best technology or process.

A panel of experts could determine a baseline for a number of project types, which could serve as a benchmark for the UNFCCC. This project categorization could be expanded to a categorization by regions or countries, resulting in a region-by-project matrix. Project developers could check the relevant element in the matrix to determine the baseline of their project. Most of the costs in this approach relate to the establishment of the matrix and its periodical update. Before moving forward with this approach, analysis is needed to consider the costs in developing the matrix and its update, the potential for projects to qualify, and the potential for free riders. The U.S. EPA is assessing the feasibility and desirability of implementing a benchmark approach for evaluating additionality (e.g., see Hagler Bailly 1998). 


\section{Monitoring and Evaluation of Changes in Carbon Stock}

In Figure 5, we present an overview of the approach used in LBNL's MERVC guidelines for evaluating changes in the carbon stock. During the monitoring and evaluation stage, gross changes in the carbon stock are measured, using one or more of the following monitoring and evaluation methods: modeling, remote sensing, and field/site measurements (Section 4.2). The baseline is also re-estimated, accounting for free riders (Section 4.3). The net change in the carbon stock is equal to the gross change in the carbon stock minus the re-estimated baseline.

During the implementation of the project, monitoring of project activities is conducted periodically to ensure the project is performing as designed. We expect most, if not all, of the above activities to be performed by project developers and their contractors. ${ }^{1}$ While the project is being implemented, however, we expect periodic (e.g., annual) reviews by third-party verifiers (to avoid conflicts of interest), leading to certification (see Sections 6 and 7). These verifiers might be the same independent reviewers who assessed the project proposal at the registration stage (personal communication from Johannes Heister, The World Bank, Jan. 12, 1999). As noted in Section 6, verification of carbon sequestration would be performed at certain intervals during the time the project is scheduled to sequester carbon.

This section introduces some of the basic data collection and analysis methods used to estimate changes in the carbon stock and associated impacts. The methods vary in cost, accuracy, simplicity and technical expertise required. Tradeoffs will need to be made for choosing the appropriate methods: e.g., level of accuracy and cost of data collection.

1 An alternative approach is to require only certified professionals to conduct the monitoring and evaluation, as required when institutions of higher education enter into energy performance-based contracts in Texas (Texas Higher Education Coordinating Board 1998). 


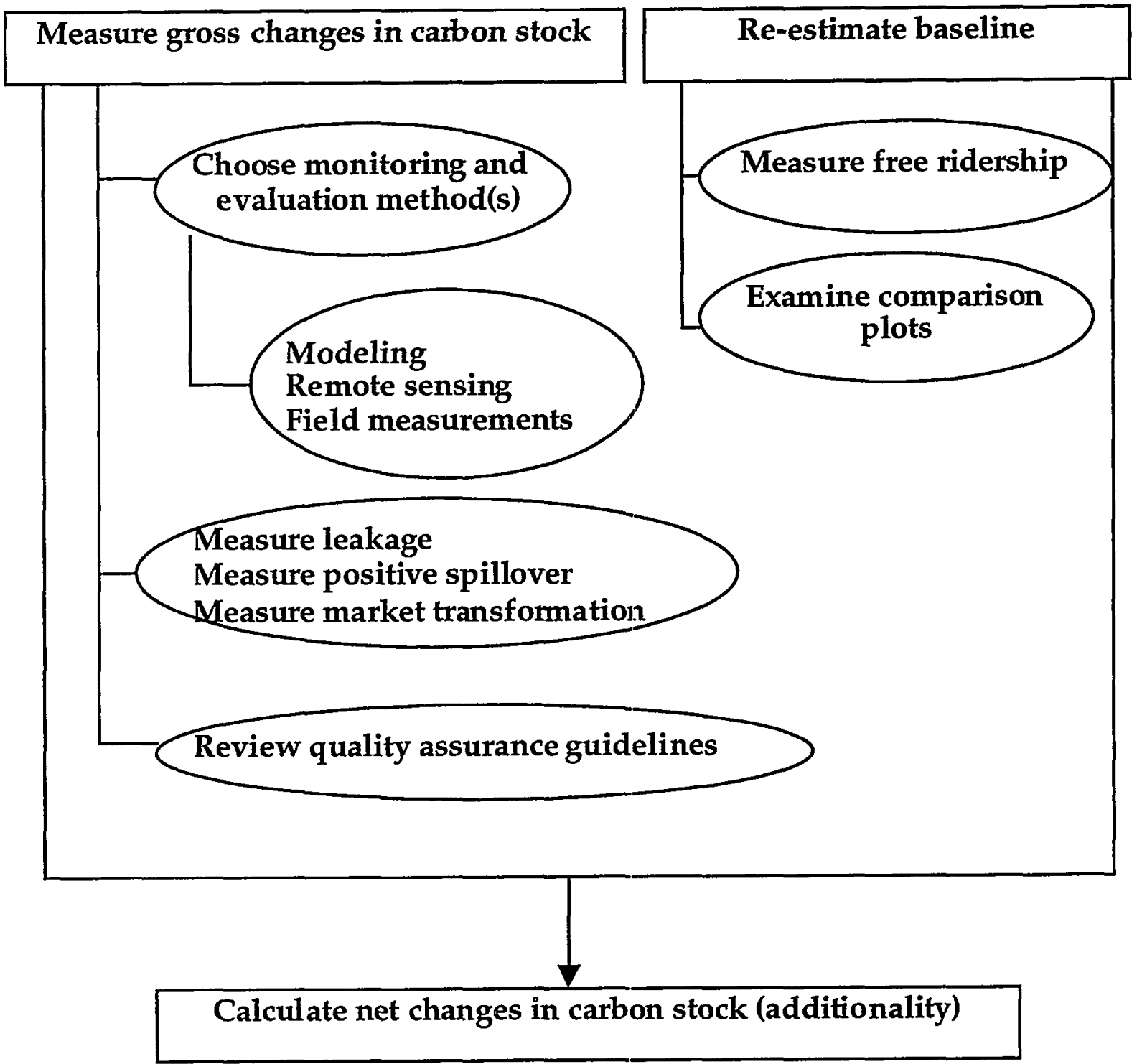

Fig. 5. Evaluation Overview

\subsection{Methodological Issues}

Prior to reviewing the data collection and analysis methods used for measuring changes in the carbon stock and associated impacts, we first discuss two key methodological issues: measurement uncertainty, and the frequency and duration of monitoring and evaluation. As indicated elsewhere, these issues are not only addressed in the monitoring and evaluation stage but should also be examined in the project design stage. 


\subsubsection{Measurement uncertainty}

While there are several types of uncertainty that can affect the actual realization of GHG reductions, uncertainty in the measurement of GHG reductions needs to be accounted for when presenting monitored and evaluated data. ${ }^{1}$ Measurement uncertainties include the following: (1) the use of simplified representations with averaged values (especially emission factors); (2) the uncertainty in the scientific understanding of the basic processes leading to carbon sequestration, and emissions and removals of non- $\mathrm{CO}_{2} \mathrm{GHG}_{;}^{2}$ and (3) the uncertainty in measuring items that cannot be directly measured (e.g., project baselines). Some of these uncertainties vary widely by type of project (depending on approach, level of detail, use of default data or project specific data, etc.), and length of project (e.g., short-term versus long-term). It is important to provide as thorough an understanding as possible of the uncertainties involved when monitoring and evaluating the impacts of forestry projects.

As an example, in the assessment of the project design of Costa Rica's Protected Areas Project (PAP), the risk and uncertainty assessment identified and quantified the carbon offsets that had any type of risk or uncertainty associated with them (SGS 1998). These were then set into a buffer to provide insurance for the carbon offsets that were authorized for sale (i.e., outside the buffer). The principal source of uncertainty in these estimates was the rate of deforestation occurring outside the protected areas (see Busch et al. 1999).

Because of the difficulties and uncertainties in estimating changes in carbon stock, the level of precision and confidence levels associated with the changes need to be identified. 3 Project

1 Other types of uncertainty include the following: (1) project development and construction uncertainty, i.e., the project won't be implemented on time or at all, even though funds have been spent on project development; (2) operations and performance uncertainty (e.g., if forest management practices are not implemented as projected, or if the project is not maintained for a reasonably long time, then net carbon sequestered will change); and (3) environmental uncertainty (IPCC 1996; USAID 1996; UNFCCC 1998a). In the case of environmental uncertainty, some sites may have a higher chance of disturbances, such as wildfire ignitions, flood overflows, avalanches, etc. Typically, fire-related species are established in places where fire is much more of a risk than in other places; similarly, riparian forests are re-established in areas where flood flows in the first few years of a project are likely to destroy the effort. Hence, project developers should provide a description of the project developer's experience, existing warranties, the performance history of previous projects, and plans to reduce uncertainty. The political and social conditions that exist that could potentially affect the credibility of the implementing organizations (e.g., political context, stability of parties involved and their interests, and potential barriers) also need to be described.

2 For example, many knowledge gaps still remain in our understanding of the fundamental mechanisms responsible for soil carbon dynamics (Lal et al. 1997).

3 Unless otherwise noted, we assume normal distributions, represented by a normal, bell-shaped curve in which the mean, median and mode all coincide. 
developers and evaluators should report the precision of their measurements and results in one of two ways: (1) quantitatively, by specifying the standard deviation around the mean for a bellshaped distribution, or providing confidence intervals around mean estimates; or (2) qualitatively, by indicating the general level of precision of the measurement (e.g., low, medium or high).

It is unclear at this time on how uncertainty will be treated in the calculation and crediting of reduced carbon emissions and increased carbon sequestration. At a minimum, the most conservative figures should be used at every stage of calculation (e.g., the lower boundary of a confidence interval). The qualitative assessment of uncertainty is more problematic, however, some type of discounting or debiting could be used to adjust the amount of carbon sequestered in situations where there is a great deal of uncertainty. Where there is substantial uncertainty, project developers need to design higher quality forestry projects so that impacts are more certain.

In conclusion, the evaluation of forestry projects should: (1) evaluate the project's contingency plan, where available, that identifies potential project uncertainties and discusses the measures provided within the project to manage the uncertainties; (2) identify and discuss key uncertainties affecting all emission estimates; (3) assess the possibility of local or regional political and economic instability and how this may affect project performance; and (4) provide confidence intervals around mean estimates.

\subsubsection{Frequency and duration of monitoring and evaluation}

The frequency of monitoring and evaluation will most likely be linked to the schedule of transfer of carbon credits. It is possible that these credits could be issued on an annual basis. ${ }^{1}$ The monitoring period may last longer than the project implementation period: for example, if it takes three years to complete a reforestation project, net carbon sequestered from the project will continue beyond the three years. Moreover, after the crediting of the emissions reductions is over, a system is still needed for keeping track of the carbon from these projects. Hence, the sustainability of forestry projects (excluding substitution projects, such as bioenergy plantations) is critical if the impacts from these projects are to persist. Therefore, information is needed on the institutional capabilities and support for implementing the project over the project's lifetime and on the uncertainties of a project (see Section 4.1.1).

1 Other models are possible (e.g., up-front lump-sum payment), but unlikely since the issuance of certified emission reductions occurs after a verification process. 
The institutional, community, technical and contractual conditions likely to encourage sustainability of forestry projects are of utmost concern. In some cases, encouraging the participation of community members in the development and implementation of forestry projects will help to ensure the longevity of a project, although the design and implementation process may take longer and costs will increase. Sustainability will also increase by. encouraging operations and maintenance, providing spare parts and equipment, and making sure technical expertise is available. Finally, contracts can incorporate provisions that lead to debiting of emission reduction units (for the host and/or investor country) if a project does not last as long as expected.

The frequency of monitoring and evaluation will also depend on the carbon pools being affected by the project (Section 2.1). Each carbon pool has a different rate of change: e.g., above-ground biomass often experiences greater rates of change in carbon than soils. For those carbon pools that undergo relatively rapid changes in carbon (e.g., above-ground biomass, for fast-growing species), monitoring of the carbon pools should be done on an annual basis. As discussed in Section 4.2.5, sampling will help to reduce these costs. However, monitoring should also account for the type of project being implemented. For example, for afforestation projects, monitoring and evaluation could be done less frequently in the first few years of the project, since significant changes in carbon will not be occurring (in fact, the standard error of the estimates may be larger than the actual growth). After five years, annual monitoring may be warranted.

The monitoring of soil carbon may not need to be conducted on an annual basis, for two reasons. First, the monitoring of soil carbon is relatively more expensive. Second, in undisturbed areas, soil carbon does not change dramatically from year to year. Hence, soils could be visually inspected annually to note the absence or presence of soil-altering events, and detailed monitoring could be done every five years. However, for areas experiencing severe disturbances (or continuous soil disturbances, like farming), monitoring should be conducted more frequently, perhaps annually. In addition, because organic carbon levels in soils go up and down due to seasonal variation during the year (Lal et al. 1998), monitoring of soil carbon should be conducted consistently: i.e., at the same time each year. If sampling is not done consistently, then the temporal fluctuations may overwhelm the real changes in carbon. While seasonal changes in total soil organic matter are hard to detect, some components of soil organic matter (e.g., dissolved organic carbon or the biomass carbon) may change among seasons (personal communication from Rattan Lal, Ohio State University, Jan. 30, 1999). On the other hand, significant changes in total soil organic matter may be only detectable over a 2 to 3 year period, 
with longer periods more desirable. ${ }^{1}$ Ideally, measurement of soil carbon levels should be done when the soil carbon levels are at their average levels for both reference and project cases.

In addition to measurements, records should be kept on disturbances at the sites, whether humanmade (e.g., thinnings) or natural (e.g., pest infestation). For forest products, guidance for the frequency of monitoring is more difficult to provide, since the removal of (i.e., demand for) wood products is a function of socioeconomic pressures, as well as natural replacement. As a conservative estimate, we encourage annual monitoring of wood products.

Finally, where more than one project is being implemented, evaluators should evaluate a project by its permanence or lack of permanence - this will be reflected in "project lifetime," which may be different than an expected lifetime of a project as initially proposed by developers. The project lifetime is a function of the type of carbon pool affected (e.g., soils versus above-ground woody biomass) and the probability of an occurrence of a natural or human-made disturbance (e.g., fires). For example, if a project area is likely to undergo serious changes after 20 years, then the changes in the carbon stock for that project are limited to that 20-year lifetime. The value of those changes may be less than for changes in the carbon stock from similar projects with longer project lifetimes (e.g., 30 years). Accompanying the evaluation, the evaluator should provide a list of indices that demonstrate the potential for permanence: e.g., type and number of income groups targeted by project, potential socioeconomic impacts addressed (see Section 8.2), potential sources of uncertainty addressed (see Section 4.1.1), etc.

\subsection{Measurement of Gross Changes in Carbon Stock}

These guidelines are to be used to measure the changes in carbon stocks as accurately as is practical, accounting for all positive emissions of carbon from forests (e.g., from the combustion and decay of organic matter and the use of fossil fuels in machinery) and negative emissions (capture) of carbon through photosynthesis in forests. Since forestry activities typically trigger a sequence of effects that change through time, the measurement of changes in carbon stocks must account for these dynamic effects (e.g., from the time a forest is established until a forest is removed by harvest or a natural disturbance).

${ }^{1}$ For example, after sufficient time (e.g., 5 to 10 years), statistically, significant differences in soil organic carbon have been observed in natural, inadvertent, and planned experiments (e.g., Izaurralde et al. 1998; Paul et al. 1997; Smith et al. 1997). 
The measurement of a project's carbon fixation necessitates specialized tools and methods drawn largely from experience with forest inventories and ecological research. Monitoring and verifying carbon accumulation in forestry projects must be cost effective and accurate. Monitoring systems should be built upon standard forestry approaches to biomass measurement and analysis, and apply commonly accepted principles of forest inventory, soil science and ecological surveys. Specific methods and procedures should be assembled on a project-specific basis, with the types and extent of monitoring ultimately determined by the relative costs and quantity of carbon return by each measurement type.

Three general monitoring techniques can be used to monitor carbon fixed through forestry projects (based on MacDicken 1997): (1) modeling, (2) remote sensing, and (3) field/site measurements, including biomass surveys (which includes research studies; surveys; the monitoring of wood production and end products; and forest inventories) and destructive sampling. Many of these techniques can be used together.

\subsubsection{Establishing the monitoring domain}

Different techniques are available for assessing multiple monitoring domains in forestry projects (Andrasko 1997). At the national scale, remote sensing can be used to detect land-use and land-cover changes. At the regional scale, remote sensing can be used with ground-truthing and forest inventory techniques. And at the project level, remote sensing, ground-truthing, creation of permanent plots, forest inventory data or surveys, or allometric techniques can be used (see Section 3.2 and Box 2).

Currently, there are weak linkages in assessing multiple monitoring domains (Andrasko 1997). One potential solution to strengthening these linkages is the use of "nested monitoring systems" where an individual project's monitoring domain is defined to capture the most significant GHG fluxes and where provisions are made for monitoring carbon stocks and GHG flows outside of the project area by regional systems or national GHG inventory monitoring systems (Andrasko 1997).

\subsubsection{Modeling}

Modeling the impacts of certain forestry practices on carbon flows into and out of forest carbon sinks can be used for estimating annual flows of carbon. The models are used to predict future carbon flows, but they do not measure the actual changes. The modeled estimates of carbon storage over time must be checked using one of the techniques described below (i.e., remote sensing with ground truthing or field/site measurement). 
Models start from an estimate of a carbon stock for a specific forest type at a specific site. Then, based on information from forest practices, the models develop estimates of annual carbon flows. This approach relies on a series of highly simplified assumptions to estimate total carbon sequestration. For example, assumptions may include: the number of trees planted in either woodlots or agroforestry systems, initial stocking rates, mean annual stemwood volume increments, a biomass multiplier factor, and harvest rates. The assumptions are then inputted into a model to estimate the amount of sequestered carbon. The models need to be corrected/calibrated with measured data periodically as well as with other approaches. For example, approaches that estimate forest productivity by timber volume may be compared with other approaches, such as allometrically derived carbon estimates that incorporate relationships between tree or stand physiological parameters (e.g., diameter, height, weight, tapper (the change in diameter over height) and carbon content (Box 2) (Hamburg et al. 1997; Schroeder et al. 1997; Brown 1997). The accuracy of these methods will depend on many factors, including the precision of the equations and the homogeneity of the forest (e.g., allometric equations are simpler and more accurate for homogeneous forests and more complex and less accurate for heterogeneous forests).

Some models are already available for simple conclitions and standard treatments, such as tree planting on agricultural land. The Land Use and Carbon Sequestration (LUCS) model is a projectbased computer model that tracks the changes in carbon density associated with land use changes (e.g., conversion of forested areas to agriculture) (Faeth et al. 1994; MacDicken 1998). ${ }^{1}$ Direct measurements and default assumptions are used to calculate the changes and impacts. The LUCS model has been used in evaluating an agroforestry project on marginal hillsides in Guatemala (Trexler et. al. 1992).

1 The LUCS model is available from the Lawrence Berkeley National Laboratory. 
Box 2

\section{Modeling Example}

To reduce the costs of carrying out forest mitigation projects, there is an incentive to use volumebased estimates of carbon content of forested lands and existing allometric equations developed outside the project region to estimate forest carbon. The comparison of generalized allometric equations with volumetric estimates was conducted in a study of Russian forests. In addition to comparing volume and allometrically derived carbon estimates, the applicability of using generalized allometric equations was evaluated by comparing estimates generated utilizing North American allometric equations with locally derived Russian equations.

Evaluation method: The volume and allometrically derived carbon estimates of 51 Russian forests were compared. Russia provided an ideal setting for comparing these two approaches since large data sets, collected from across the country, included tree volume, tree weights, and stand characteristics. Representative stand data were selected from information in the Russian National Forest Inventory for forests with species compositions representative of the dominant vegetation of the two regions of interest. A system of phytomass/volume ratios was developed to convert timber volume to stand carbon. Construction of the allometric equations utilized data from individual trees and shrubs collected in the regions. One thousand individual trees of the five dominant species found in the regions were destructively sampled: all trees were cut and divided into four parts for development of the allometric equations: stem, branches, leaves, and roots. Allometric equations were developed for the trees of interest. On each plot, the heights of 10-12 trees were measured and allometric equations relating tree height to diameter at breast height were developed and carbon contents were assumed. Volume-based estimates of carbon content of forest stands involved the application of zonal and regional species phytomass/volume ratios, evaluated using the forest phytomass and productivity database available in Russia. The phytomass/volume ratios utilized the same carbon/dry weight percentages as were used in the allometric equations.

Findings: Volumetrically and allometrically derived carbon estimates of 51 Russian forests were very similar. The error associated with volumetrically derived carbon estimates varied with species composition. For some species, there was no apparent difference between volumetric and allometric estimates, but for others it averaged $15 \%$. The results also suggest that it is appropriate to utilize allometric equations developed for one species for estimating the carbon content of another species growing in a different region, as long as they are phenotypically similar. Both volumetric and allometric approaches for estimating carbon are useful. For regional based studies of forest carbon, volumetric approaches are preferred because they are easy to use. For stand-based estimates of forest, carbon allometric approaches provide greater reliability.

Sources: (1) Hamburg, S., D. Zamolodchikov, G. Korovin, V. Nefedjev, A. Utkin, J. Gulbe, and T. Gulbe. 1997. "Estimating the Carbon Content of Russian Forests: A Comparison of Phytomass/Volume and Allometric Projections," Mitigation and Adaptation Strategies for Global Change 2(2-3): 247-265; (2) Schroeder, P., S. Brown, J. Mo, R. Birdsey and C. Cieszewski. 1997. "Biomass Estimation for Temperate Broadleaf Forests of the United States Using Inventory Data," Science 43(3): 424-434; (3) Brown, S., 1997. Estimating Biomass and Biomass Change of Tropical Forests: A Primer. FAO Forestry Paper 134, Food and Agricultural Organization of the United Nations, Rome, Italy.

Soil organic matter and ecosystem models play an important role in understanding land management and soil organic carbon sequestration relationships and for projecting changes ị soil organic carbon through time (Parton et al. 1995; Smith et al. 1997). The rate of soil organic carbon decomposition is usually well represented as a first-order process where the amount converted to $\mathrm{CO}_{2}$ per unit time 
depends on the current size of the various soil organic carbon fractions times their rate constants (Smith et al. 1997). Since the amounts present in each carbon fraction depends on management history, these amounts must be accurately accounted if the model estimates of soil organic carbon dynamics are to be realistic. Generally, information on previous management history is less complete than needed to establish adequate initial conditions for models. When management history is well known for a period of at least 20-50 years, many soil organic carbon models do well in simulating management-induced soil organic carbon changes (Smith et al. 1997). Model validation remains an important step for validating models assumptions.

The Graz/Oak Ridge Carbon Accounting Model (GORCAM) is another model that can be used to examine the impact of forestry projects on carbon emissions (Schlamadinger and Marland 1996). GORCAM provides a simplified description of carbon stocks and flows associated with the management of forests. GORCAM calculates carbon accumulation in plants, in short- and long-lived wood products, in fossil fuels not burned because biofuels are used instead, and in fossil fuels not burned because production and use of wood products requires less energy than does production and use of alternative materials that provide the same service (Marland et al. 1997). GORCAM has been used to evaluate the impact on carbon emissions by biofuel district heating systems being installed or proposed in Vermont (McLain 1998), as well as estimating the amount of carbon sequestered by a sustainable forestry management project in Mexico (Bird et al. 1997).

More complex but promising models are being developed (USDOE 1994). Simple modeling requires relatively little time and effort, however, the gross estimates are probably neither accurate nor precise (MacDicken 1997). In general, field/site measurements are preferred over standard tables and computer models, because site-specific field studies provide higher quality data and thus higher credibility, although at a higher cost.

\subsubsection{Remote sensing}

Remote sensing (along with ground-based measurements) can be used to monitor land area changes, map vegetation types, delineate strata for sampling, and assess leakage and base case assumptions (Box 3). Remote sensing is defined as the acquisition of data about an object or scene by a sensor that is far from the object (Colwell 1983; see also Slater 1980; Swain and Davis 1978; Wilkie and Finn 1996). Aerial photography, satellite imagery, and radar are all forms of remotely sensed data. Usually, remote sensing refers to the following two types: (1) "high-level" remote sensing that uses satellite imagery, and (2) "low-level" remote sensing that relies on aerial photography. 


\section{Box 3}

\section{Remote Sensing Example}

The need for a statistical approach to sampling remote sensing databases is crucial for monitoring deforestation and other more comprehensive land use/land-cover processes. Even though a great deal of information exists at the project level, there is still much uncertainty when there is a need to scale up from the project scale to regional or national scales. In addition to sampling, additional aspects such as sensor spatial and spectral resolution, frequency of acquisition of remote sensing information, and economic costs are key components of the monitoring program and its methodological development.

Evaluation method: Sanchez-Azofeifa et al. (1997) used the Landsat tile system (World Reference System 2) as a sampling frame for the selection of remote sensing data. A remotely sensed data set of a wall-to-wall assessment of deforestation in the Amazon basin was used. The data base consisted of land cover change information extracted from 228 satellite scenes for 1978 and 1988. Deforestation, primary forest, clouds, and naturally occurring non-forest were the main topological attributes. A stratified population was used prior to selecting a sample for random sampling. The population was stratified first by eliminating all scenes with an area of more than $30 \%$ of non-natural forest area and then stratified by total deforestation, deforestation rate, and the permanence of deforestation.

Evaluation concerns: Because of the patchiness of deforestation, random sampling of Landsat scenes can produce significant errors when the goal is to estimate total deforestation.

Findings: Stratification based on permanence contributed to the reduction of error in the estimation of total deforestation when contrasted to random sampling without stratification. Random sampling has the potential for extreme over- or under-estimation of total deforestation. Reductions in error were achieved only when very high sampling densities were obtained. When a new level of stratification was applied, very accurate estimates of the total area deforested were obtained using low sample densities.

FAO Study: In the second phase of the 1990 Forest Resources Assessment, the Food and Agricultural Organization (FAO) of the United Nations employed a statistical survey using remote sensing to sample the forest cover in tropical forests. The same analyst based the approach for the second phase on the comparison of satellite imagery from two dates at the same time, using a uniform classification throughout the tropics. By using this approach, class to class changes in land cover (e.g., from grassland to forest, or vice versa) could be detected and depicted in change matrices according to regions and climatic zones. Information on class to class changes is new and adds substantially to the understanding of the processes of vegetation and deforestation.

Sources: (1) Sanchez-Azofeifa, G., D. Skole, and W. Chomentowski. 1997. "Sampling Global Deforestation Databases: The Role of Persistence," Mitigation and Adaptation Strategies for Global Change, 2(2-3):177-189. (2) Food and Agricultural Organization (FAO) of the United Nations. 1996. Forest Resources Assessment 1990: Survey of Tropical Forest Cover and Study of Change Processes. FAO Forestry Paper 130, Food and Agricultural Organization of the United Nations, Rome, Italy.

High-level remote sensing. Many national and international projects and programs have made use of remote sensing with satellites for land cover change research at a national or international level (FAO 1996; Skole et al. 1997). This type of remote sensing can be done every 5-10 years, in combination with low-level remote sensing. The Face Foundation in the Netherlands and Winrock International have used satellite imagery for evaluating forestry projects (Face Foundation 1997; 
MacDicken 1998). ${ }^{1}$ Remote sensing has been used by several researchers in measuring deforestation in tropical forests in Central and South America (e.g., Dale et al. 1994; Sanchez-Azofeifa et al. 1997; Sanchez-Azofeifa and Quesada-Mateo 1995; Skole and Tucker 1993; Stone et al. 1991). Attempts to estimate biomass from remote sensors have generally been costly and have had mixed results (MacDicken 1997). To date, no one has measured carbon using remote sensing (Brown 1996; MacDicken 1997).

Skole et al. (1997) have proposed an international system for monitoring land cover change which includes studies in specific locations for field validation and accuracy assessments for the large area analyses; these sites could also be useful for evaluating project impacts, if integrated with the approach described next.

Low-level remote sensing. Using aerial photography, videography, and orthophotographs, photographs of land areas can be taken on an annual basis to see whether the project is proceeding according to design. ${ }^{2}$ Field/site measurements and ground truthing will also need to be conducted periodically.

\subsubsection{Field/site measurements}

Field/site measurements include two types of techniques (biomass surveys and destructive sampling) which can be used together in monitoring carbon in forestry projects (Box 4).

1 The Face Foundation was set up by Sep (the Dutch Electricity Generating Board) to fund projects to sequester some of the carbon dioxide emitted into the atmosphere by the burning of fossil fuels when generating electricity in the Netherlands. Face stands for Forests Absorbing Carbon dioxide Emissions.

2 An orthophotograph is a vertical aerial photograph from which the distortions due to varying elevation, tilts and surface topography have been removed, so that it represents every object as if viewed directly from above, as in a map. 


\section{Box 4}

\section{Field/Site Measurement Example}

The Reduced-Impact Logging (RIL) Project, a pilot carbon offset project in Sabah, Malaysia, was initiated in 1992 when a power company provided funds to a timber concessionaire to implement timber-harvesting guidelines in a commercial forest reserve. The rationale for the offset is that when logging damage is reduced, more carbon is retained in living trees and, because soil damage is minimized, forest productivity remains high. It is estimated that logging damage to the remaining biomass can be reduced by as much as $50 \%$ through pre-cutting vines, directional felling, and planned extraction of timber on properly constructed and utilized skid trails. Other benefits include the preservation of biodiversity and reduced susceptibility to weed infestations and destructive fires.

Evaluation method: To estimate the carbon benefit associated with implementation of harvesting guidelines, a monitoring program was developed based on computer modeling and simulation, as well as field studies for measuring carbon stocks and flows. Prior to logging, four logging units (30-50 h a each) were randomly selected from the 450 ha pilot project area; four additional logging units were randomly selected from an adjacent area to be logged conventionally Within each unit, 20-40 permanent plots $\left(1600 \mathrm{~m}^{2}\right)$ were established for pre- and post-harvest measurements. Trees within the plots were tagged, mapped, measured (diameter at breast height, $\mathrm{dbh}$ ) and identified to species or timber species group. Above-ground tree biomass was estimated allometrically using tree inventory data and stem volume-dbh relations and a biomass expansion factor. Below-ground biomass was measured using pits for coarse roots and cores for fine roots. After logging, permanent plots were revisited, and tagged trees were classified by type and degree of damage. From the damage assessment data, the following parameters were estimated: timber volume extracted; necromass produced from harvested trees; necromass produced from trees destroyed during harvesting; and necromass produced from damaged trees that died within the first 8-12 months after logging. Soil disturbance was mapped and measured in the eight logging units that contained permanent plots. Trees in permanent plots were re-measured three years after logging and are scheduled to be remeasured every five years.

Evaluation concerns: the models chosen for calculating biomass were expected to provide reasonable predictions for trees up to $300 \mathrm{~cm} \mathrm{dbh}$, but few data were available for large diameter trees: additional biomass data for large trees from tropical wet and moist forests are needed to improve biomass estimates for old growth forests. For the purposes of monitoring carbon offset projects in natural forest, direct sampling of coarse roots, unless conducted at a relatively high intensity, may not provide a biomass estimate with the desired level of precision. In this study, coarse roots contributed disproportionately to the variance in the estimate for pre-harvest biomass and, consequently, to the difference between the two methods in necromass produced.

Findings: Prior to logging, total plant biomass was about $400 \mathrm{Mg} \mathrm{ha}^{-1}$; root biomass represented $17 \%$ of the above-ground biomass. During the first year after logging, the mean difference between RIL and conventional logging areas in necromass produced per ha was $86 \mathrm{Mg}$; about $62 \%$ of the difference was due to more trees killed in conventional as compared to RIL areas. Fifty-nine percent of the total biomass was in trees ( $\geq 60 \mathrm{~cm} \mathrm{dbh}$ ), placing particular importance on the reliability in estimates of variables related to big trees. The use of a simple factor adjustment to convert aboveground biomass to total biomass may be a reasonable approach to estimating carbon benefits for offset projects when resources for monitoring are limited and below-ground biomass is unlikely to be a major contributor to the carbon benefit.

Sources: (1) Pinard, M. and F. Putz. 1997. "Monitoring Carbon Sequestration Benefits Associated With a Reduced-Impact Logging Project in Malaysia," Mitigation and Adaptation Strategies for Global Change, 2(2-3): 203-215; (2) Pinard, M., F. Putz, J. Tay and T. Sullivan. 1995. "Creating Timber Harvesting Guidelines for a Reduced-Impact Logging Project in Malaysia," Journal of Forestry 93:41-45; (3) Pinard, M. and F. Putz. 1996. "Retaining Forest Biomass by Reducing Logging Damage," Biotropica 28:278-295; (4) Jepma, C. 1997. "Reduced-impact Logging in Indonesia," Joint Implementation Quarterly 3(3): 2. 


\section{Biomass surveys}

Biomass surveys can include one or more of the following methods: research studies; surveys; the monitoring of wood production and end products; and forest inventories. Research studies use intensive data collection and analysis methodologies to typically test research hypotheses. Surveys of project field activities are conducted to see what was actually implemented in the project. This type of monitoring would provide useful data for the evaluation of GHG reduction and sequestration projects, especially if the surveys are combined with other approaches. The monitoring of wood production and end product data is needed to develop historical and trend data for the development of accurate baselines. An account needs to be made of what happens to the wood once it is felled or trees and branches die. If dead wood is regularly collected, it should be measured and its use recorded.

Carbon inventories can be performed at virtually any level of precision desired by inventory sponsors and provide flexibility in the selection of methods, depending on the costs and benefits of monitoring. Monitoring systems need to assess the net difference in each carbon pool for project and nonproject (or pre-project) areas over a period of time. By comparing these changes in the project area to changes in pools unaffected by project activities (i.e. comparison plots), the monitoring effort can assess the impact of the project on carbon storage. Detailed biomass measurement methods can be found in MacDicken (1998).

Above-ground woody biomass. Two approaches are commonly used for assessing the total aboveground biomass of forests (defined as biomass density when expressed as dry weight per unit area): (1) the first approach is based on the use of existing measured volume estimates (volume of biomass per hectare) converted to biomass density (tons/hectare) using a variety of tools; and (2) the second approach directly estimates biomass density using biomass regression equations that relate oven-dry biomass per tree as a function of a single or a combination of tree dimensions (Brown 1997). The regression equations are applied to stand tables or measurements of individual trees. The advantage of this second method is that it produces biomass estimates without having to make volume estimates, followed by application of expansion factors to account for non-inventoried tree components. The disadvantage is that only a few inventories contain stand tables for small diameter classes for all species. The UN Food and Agricultural Organization has recently published a primer on using these two approaches, including a discussion of the limitations of the approaches (Brown 1997). 
Below-ground woody biomass. Roots store carbon and contribute to the build-up of organic soil carbon. The amount of below-ground biomass can be significant: e.g., the ratio of roots to above-ground biomass (i.e., the root:shoot ratio, or $\mathrm{R} / \mathrm{S}$ ) is approximately $25 \%$ (Cairns et al. 1997), and others have estimated that approximately one-third of the mass of a tree is below ground (World Bank 1994a). Hence, it may be necessary to measure tree roots - either on the plots or on trees felled outside the project area - to obtain ratios between above- and below-ground woody biomass.

Calculating carbon storage in woody biomass. Once stand, total tree volume, or weight has been estimated, this measure must be converted into organic carbon weight. There is very little variation in chemical composition of all wood species and on an ash free, moisture free (bone dry) basis, approximately $50 \%$ of wood by weight is carbon, $6 \%$ is hydrogen, and $44 \%$ is oxygen (World Bank 1994a). Although the chemical composition of wood does not vary much, density and moisture content vary considerably by species (e.g., coniferous wood species are generally much less dense than hardwood species). Density can be determined by taking pieces of wood of known dimensions, weighing them, subtracting the weight of water, and dividing the volume into the bone dry weight. Moisture content can be measured by weighing the wood as received and reweighing it after it has been dried in an oven until its weight is constant. Alternatively, a moisture content meter can be used which will give a direct reading of moisture content.

Soil carbon. There is no official internationally agreed upon method for monitoring changes in soil carbon. For most lands, soil is usually a greater store of carbon than is biomass tissue, with the most carbon found in forest soils, followed by grassland soils and arable agricultural soils (Bouwmann 1990; World Bank 1994a). Soil accumulation is a function of soil bulk density, which is a function of other parameters, such as the rates of deposition, decomposition, and translocation ${ }^{1}$. Carbon may be lost from some soils under some forest management schemes: e.g., agroforestry projects will disturb the soil, speeding up heterotrophic decomposition which is the main route for carbon to return to the atmosphere from organic matter, and forest management projects on erosion prone areas will lead to reduced soil carbon through translocation.

The buildup of organic carbon in the soil needs to be measured throughout the project site, down to a depth of $30 \mathrm{~cm}$, since land use change has the greatest effect on the upper soil layers (IPCC 1996;

1 As a consequence of root growth and subsequent decomposition, litter fall and decomposition, microbial degradation and synthesis, mixing by soil fauna, and moisture and temperature cycles, soil organic carbon is allocated over time to different "pools" that are variously defined on the basis of relative recalcitrance which, in turn, governs residence and turnover times. For one typology of soil carbon pools, see Eswaran et al. (1995). 
MacDicken 1997). ${ }^{1}$ Ideally, soil samples should be taken at permanent sample sites in different age and land use classes, and the buildup of soil carbon recorded. The carbon content of the soil can be calculated using a Leco furnace (which measures carbon by high temperature ignition in a stream of oxygen), a thermal conductivity detector (for separating carbon and nitrogen), or chemical treatment (e.g., Walkley-Black method) (Allison 1975). The potentially high cost of measuring soil carbon may suggest that consideration of changes in soil carbon in many forestry projects is not economically prudent.

Forest products. The long-term effectiveness of wood products as a stock for carbon depends on the uses of the wood produced through project activities. The more durable the wood product, the greater the project's carbon storage effect in the medium and long term. However, carbon stored in wood is obviously not stored permanently; organic compounds usually decay and some will ultimately reappear as GHG emissions. A monitoring and evaluation system to measure post-harvest carbon storage, particularly for medium to highly durable products, could allow reporting of additional carbon and improve the economics of projects that seek to grow higher value timber (Brown et al. 1998; MacDicken 1997 and 1998; Winjum et al. 1998).

Although forest products are not accounted for in the International Panel on Climate Change's 1996 Revised Guidelines (see Section 2.4), an account should be made of what happens to the wood once it is felled or trees and branches die. ${ }^{2}$ If dead wood is regularly collected, it should be measured and its use recorded. If it is used as firewood, it may result in lower GHG impacts than if it is left to decompose (due to methane emissions from decomposition). When logs, pulpwood, cord wood and chips are taken to a factory, a record should be made of the fate of this wood: e.g., waste, pulp and board products, animal bedding, fuel within the factory, fuel by households, industry, etc. Similarly, the kinds and quantity of finished products should be recorded: e.g., furniture, recycled paper, or substitute for fossil fuel.

Given the inherent difficulty in determining the exact fate of wood products after they leave the forest or project area, another approach is to determine the proportion of timber that is converted into different products, and use general default values to estimate their average lifetime and decay rates (EcoSecurities 1998). For example, in an analysis of the carbon costs and benefits of silvicultural plantations in Brazil, all pulpwood was assumed to go into the short-term wood

1 Deeper soil layers can also have appreciable carbon stocks, particularly in tropical soils, but they are generally much less impacted by changes in land use/management than are topsoil layers (IPCC 1996).

2 An IPCC expert meeting in Dakar, Senegal, examined a range of approaches for estimating the emissions and removals of $\mathrm{CO}_{2}$ from forest harvesting and wood products (IPCC 1998). 
products pool (average residence time of 0.5 years), while sawlog wood was assumed to be allocated with $40 \%$ entering the short-term pool, $50 \%$ the medium-term pool (average residence time of 5 years), $8 \%$ the long-term pool (average residence time of 50 years), and $2 \%$ the very long-term pool (average residence time of 500 years) (Fearnside 1995).

\section{Destructive sampling}

Destructive sampling is the oldest methodology for estimating biomass density at a site. It involves selection of representative sites in the ecosystem (usually a few square meters each, and in a few rare cases as large as one hectare each). All the vegetation is uprooted and the pertinent parameters obtained, e.g., volume, weight at different moisture contents, proportions of various components like branches, stem and roots, and chemical composition of the biomass. Detritus is also collected and similarly analyzed. This is usually accompanied with similar measurements of parameters of interest in the soil profile, including soil layers, structure, texture and cation exchange capacity, organic carbon, inorganic nutrients, etc.

\subsubsection{Sampling}

Sampling allows overall project performance to be assessed based on the performance of a manageable number of plots. For large, heterogeneous areas, a multi-stage approach may be appropriate, in which each stratum is divided into primary sampling units which are then subsequently divided into secondary sampling units. The type and intensity of sampling depends on the variations within each stratum. Biomass sampling studies typically aim for estimates of biomass weight or volume accurately to within $\pm 15 \%$ with a relatively high confidence (e.g., 90 or 95\%) (World Bank 1994a); biomass estimates within 2-10\% of the true value are also realistic (MacDicken 1997).

A universally accepted level of precision for estimates of carbon benefits does not currently exist. As a general rule, the cost of a monitoring program is related to the precision of the estimate of the carbon benefit: the higher the precision, the higher the cost of measurement. To a certain extent, the market value of carbon sequestered in carbon offset projects will determine the level of precision that is cost-effective. Some experts suggest that a reasonable target for the precision of a project's carbon benefit is a standard error of $20-30 \%$ of the mean (EcoSecurities 1998). Another option would be to adjust the carbon claims by discounting the standard error of measurements. Finally, it is 
unlikely that a common level of precision will be used for each of the significant carbon pools and flows.

The use of permanent sample plots is generally regarded as a statistically superior means of evaluating changes in forest conditions (MacDicken 1998). Permanent plots allow reliable and efficient assessment of changes in carbon fixation over time, provided that the plots represent the larger area for which the estimates are intended. This means that the sample plots must be subject to the same management as the rest of the project area. The use of permanent plots also allows the inventory to continue reliably over more than one rotation. Finally, permanent plots permit efficient verification at relatively low cost, compared to those that use temporary plots or plotless methods: a verifying organization can find and measure permanent plots at random to verify the design and implementation of a project's carbon monitoring plan. The size of the permanent plots will depend on the heterogeneity of the site.

Instead of conducting a census, three sampling approaches may be used: simple random sampling, systematic sampling, and stratified random sampling. For carbon inventory, stratified random sampling is generally preferred, since this often yields more precise estimates for a fixed cost than the other options (see Box 3) (MacDicken 1998). Stratified random sampling requires dividing the population into nonoverlapping groups. Each stratum can be defined by vegetation type, soil type, or other parameters for sampling purposes.

Useful tools for defining strata include satellite images, aerial photographs, and maps of vegetation, soils or topography (see Box 3). These should be combined with ground measurements for verifying remotely-sensed images. A geographic information system can be used to determine stratum size and the size of exclusions or buffer zones.

MacDicken (1998) provides a spreadsheet for inventory decisions which calculates sample sizes using standard formulas based on measured variation for the carbon pool to be sampled. Two approaches are proposed: (1) sample plot allocation based on fixed precision levels; and (2) optimum allocation of plots among strata given fixed inventory costs.

\subsubsection{Application of forestry monitoring techniques}

The unique features and diversity of forestry projects, the monitoring domain and socioeconomic issues pertaining to forestry projects, and the variety of carbon pools that might be impacted by forestry projects makes the monitoring and evaluation of forestry projects very challenging. While 
forestry projects offer the potential for significant carbon sequestration, the verification of carbon credit claims will necessitate significant technical and financial resources. A variety of monitoring techniques are available for forestry projects (i.e., módeling, remote sensing, and field/site measurement) for determining the amount of carbon sequestered by forestry projects, each having its own advantages and disadvantages (Table 2). ${ }^{1}$ One of the key decisions that will need to be made will be determining the optimal level of costs for implementing these techniques.

We expect the use of these techniques will vary by the size of the project area, region, type of forest, and the purpose of the project (e.g., to protect forests, supply energy, or provide wood products). Using some of these criteria, we provide a table classifying monitoring techniques by forestry typology (Table 3). The threshold for distinguishing small from large projects is not known and will be left to the project developer to decide.

${ }^{1}$ As noted in Section 2.3, the monitoring and evaluation of the impacts of biomass energy projects will rely on the methods described in this section as well as methods used in monitoring and evaluating energy-efficiency projects (Vine and Sathaye 1999). 
Table 2. Advantages and Disadvantages of Forestry Monitoring Techniques

\begin{tabular}{|c|c|c|}
\hline Techniques & Advantages & Disadvantages \\
\hline Modeling & $\begin{array}{l}\text { Relatively quick and } \\
\text { inexpensive. Useful for baseline } \\
\text { development. Can be used for } \\
\text { bioenergy projects. Most useful } \\
\text { as a complement to other } \\
\text { methods. }\end{array}$ & $\begin{array}{l}\text { Relies on highly simplified } \\
\text { assumptions. Need to be } \\
\text { calibrated with onsite data. }\end{array}$ \\
\hline High-Level Remote Sensing & $\begin{array}{l}\text { Provides relatively rapid } \\
\text { regional-scale assessments of } \\
\text { land cover, land use, and green } \\
\text { vegetation biomass. Useful for } \\
\text { monitoring leakage. }\end{array}$ & $\begin{array}{l}\text { Time and knowledge needed to } \\
\text { transform spectral } \\
\text { classifications into accurate } \\
\text { land use or land-cover } \\
\text { classifications. Access to high- } \\
\text { quality imagery may not be } \\
\text { available during certain } \\
\text { seasons or due to sun angles. } \\
\text { Has not been used to measure } \\
\text { carbon. Can be quite expensive. }\end{array}$ \\
\hline Low-Level Remote Sensing & $\begin{array}{l}\text { Complements high-level remote } \\
\text { sensing. Useful for monitoring } \\
\text { leakage. }\end{array}$ & $\begin{array}{l}\text { In test phase. Less expensive } \\
\text { than high-level remote sensing. }\end{array}$ \\
\hline Field/Site Measurements & $\begin{array}{l}\text { Useful for determining what } \\
\text { was actually implemented in } \\
\text { project and for tracking fate of } \\
\text { wood products. Flexible in } \\
\text { selection of methods and } \\
\text { precision. Peer reviewed and } \\
\text { field tested systems available. } \\
\text { Using control plots, can } \\
\text { calculate net carbon } \\
\text { sequestration. }\end{array}$ & $\begin{array}{l}\text { May be more expensive than } \\
\text { other methods. }\end{array}$ \\
\hline
\end{tabular}




\section{Table 3. Forestry Monitoring Methods by Forestry Project Type}

$$
(\checkmark=\text { applicable; blank }=\text { not applicable })
$$

\begin{tabular}{|c|c|c|c|c|c|}
\hline \multirow[b]{2}{*}{ Methods } & \multicolumn{2}{|c|}{$\begin{array}{c}\text { Carbon } \\
\text { conservation }\end{array}$} & \multicolumn{2}{|c|}{$\begin{array}{c}\text { Carbon } \\
\text { sequestration } \\
\text { and storage }\end{array}$} & \multirow[t]{2}{*}{$\begin{array}{c}\text { Carbon } \\
\text { substitution }\end{array}$} \\
\hline & $\begin{array}{l}\text { Small } \\
\text { Project }\end{array}$ & $\begin{array}{c}\text { Large } \\
\text { Project }\end{array}$ & $\begin{array}{l}\text { Small } \\
\text { Project }\end{array}$ & $\begin{array}{c}\text { Large } \\
\text { Project }\end{array}$ & \\
\hline Modeling & $\mathcal{V}$ & $\mathcal{V}$ & $\mathscr{N}$ & $\boldsymbol{v}$ & \\
\hline Remote Sensing & & $\checkmark$ & & $\checkmark$ & $\checkmark$ \\
\hline Field/Site Measurements & $\checkmark$ & $\checkmark$ & $\sim$ & $\checkmark$ & $\checkmark$ \\
\hline
\end{tabular}

The monitoring process is an evolving process that is expected to change over time. For example, in the early stages of a reforestation project, monitoring will most likely be visual, with widely scattered sample plots, because the focus is on seedling survival, not on carbon sequestration (carbon sequestration is likely to be minimal for the first five years of the project). Soil measurements would also not be necessary in the first few years of the project. Once the stand is established, monitoring would switch to growth evaluation and soil monitoring. The results from the monitoring would provide feedback to reporting and financial planning models (i.e., calibration and real-time adjustment).

\subsubsection{Quality assurance guidelines}

Implementing data collection and analysis methods is both an art and a science, and there are known problems associated with these methods. Thus, simply adhering to minimal standards contained in these guidelines is no guarantee that an evaluator is doing a professional job. Accordingly, we have included Quality Assurance Guidelines (QAG) that require evaluators and verifiers to indicate specifically how basic methodological issues and potentially difficult issues 
were addressed (see Appendices B and C). ${ }^{1}$ The guidelines are contained in two tables, covering all of the data collection and analysis methods.

The QAG should be seen as practice and reporting standards, rather than highly prescriptive methodological standards: the QAG require evaluators to describe how certain key issues were addressed rather than to require them to address these issues in a specific way. Adherence to such guidelines still allows the methods to be shaped by the interaction of the situation, the data, and the evaluator.

The QAG are to be used in three ways. First, they are included in the Monitoring and Evaluation Reporting Form (Appendix B), so that evaluators will know that they will be held accountable for conducting a sound analysis. Second, they are included in the Verification Reporting Form (Appendix C), so that policymakers and other stakeholders could review a verification report and quickly assess whether the evaluator addressed the most basic methodological issues. This is especially important since most stakeholders do not have the time nor personnel to carefully scrutinize every written evaluation report, let alone attempt to replicate the results of all of these studies. The details of how evaluators addressed these methodological issues should be contained in the very detailed documentation that would be in the technical appendix of any evaluation report, or in working papers. Finally, the QAG can be used to create a common language to facilitate communication among project developers, evaluators, verifiers, policymakers, and other stakeholders.

Evaluators and verifiers should consider the issues involved in conducting these methods, some of which have been described previously, and which are listed in Table 4 and described in more detail in Appendices B and C. The column headings refer to the data collection and analysis methods described in Section 4.2. The rows refer to the types of issues to be considered when addressing each method. Examples of each of these issues are mentioned below:

- Calibration: e.g., were the assumptions and estimated results of models compared and adjusted to actual data?

- Sample and sampling: e.g., what kind of sampling design was used?

- Data type and sources: e.g., what was the source of the data and the methods used in collecting data?

1 These guidelines are primarily based on the QAG that were developed for the California Demand-Side Management Advisory Committee (CADMAC) (Ridge et al. 1997). In theory, the QAG could be used in the estimation stage, but are not included in the Estimation Reporting Form. 
- Specification and error: e.g., what kind of errors were encountered in measuring variables and how were these errors minimized?

- Outliers: e.g., how were outliers and influential observations identified and handled?

- Missing data: e.g., how were missing data handled?

- Weather: e.g., what was the source of weather data used for the analysis?

- Comparison group: e.g., how was a comparison group defined for estimating net carbon sequestered?

- Measurement duration: e.g., what was the duration and interval of measuring carbon?

- Variance: e.g., how were confidence intervals derived?

Table 4. Quality Assurance Issues for Data Collection and Analysis Methods ${ }^{1}$

$$
(\mathscr{V}=\text { applicable; blank }=\text { not applicable })
$$

\begin{tabular}{|c|c|c|c|}
\hline & Modeling & $\begin{array}{c}\text { Remote } \\
\text { Sensing }\end{array}$ & $\begin{array}{c}\text { Field/Site } \\
\text { Measurements }\end{array}$ \\
\hline \hline Calibration & $\checkmark$ & & \\
\hline $\begin{array}{c}\text { Sample and } \\
\text { sampling }\end{array}$ & & $\checkmark$ & $\checkmark$ \\
\hline $\begin{array}{c}\text { Data type } \\
\text { and sources }\end{array}$ & $\checkmark$ & $\checkmark$ & $\checkmark$ \\
\hline $\begin{array}{c}\text { Specification } \\
\text { and error }\end{array}$ & & $\checkmark$ & $\checkmark$ \\
\hline Outliers & & $\checkmark$ & $\checkmark$ \\
\hline Missing data & $\checkmark$ & $\checkmark$ & $\checkmark$ \\
\hline Weather & $\checkmark$ & $\checkmark$ & $\checkmark$ \\
\hline $\begin{array}{c}\text { Comparison } \\
\text { group }\end{array}$ & & $\checkmark$ & $\checkmark$ \\
\hline $\begin{array}{c}\text { Measurement } \\
\text { duration }\end{array}$ & & $\checkmark$ & $\checkmark$ \\
\hline Variance & $\checkmark$ & $\checkmark$ & $\checkmark$ \\
\hline
\end{tabular}

1 Quality assurance issues (rows) are described in Appendices B and $C$, and the data collection and analysis methods are described in Section 4.2. 


\subsubsection{Project leakage and positive project spillover}

In the beginning stages of a project, project leakage and positive project spillover are likely to be modest, so that the MERVC of such impacts may not be a priority. These effects are also likely to be insignificant or small for small projects and for certain types of projects. Under these circumstances, it may be justified to disregard these impacts. This would help reduce MERVC costs. As the projects become larger or are more targeted to market transformation (see Section 4.2.9), these impacts should be evaluated. As an example, in the Rio Bravo Carbon Sequestration Pilot Project, secondary impacts were deemed to be significant if the impacts resulted in an alteration in emissions of $5,000 \mathrm{tC} / \mathrm{yr}$ or above (i.e., $20 \%$ of the 1 million $\mathrm{tC}$ estimated to be sequestered through the purchase of forested land, or $200,000 \mathrm{tC}$, divided by the 40 years of the project life) (Programme for Belize 1997). Furthermore, to be "clearly and directly" attributable to the project, the secondary impacts had to manifest themselves within 1 year (Programme for Belize 1997); for the evaluation of forestry projects, longer periods (e.g., 5 years) may be necessary.

\subsubsection{Market transformation}

The focus of most evaluations of market transformation projects is on market effects (Eto et al. 1996; Schlegel et al. 1997): e.g., the effects of forestry projects on the structure of the market or the behavior of market actors that lead to increases in the adoption of forestry products, services, and/or practices. In order to claim that a market has been transformed, project developers and evaluators need to demonstrate the following (adapted from Schlegel et al. 1997):

- There has been a change in the market that resulted in increases in the adoption and penetration of forestry technologies and/or practices.

- That this change was due at least partially to a project (or program or initiative), based both on data and a logical explanation of the program's strategic intervention and influence.

- That this change is lasting, or at least that it will last after the project is scaled back or discontinued.

The first two conditions are needed to demonstrate market effects, while all three are needed to demonstrate market transformation. The third condition is related to the discussion on permanence: if the changes are not lasting (i.e., they do not persist), then market transformation has not occurred. Because fundamental changes in the structure and functioning of markets may occur only slowly, evaluators should focus their efforts on the first two conditions, rather than waiting to prove that the effects will last. 
To implement an evaluation system focused on market effects, one needs to carefully describe the scope of the market, the indicators of success, the intended indices of market effects and reductions in market barriers, and the methods used to evaluate market effects and reductions in market barriers (Schlegel et al. 1997). Evaluation activities will include one or more of the following: (1) measuring the market baseline; (2) tracking attitudes and values; (3) tracking sales; (4) modeling of market processes; and (5) assessing the persistence of market changes (Prahl and Schlegel 1993). As one can see, these evaluation activities will rely on a large and diverse group of data collection and analysis methods, such as: (1) surveys of customers, forestry companies, furniture manufacturers, government organizations, etc.; (2) analytical and econometric studies of cost data and sales data; and (3) process evaluations.

\subsection{Re-estimating the Baseline}

During project implementation, the baseline needs to be re-estimated, based on monitoring and evaluation data collected during this period. In some cases, allometric equations for estimating carbon emissions may be used, but only under special conditions (see Section 3.2). In the re-estimation of a baseline, free ridership needs to be examined.

\subsubsection{Free riders}

The most common method of developing an estimate of free riders is to ask project developers what they would have done in the absence of the project (also referred to as "but for the project" discussions). Based on answers to carefully designed survey questions, project developers are classified as free riders (yes or no). For example, would the construction of an energy-efficient sawmill have been constructed without a joint implementation project. There are at least two problems in using this approach: (1) very inaccurate levels of free ridership may be estimated, due to questionnaire wording; ${ }^{1}$ and (2) there is no estimate of the level of inaccuracy, for adjusting confidence levels. Nevertheless, some interviewing of project developers needs to be conducted for deriving estimates of free ridership.

1 For example, in an analysis of free ridership in a high-efficiency refrigerator program, estimates of free ridership varied from $37 \%$ to $89 \%$, depending on questionnaire wording (Boutwell et al. 1992). 


\subsubsection{Comparison plots}

For some projects, the comparison of the amount of carbon storage achieved under a project with the amount that would have been achieved without the project requires monitoring the project area as well as nonproject comparison sites prior to project startup. One can have comparison plots within the project area or outside the project area to supplement the sites within the project area. To establish the internal validity of the evaluation results, the comparison plots must be similar enough to the project area so that they can serve as a proxy for the project area under the assumption that the project was not implemented. ${ }^{1}$ Similarity can be established on the basis of the key factors that determine biomass productivity: rainfall, temperature, insolation, soil characteristics, species and land management. Land management is the most difficult criterion to meet since it could diverge significantly between comparison site and project areas. By selecting comparison plots within the project area, these divergences can be eliminated or minimized. Also, there is no general way to ensure that the comparison plots will remain valid throughout the life of the project; special care and monitoring are needed.

1 This is particularly important when trying to estimate deforestation rates for protected areas. The estimation of deforestation rates is critical in establishing project baselines, and slight changes in the estimates of deforestation can significantly affect the amount of carbon saved by a carbon offset project (see Busch et al. 1999). 


\section{Reporting of GHG Reductions}

Reporting occurs throughout the MERVC process and refers to measured GHG and non-GHG benefits and costs of a project (in some cases, organizations may report on their estimated impacts, prior to project implementation, but this is not the focus of these guidelines). ${ }^{1}$ Reporting guidelines for each of the Kyoto Protocol's flexibility mechanisms (e.g., joint implementation (Article 6), Clean Development Mechanism (Article 12), and emissions trading (Article 17)) are to be developed by the Conference of Parties.

The Framework Convention on Climate Change's (FCCC) Subsidiary Body for Scientific and Technological Advice (SBSTA) developed a Uniform Reporting Format (URF) for activities implemented jointly under a pilot program; the format was approved by the SBSTA as part of the implementation of the FCCC (SBSTA 1997). In completing the URF, the project proposers need to estimate the projected emissions for their project baseline scenario and project activity scenario. They must estimate cumulative effects for carbon dioxide, methane, nitrous oxide, and other greenhouse gases. This format contains a section on benefits (environmental and socioeconomic) which requires quantitative information; qualitative information is acceptable when quantitative information is not available. Project developers need to describe how their project is compatible with, and supportive of, national economic development and socioeconomic and environmental priorities and strategies. Furthermore, the URF requests information on the "practical experience gained or technical difficulties, effects, impacts or other obstacles encountered" (either quantitatively or qualitatively). The impacts include environmental or socioeconomic impacts. This type of information will continue to be necessary, since sustainable development is one of the principal goals of the Clean Development Mechanism (Section 8).

We have developed a Monitoring and Evaluation Reporting Form (MERF) that we recommend that evaluators use when reporting changes in carbon stock (Appendix B). It is expected that the MERF will be distributed to project participants, the host country, the investor country, the FCCC Secretariat, and the CDM Executive Board. Project developers and evaluators may modify this form based on their past experience in using similar forms. The MERF complements, but does not substitute for, the SBSTA's URF. In completing the MERF, in addition to providing basic contact information and a description of the project, evaluators need to present the estimated and measured changes in carbon stock for the project baseline and the project activity cases, and net changes in carbon stock.

1 Appendix A contains an Estimation Reporting Form that provides some guidance to project developers at the design stage; however, we expect that additional information will need to be provided for registering a project. 
Evaluators also need to provide information on the precision of the results, the data collection and analysis methods used in re-estimating the baseline and in calculating changes in carbon stock; in particular, how estimates of free ridership, project leakage, positive project spillover, and market transformation were estimated (where calculated). Evaluators must provide information on key uncertainties affecting all estimates of changes in carbon stock. At the end of the MERF, evaluators are asked to provide information on environmental and socioeconomic impacts and indicate whether there is consistency between environmental laws, environmental impact statements and expected environmental impacts.

\subsection{Multiple Reporting.}

Several types of reporting might occur in forestry projects: (1) impacts of a particular project could be reported at the project level and at the program level (where a program consists of two or more projects); (2) impacts of a particular project could be reported at the project level and at the entity level (e.g., a utility company reports on the impacts of all of its projects); and (3) impacts of a particular project could be reported by two or more organizations as part of a joint venture (partnership) or two or more countries. The MERF reports project results, although these results could be combined with other project results for reporting at the program or entity level. To mitigate the problem of multiple reporting, project-level reporters should indicate whether other entities might be reporting on the same activity and, if so, who. If there exists a clearinghouse with an inventory of stakeholders and projects, multiple reporting might not constitute a problem. For example, in their comments on an international emissions trading regime, Canada (on behalf of Australia, Iceland, Japan, New Zealand, Norway, Russian Federation, Ukraine and the United States) proposed a national recording system to record ownership and transfers of assigned amount units (i.e., carbon offsets) at the national level (UNFCCC 1998b). A synthesis report could confirm, at an aggregate level, that bookkeeping was correct, reducing the possibility of discrepancies among Parties' reports on emissions trading activity. 


\section{Verification of GHG Reductions}

Verification refers to establishing whether the GHG reductions assessed by the evaluators actually occurred, similar to an accounting audit performed by an objective, certified party. If carbon credits become an internationally traded commodity, then verifying the amount of carbon reduced or fixed by projects will become a critical component of any trading system. Investors and host countries may have an incentive to overstate the GHG emissions reductions from a given project, because it will increase their earnings when excessive credits are granted. For example, these parties may overstate baseline emissions or understate the project's emissions. To resolve this problem, there is a need for external (third-party) verification.

The verifier is expected to conduct an overall assessment of the quality and completeness of each of the GHG impact estimates. To this end, the verifier will request information in a Verification Reporting Form (VRF) (Appendix C), similar to the Monitoring and Evaluation Reporting Form (Appendix B). It is expected that the VRF will be distributed to project participants, the host country, the investor country, the FCCC Secretariat, and the CDM Executive Board. Verifiers may modify this form based on their past experience in using similar forms. Verifiers will use additional material and data for evaluating the performance of forestry projects. For example, verifying baseline and post-project conditions may involve inspections, spot measurement tests, or assessments, as well as requesting documentation on key aspects of the project. In addition, the following general questions regarding quality and validity need to be asked: (1) are the monitoring and evaluation methods well documented and reproducible? (2) have the results been checked against other methods? and (3) have results been compared for reasonableness with outside or independently published estimates? Verification can occur without certification.

Verifiers could be active from the beginning of the project's operations, but in our mind, verification occurs after the project begins regular operations. After the project's first operational interval (e.g., one year), and periodically thereafter (e.g., annually), the verifier would verify the project's carbon sequestration in the preceding period. This may include the following tasks (personal communications from Johannes Heister, The World Bank, Jan. 12, 1999 and Bill Stanley, The Nature Conservancy, Jan. 13, 1999):

- Review continued compliance of the project operator with the agreed procedures for project maintenance and monitoring.

- Audit the relevant physical measurements and statistical data collected at the project site and, if so required by the monitoring and evaluation plan, also outside 
of the project boundaries (especially if project leakage, positive project spillover, and market transformation are expected).

- Check whether carbon sequestration estimates have been calculated correctly (including a check of the data used in the calculation of the baseline).

- Examine the comparison of the actual, verified carbon sequestration with the estimated carbon sequestration.

- Assess whether significant environmental and socioeconomic impacts have been identified, quantified, and addressed.

- Alert the project participants of any developments that could lead to increased risks and that could jéopardize the success of the project.

The verifier would issue a report for each verification period. The report would cover the above tasks in a transparent manner and in such a way that the quantification of the carbon sequestration achieved during the verification period could, in principle, be reproduced by other interested parties. Based on the verification report and other lessons learned, the project participants may want to amend their monitoring and evaluation plan or other procedures. 


\section{Certification of GHG Reductions}

Certification refers to certifying whether the measured GHG reductions actually occurred. This definition reflects the language in the Kyoto Protocol regarding the Clean Development Mechanism and "certified emission reductions." However, as noted in Section 1.1, some argue that "certification" could be done ex-ante, to certify a proposed offset, assuming that it is carried out as planned. Similarly, some propose CDM projects to be "certified" when they are approved by a host country; however, in this situation, "registered" or "validated" appears to be a more accurate descriptor (see UNFCCC 1998b).

At this time, certification is expected to simply be the outcome of a verification process: i.e., no other measurement and evaluation activities are expected to be conducted. Each of the Kyoto Protocol's flexibility mechanisms (e.g., joint implementation (Article 6), Clean Development Mechanism (Article 12), and emissions trading (Article 17)) requires some form of "government approval" either at the point of transfer, or under Article 3, at the point that the part of the assigned amount or emissions reduction unit is added to or deducted from Annex I Parties' assigned amount. However, only Article 12 provides for a process of auditing and certification that would provide for an objective assessment of whether the transfer was likely to result in net emissions reduction. Hence, part of the discussions in implementing the Kyoto Protocol will focus on the establishment of certification procedures for emissions reduction units generated and traded through these mechanisms.

The value-added function of certification is in the transfer of liability/responsibility to the certifier (personal communication from Marc Stuart, EcoSecurities, Ltd., Jan. 21, 1999). The amount of liability will be negotiated for each specific contract. Ultimately, sellers of emissions reduction units (credits) are responsible for the quality of the credits they deliver. The sellers would, therefore, need to provide the appropriate documentation before they could transfer the credits. This is what certification provides. In the case of CDM credits, there is a great responsibility on the part of the certifiers, since non-Annex I countries are unlikely to have UNFCCC-level penalties in place. A private entity that comes under liability due to credit delivery failure would have some recourse against the certifier of the failed emission credit.

Certification companies need to be accredited by some higher body: e.g., an international accreditation board, established under the auspices of the UNFCCC. ${ }^{1}$ This board would certify

1 An alternative accreditation option is to place all accreditation procedures into the International Standards Organization (ISO) process. The ISO is the standard keeper for a variety of process 
companies and make sure these companies are abiding by certain standards (e.g., via spot auditing). For instance, SGS (see Section 1.6.3), Rainforest Alliance, and the Soil Association are certification companies that are accredited by the Forest Stewardship Council to certify that forests meet the standards of the Forest Stewardship Council as set forth in their "Principles and Criteria for Forest Management" (see Section 1.6.7) (personal communication from Pedro Moura-Costa, EcoSecurities, Ltd., Jan. 28, 1999).

evaluations and quality standards (e.g., ISO 9001 or 14001) and, for many industries, certification under the ISO guidelines has become a de facto international performance standard. However, ISO is a non-governmental process and has not been involved in the type of certification activities which result in quantitative output (e.g., varying levels of emission reductions), rather than passing a series of qualitative evaluations (personal communication from Marc Stuart, EcoSecurities, Ltd. Jan. 21, 1999). The involvement of the ISO would require that this organization work closely with the UNFCCC and governments. 


\section{Environmental and Socioeconomic Impacts}

The Kyoto Protocol exhorts Annex B parties, in fulfilling their obligations, to minimize negative social, environmental and economic impacts, particularly on developing countries (Articles 2.3 and 3.14). ${ }^{1}$ Furthermore, one of the primary goals of the Clean Development Mechanism is sustainable development. ${ }^{2}$ At this time, it is unclear on what indicators of sustainable development need to be addressed in the evaluation of forestry projects. Once there is an understanding of this, then MERVC guidelines for those indicators will need to be designed. For example, if biodiversity needs to be monitored and evaluated, then items similar to the Biodiversity Convention may need to be addressed (Box 5). At a minimum, forestry projects should meet current country guidelines for nonClean Development Mechanism projects.

LBNL's MERVC guidelines for forestry projects include environmental and socioeconomic impacts for two additional reasons. First, the permanence of GHG reductions and carbon sequestration and the sustainability of forestry projects depend on individuals and local organizations that help support a project during its lifetime. Both direct and indirect project benefits will influence the motivation and commitment of project participants. Hence, focusing only on GHG impacts would present a misleading picture of what is needed in making a project successful or making its GHG benefits sustainable. Second, a diverse group of stakeholders (e.g., government officials, project managers, non-profit organizations, community groups, project participants, and international policymakers) are interested in, or involved in, forestry projects and are concerned about their multiple impacts. In the monitoring and verification forms (Appendices B and C), checklists are provided for developers, evaluators, and verifiers to qualitatively assess the impacts described in this section. These checklists are not exhaustive but are included to indicate areas that need to be assessed. Other existing guidelines are better suited for addressing these impacts: e.g., third-party forestry certifiers are examining these impacts under the aegis of the Forest Stewardship Council (Forest Stewardship Council 1996), and the World Bank has developed guidance documents for World Bank-supported projects (World Bank 1989). LBNL's checklists should help to improve the credibility of the project (by showing

1 As defined in the Kyoto Protocol, Annex B countries are OECD countries and countries undergoing the process of economic transition to a market economy (UNFCCC 1997).

2 In one definition, development is sustainable when it "meets the needs of the present without compromising the ability of future generations to meet their own needs" (World Commission on Environment and Development 1987). In order to translate this general definition to specific applicable policies, a variety of definitions have appeared, sometimes serving different objectives and interest groups (see Makundi 1997; Michael 1992; O'Riordan 1988). 
stakeholders that these impacts have, at least, been considered) as well as to facilitate the review of forestry projects.

\section{Box 5}

\section{Items to Monitor under the Biodiversity Convention}

Under the UN Convention on Biodiversity, the following specific elements in the mentioned articles of the Convention can be classified as requiring some specific action for the purpose of compliance. If the MERVC guidelines for climate change projects require non-contravention (or enhancement) of the Biodiversity Convention, then to the extent applicable in the climate change project, these items need to be monitored, evaluated, reported, verified and certified.

\section{Article 7:}

Article 8:

- Inventory of species, genetic materials, habitats, ecosystems and adverse impacts

- Manage and monitor adverse impacts on biological diversity, including ecosystem fragmentation, pollution, and loss of species and nutrients.

- Monitor changes in the processes that generate and maintain biodiversity e.g. natural disturbance regimes, species dispersal and migration, reproduction, succession, trophic dynamics, etc.

- Institute a plan to protect and sustainably manage vulnerable ecosystems, including establishment of buffer zones

- Maintain viable populations of species in natural surroundings.

- Prevent the introduction of, control or eradicate those alien species which threaten ecosystems, habitats or other species.

- Preserve and maintain knowledge, innovations and practices of indigenous and

Article 9: local communities and equitably share benefits.

Article 10:

Recover and reintroduce threatened species.

Article 12:

Protect and encourage compatible customary uses of biological resources.

Article 14:

Cooperate in the application of scientific and technological advances in conservation and use of biological resources.

Article 15:

Coordinate and share information on biodiversity adverse activities with other parties, including those outside the national boundaries.

- Facilitate access to genetic resources for environmentally sound uses by other parties to the Convention.

- Carry out relevant scientific research with participation of all involved

Article 16: parties, and equitably share the results and benefits of such research.

Provide and facilitate access to and transfer of technology, consistent with intellectual property rights.

Source: UNEP. 1992. Convention on Biodiversity, Nairobi, United Nations Environmental Program. 


\subsection{Environmental Impacts}

Forestry projects have widespread and diverse environmental impacts that go beyond GHG impacts (Frumhoff et al. 1998). The environmental benefits associated with forestry projects can be just as important as the global warming benefits. Potential environmental impacts that need to be considered are presented in Table 5. Direct and indirect project impacts need to be examined, as well as "avoided negative environmental impacts" (e.g., the deferral of the construction of a new dam). Both gross and net impacts need to be evaluated.

At a minimum, developers need to describe the environmental impacts associated with the project. ${ }^{1}$ In addition, the developer needs to identify any proposed mitigation activities to address the negative impacts (e.g., draining of wetlands and planting of monocultures of exotic species in sites where natural or assisted restoration of indigenous forests is feasible). The filing of an environmental impact statement (EIS) is likely to help ensure the permanence of forestry projects. Where applicable, developers need to indicate whether an EIS has been filed and that their response to the checklist in Table 5 is consistent with the EIS. In addition, developers need to indicate if any existing state laws require these impacts to be examined.

At a minimum, evaluators need to review the checklist of environmental impacts and the EIS, if available. Evaluators need to collect some minimal information on potential impacts via surveys or interviews with key stakeholders. The evaluator should also check to see: (1) whether any existing state laws require these impacts to be examined, (2) if any proposed mitigation efforts were implemented, and (3) whether expected positive benefits ever materialized. Evaluators may want to conduct some short-term monitoring to provide conservative estimates of environmental impacts. The extent and quality of available data, key data gaps, and uncertainties associated with estimates should be identified and estimated.

The information collected and analyzed by evaluators will be useful for better describing the stream of environmental services and benefits of a project, in order to attract additional investment and to characterize the project's chances of maintaining reduced GHG emissions over time. This information will, hopefully, also help in mitigating any potentially negative environmental impacts and encouraging positive environmental benefits.

${ }^{1}$ An issue that still needs to be resolved: does an investor abide by its country's environmental laws, or must it abide only by the host country's laws? 
Table 5. Potential Environmental Impacts

\begin{tabular}{|l|l|}
\hline \multicolumn{1}{|c|}{ Impact Category } & \multicolumn{1}{c|}{ Comments } \\
\hline \hline Agrochemicals & Application and disposal of pesticides and fertilizers \\
\hline Biological diversity & $\begin{array}{l}\text { Endangered plants and animal species, critical habitats, } \\
\text { and protected areas }\end{array}$ \\
\hline $\begin{array}{l}\text { Coastal and marine resources } \\
\text { management }\end{array}$ & Coral reefs, mangroves, and wetlands \\
\hline $\begin{array}{l}\text { Dams and reservoirs* } \\
\text { agreements on environment } \\
\text { and natural resources }\end{array}$ & $\begin{array}{l}\text { Status and application of current and pending treaties and } \\
\text { agreements, including notification requirements }\end{array}$ \\
\hline International waterways & Quality or quantity of water flows \\
\hline Natural hazards & Measures to address earthquakes, floods, volcanic activity, \\
etc.
\end{tabular}

*Without project

Source: Adapted from World Bank (1989). 


\subsection{Socioeconomic Impacts}

A project's survival is dependent on whether it is economically sound (i.e., the benefits (including the value of carbon) outweigh the costs) and are equitably distributed. Developers should use one or more economic indicators for assessing the economics of forestry projects: e.g., cost-benefit ratio, net present value, payback period, rate of return on investment, or dollars per ton of carbon emissions reduced. These indicators should be calculated from different perspectives (e.g., government, investor, and consumer), and all assumptions (e.g., lifetime, discount rate, project costs) should be described. In addition, the distribution of project benefits and costs needs to be evaluated to make sure one population group is not being unduly affected (equity impacts).

In constructing these indicators, the developer should also consider possible macro-economic impacts from the project: e.g., gross domestic product, jobs created or lost, effects on inflation or interest rates, implications for long-term development, foreign exchange and trade, other economic benefits or drawbacks, and displacement of present uses.

The socioeconomic benefits of forestry projects have made these kinds of projects beneficial in the minds of supporters of forestry projects. However, the evaluation of socioeconomic impacts is challenging and requires different resources and expertise than those associated with the monitoring of carbon stocks in forests. The socioeconomic impacts are particularly relevant for forestry projects because they are more likely to address the root causes of deforestation and forest use (Andrasko et al. 1996). The socioeconomic benefits of forestry projects are particularly important for rural and developing countries, where forestry projects can have very positive impacts for the local population (e.g., ecotourism or forest warden jobs), although they may be relatively small. However, sometimes these projects may have negative impacts (Box 6). The sustainability of forestry projects will be improved if these kinds of impacts are accounted for and recognized. Both gross and net impacts need to be evaluated.

In examining socioeconomic impacts, developers and evaluators need to ask the following questions: who the key stakeholders are, what project impacts are likely and upon what groups, what key social issues are likely to affect project performance, what the relevant social boundaries and project delivery mechanisms are, and what social conflicts exist and how they can be resolved (World Bank 1994b). To address these questions, developers and evaluators could conduct informal sessions with representatives of affected groups and relevant non-governmental organizations.

The need to analyze social factors that influence a project continues throughout the entire life of a project. The evaluation of the social dimensions of a project is called a social analysis or social 
impact assessment (Asian Development Bank 1994). The social analysis typically includes an assessment of the benefits to the clientele participating in the project (e.g., does the project meet their needs), their capability to implement the project (e.g., level of knowledge and skill and capabilities of community organizations), and any potential adverse impacts on population groups affected by the project (e.g., involuntary resettlement, loss of livelihood, and price changes).

\section{Box 6}

\section{Socioeconomic Impacts Example}

The major concerns regarding large-scale expansion of plantations in Brazil as a climate change mitigation option are social rather than environmental or technical (Fearnside 1998). The attractiveness of charcoal manufacture from the standpoint of carbon benefits contrasts sharply with the social effects of charcoal as compared to other plantation end uses, such as pulpwood. Charcoal manufacture in Brazil is closely linked to a system of debt slavery that has been the center of domestic and international outrage.

Charcoal is frequently manufactured by families, including children, who work for an intermediary who supplies charcoal to legitimate businesses such as pig-iron mills. The charcoal workers are obliged to buy all supplies from their patron and, given the high prices charged for the supplies and the small amounts credited per unit volume of charcoal produced, the debts grow inexorably and become impossible to liquidate. In practice, the workers never receive any payment in cash - only credit towards paying of past debts (Fearnside 1998).

Source: Fearnside, P. 1998. "Forests and Global Warming Option in Brazil: Opportunities in the Brazilian Forest Sector for Responses to Global Warming under the 'Clean Development Mechanism' and 'Joint Implementation' Programs." Manaus, Amazonas, Brazil: National Institute for Research in the Amazon.

During the project development stage, projects are approved if they are consistent with the general development objectives of the host country, in terms of social and economic effects (Table 6). After a project has been implemented, MERVC activities should assess whether the project led to any of these impacts and whether any mitigation was done if negative impacts were experienced. Direct and indirect project impacts need to be examined, as well as "avoided negative socioeconomic impacts" (e.g., the preservation of an archaeological site as a result of the deferral of the construction of a new dam). 


\section{Table 6. Potential Socioeconomic Impacts}

\begin{tabular}{|l|}
\hline $\begin{array}{l}\text { Concerns of local communities and indigenous peoples regarding all project } \\
\text { operations }\end{array}$ \\
\hline $\begin{array}{l}\text { Cultural properties (archeological sites, historic monuments, and historic } \\
\text { settlements) }\end{array}$ \\
\hline Distribution of income and wealth \\
\hline Employment rights \\
\hline Gender equity \\
\hline Human rights \\
\hline $\begin{array}{l}\text { Induced development and other sociocultural aspects (secondary growth of } \\
\text { settlements and infrastructure) }\end{array}$ \\
\hline Involuntary resettlement \\
\hline Land settlement \\
\hline $\begin{array}{l}\text { Legal and customary land and resource use rights of local communities and } \\
\text { indigenous peoples }\end{array}$ \\
\hline Long-term income opportunities for local populations (e.g., jobs) \\
\hline Maintaining and fostering local cultures \\
\hline Public participation and capacity building \\
\hline Quality of life (local and regional) \\
\hline Tenure and land use rights \\
\hline $\begin{array}{l}\text { Tribal peoples (measures to address the rights of tribal peoples, including } \\
\text { traditional land and water rights) }\end{array}$ \\
\hline
\end{tabular}

Source: Adapted from World Bank (1989) and EcoSecurities (1998).

Developers need to indicate whether their project will have one or more of these socioeconomic impacts and, where appropriate, describe the type of impact. In addition, the developer should identify any proposed mitigation activities to address the negative impacts and that may lead to positive impacts.

Evaluators need to review the checklist of socioeconomic impacts and should collect some minimal information on potential impacts via surveys or interviews with key stakeholders. The evaluator should also check to see if any proposed mitigation efforts were implemented and whether expected positive benefits ever materialized. The extent and quality of available data, key data gaps, and uncertainties associated with estimates may need to be identified and estimated. 


\section{MERVC Costs}

Monitoring and evaluation costs will depend on what information is needed, what information and resources are already available, the size of the project area, the monitoring methods to be used, and frequency of monitoring. Furthermore, some methods require high initial costs: e.g., in remote sensing, start-up costs in terms of equipment and personnel training may make a one-time digital image survey prohibitively expensive, while making multiple surveys exceedingly cost effective. The cost for monitoring a forestry project in India has been estimated at $8.5 \%$ of the total project cost, and it seems that monitoring similar projects would not exceed $10 \%$ of the total cost (Ravindranath and Bhat 1997). In some cases, the monitoring and evaluation costs can be as high as $20 \%$ (personal communication from Margo Burnham, The Nature Conservancy, Jan. 28, 1999). ${ }^{1}$

Due to the availability of funding, we realize that some project developers and evaluators will not be able to conduct the most data intensive methods proposed in this report; however, we expect each project to undergo some evaluation and verification in order to receive carbon credits (especially, certified emission reduction units). Moreover, we believe that monitored projects will sequester more carbon and offset the cost of the monitoring because: (1) installations following a monitoring and evaluation protocol should come in near or even above the projected level of carbon sequestration; and (2) installations with some measurement of carbon sequestration should tend to have higher levels of sequestered carbon initially and experience carbon sequestration levels that remain high during the lifetime of the measure (e.g., see Kats et al. 1996). In the end, the cost of monitoring and evaluation will be partially determined by its value in reducing the uncertainty of carbon credits: e.g., will one be able to receive carbon credits with a value greater than $10 \%$ of project costs that are spent on monitoring and evaluation?

Because of concerns about high costs, MERVC activities cannot be too burdensome: in general, the higher the costs, the less likely organizations and countries will try to develop and implement forestry projects. However, in some cases, due to the enormous cost differential between the carbon reduction options of UNFCCC Parties, fairly high costs can be accommodated before these costs become prohibitive. Nevertheless, MERVC costs should be as low as possible. In sum, actual (as well as perceived) MERVC costs may discourage some transactions from occurring. Tradeoffs are inevitable, and a balance needs to be made between project implementation and the level of detail (and costs) of MERVC reporting guidelines.

1 This percentage is expected to decrease as other project expenditures and costs accumulate over time. 
Project estimates of impacts could be adjusted, based on the amount of uncertainty associated with the estimates and potential leakage, without conducting project-specific analyses. Projects with less accurate or less precisely quantified benefit estimates would have their estimates adjusted and therefore have their benefits rendered policy-equivalent to credits from projects that can be more accurately quantified. The U.S. Environmental Protection Agency's Conservation Verification Protocol reward more rigorous methods of verifying energy savings by allowing a higher share of the savings to qualify for tradable $\mathrm{SO}_{2}$ allowances. Three options are available for verifying subsequent-year energy savings: monitoring, inspection and a default option (Meier and Solomon 1995). In the monitoring option, a utility can obtain credit for a greater fraction of the savings and for a longer period: biennial verification in subsequent years 1 and 3 (including inspection) is required, and savings for the remainder of physical lifetimes are the average of the last two measurements. The monitoring option requires a $75 \%$ confidence in subsequent-year savings (like in the first year). In contrast, the default option greatly restricts the allowable savings: $50 \%$ of firstyear savings, and limited to one-half of the measure's lifetime. For the inspection option (confirming that the measures are both present and operating): a utility can obtain credit for $75 \%$ of first-year savings for units present and operating for half of physical lifetime (with biennial inspections), or $90 \%$ of first-year savings for physical lifetimes of measures that do not require active operation or maintenance (e.g., building shell insulation, pipe insulation and window improvements). Thus, utilities could use a simpler evaluation method at a lower cost and receive fewer credits, or they could use a more sophisticated method and receive more credits. A similar system could be applied to the crediting of forestry projects. 


\section{Concluding Remarks}

MERVC guidelines are needed for forestry projects to accurately determine the net GHG, and other, benefits and costs, and to ensure that the global climate is protected and that country obligations are met. The MERVC guidelines may be used for transferring GHG reductions into credible, internationally acceptable GHG credits that could be traded at a high degree of confidence in commodity markets.

The strictness of MERVC guidelines needs to be carefully considered. Strict guidelines may easily lead to burdensome and complex procedures, thereby increasing the costs and reducing the costeffectiveness of a project. If the guidelines for international verification are "loose", however, then project sponsors might be more able to manipulate the "measured" emissions reductions, e.g., inflating the net emissions reductions from the project. Because of concerns about high costs in responding to MERVC guidelines, the guidelines for forestry projects are designed to be not too burdensome.

The guidelines presented in this document are based on existing work that has been in use for several years (e.g., EcoSecurities 1998; MacDicken 1998). In order to follow the guidance provided in this report, we have developed common reporting forms: project developers and evaluators will need to complete a monitoring and evaluation form (Appendix B) and verifiers will need to complete a verification form (Appendix C). We have also included an Estimation Reporting From (Appendix A) to provide guidance to project developers on the issues that need to be examined during project development. As part of these forms, we have included Quality Assurance Guidelines that require analysts to indicate specifically how they addressed basic methodological issues.

The next phase of this work will be to develop a procedural handbook providing information on how one can complete the monitoring, evaluation and verification forms contained in this report. Next, we plan to test the usefulness of these guidelines in the real world. When necessary, these guidelines will be revised in order to correct for systematic errors in the guidelines. 


\section{References}

Allison, L. 1975. "Organic Carbon," in C. Black, D. Evans, J. White, L. Ensminger and F. Clack (ed.), Methods of Soil Analysis, Part 2, pp. 1367-1378. Madison, WI: American Society of Agronomy.

Andrasko, K. 1997. "Forest Management for Greenhouse Gas Benefits: Resolving Monitoring Issues Across Project and National Boundaries," Mitigation and Adaptation Strategies for Global Change, 2(2-3):117-132.

Andrasko, K., L. Carter, and W. van der Gaast. 1996. "Technical Issues in JI/AIJ Projects: A Survey and Potential Responses," a background paper prepared for the Critical Issues Working Group, for the UNEP AIJ Conference. San Jose, Costa Rica.

Asian Development Bank. 1994. Handbook for Incorporation of Social Dimensions in Projects. Manila, Philippines: Asian Development Bank.

Apps, M. and D. Price. 1996. "Introduction," in Forest Ecosystems, Forest Management, and the Global Carbon Cycle, M. Apps and D. Price (Eds.). Berlin, Germany: Springer.

Bialy, J. 1991. "Improved Cookstove Programs in Sri Lanka: Perceptions of Success," Country Studies No. 3, in Improved Biomass Cookstove Programs: A Global Evaluation, Honolulu, Hawaii: East-West Center.

Bird, D., N. Ross, and M. Ruiz Corzo. 1998. "Problems and Solutions Associated with an AIJ Project: An Example from a Forest Management Project in Central Mexico," pp. 209-214, in P. Riemer, A. Smith and K. Thambimuthu (eds.), Greenhouse Gas Mitigation: Technologies for Activities Implemented Jointly. Oxford. UK: Elsevier Science Limited.

Boutwell, R., D. Wiggins, and M. Pflum. 1992. "SDGE Residential High Efficiency Refrigerator Program Report. MIAP 91-PO7-SO1-R239. San Diego, CA: San Diego Gas and Electric Company.

Bouwmann, A. 1990. (Ed.) Soils and the Greenhouse Effect. New York, NY: John Wiley and Sons.

Brown, K. 1996. The Utility of Remote Sensing Technology in Monitoring Carbon Sequestration Agroforestry Projects. Arlington, VA: Winrock International Institute for Agricultural Development. 
Brown, P., B. Cabarle, and R. Livernash. 1997. Carbon Counts: Getting the Numbers Right. Washington, D.C.: World Resources Institute,

Brown, S. 1997. Estimating Biomass and Biomass Change of Tropical Forests: A Primer. FAO Forestry Paper 134. Rome, Italy: Food and Agricultural Organization of the United Nations.

Brown, S., A. Gillespie, and A. Lugo. 1989. "Biomass estimation methods for tropical forests with applications to forest inventory data, " Forest Science 35(4): 881-902.

Brown, S., J. Sathaye, M. Cannell, and P. Kauppi. 1996. "Management of Forests for Mitigation of Greenhouse Gas Emissions," Chapter 24 in Climate Change 1995 - Impacts, Adaptations and Mitigation of Climate Change: Scientific-Technical Analyses. Contribution of Working Group II to the Second Assessment Report of the Intergovernmental Panel on Climate Change. Editors R. Watson, M. Zinyowera, and R. Moss. Cambridge, UK: University of Cambridge.

Brown, S., B. Lim, B. Schlamadinger, and Y. Sokona. 1998. Evaluating Approaches for Estimating Net Emissions of Carbon Dioxide from Forest Harvesting and Wood Products. IPCC/OECD/IEA Programme on National Greenhouse Gas Inventories, Dakar, Senegal, May 5-7, 1998.

Busch, C., J. Sathaye, and A. Sanchez-Azofeifa. 1999. Lessons for Greenhouse Gas Accounting: A Case Study of Costa Rica's Protected Areas Project, LBNL-42289. Berkeley, CA: Lawrence Berkeley National Laboratory.

Cairns, M., S. Brown, E. Helmer, and G. Baumgardner. 1997. "Root Biomass Allocation in the World's Upland Forests," Oecologia 111:1-11.

Carpentieri, A., E. Larson and J. Woods. 1993. "Future Biomass-Based Electricity Supply in Northeast Brazil," Biomass and Bioenergy 4:149-174.

Colwell, R. (ed.). 1983. Manual of Remote Sensing. Fall Church, VA: American Society of Photogrammetry.

Dale, V., R. O'Neil, F. Southworth, and M. Pedlowski. 1994. "Causes and Effects of Land-Use Change in Central Rondonia, Brazil,' Photogrammetric Engineering and Remote Sensing 59(6): 997-1005.

De Jong, B., R. Tipper, and J. Taylor. 1997. "A Framework for Monitoring and Evaluating Carbon Mitigation by Farm Forestry Projects: Example of a Demonstration Project in Chiapas, Mexico," Mitigation and Adaptation Strategies for Global Change, 2(2-3):231-246. 
EcoSecurities, Ltd. 1998. SGS Forestry Carbon Offset Verification Services. Oxford, UK: SGS Forestry.

Embree, C. (Sid). 1994. "Monitoring, Accounting, Verifying, and Reporting on Joint Implementation Activities: Preliminary Issues and Considerations," presented at the Workshop on Designing Joint Project Mechanisms to Promote Benefits for Developing Countries. Rio de Janeiro, Brazil, Dec. 13-15.

Eswaran, H., E. Van den Berg, P. Reich, and J. Kimble. 1995. "Global Soil Carbon Resources," pp. 2743 in R. Lal, J. Kimble, E. Levine, and B. Stewart (eds.), Soils and Global Change. Boca Raton, FL: CRC Lewis Publishers.

Eto, J., R. Prahl, and J. Schlegel. 1996. A Scoping Study on Energy-Efficiency Market Transformation by California Utility DSM Programs. LBNL-39058. Berkeley, CA: Lawrence Berkeley National Laboratory.

Face Foundation. 1997. Annual Report 1996. Arnheim, The Netherlands: Face Foundation.

Faeth, P., C. Cort, and R. Livernash. 1994. "Evaluating the Carbon Sequestration Benefits of Forestry Products in Developing Countries." Washington, D.C.: World Resources Institute and U.S. Environmental Protection Agency.

Fearnside, P. 1995. "Global Warming Response Options in Brazil's Forest Sector: Comparison of Project-Level Costs and Benefits," Biomass and Bioenergy 8(5):309-322.

Fearnside, P. 1998. "Forests and Global Warming Option in Brazil: Opportunities in the Brazilian Forest Sector for Responses to Global Warming under the 'Clean Development Mechanism' and 'Joint Implementation' Programs." Manaus, Amazonas, Brazil: National Institute for Research in the Amazon.

Food and Agricultural Organization (FAO) of the United Nations. 1996. Forest Resources Assessment 1990: Survey of Tropical Forest Cover and Study of Change Processes. FAO Forestry Paper 130. Rome, Italy: Food and Agricultural Organization of the United Nations.

Forest Stewardship Council. 1996. Principles and Criteria for Forest Management. Waterbury, VT: Forest Stewardship Council, U.S. Also, on the World Wide Web: http://www.fscus.org/fscus2a01.html.

Frumhoff, P., D. Goetze and J. Hardner. 1998. "Linking Solutions to Climate Change and Biodiversity Loss through the Kyoto Protocol's Clean Development Mechanism." Briefing paper, Oct. 1998. Cambridge, MA: Union of Concerned Scientists. 
Hagler Bailly. 1998. "Evaluation of Using Benchmarks to Satisfy the Additionality Criterion for Joint Implementation Projects," prepared for the U.S. Environmental Protection Agency. Boulder, CO: Hagler Bailly.

Hall, D. 1997. "Biomass Energy in Industrialized Countries - A View of the Future," Forest Ecology and Management 91: 17-45.

Hamburg, S., D. Zamolodchikov, G. Korovin, V. Nefedjef, A. Utkin, J. Gulbe, and T. Gulbe. 1997. "Estimating the Carbon Content of Russian Forests: A Comparison of Phytomass/Volume and Allometric Projections," Mitigation and Adaptation Strategies for Global Change, 2(2-3):247265.

Heister, J. 1996. "Towards a Methodology for Quantifying Greenhouse Gas Offsets from Joint Implementation Projects and Activities Implemented Jointly," draft working paper, Global Climate Change Unit, Global Environment Division. Washington, D.C.: World Bank.

Intergovernmental Panel on Climate Change (IPCC). 1996. Revised 1996 IPCC Guidelines for National Greenhouse Gas Inventories: Volumes 1, 2, and 3. IPCC Secretariat, Geneva, Switzerland.

Intergovernmental Panel on Climate Change (IPCC). 1998. Evaluating Approaches for Estimating Net Emissions of Carbon Dioxide from Forest Harvesting and Wood Products. Meeting Report, Daka, Senegal, May 5-7, 1998. IPCC Secretariat, Geneva, Switzerland.

Izaurralde, R., M. Nyborg, E. Solberg, H. Janzen, M. Arshad, S. Malhi, and M. Molina-Ayala. 1998. "Carbon Storage in Eroded Soils After Five Years of Reclamation Techniques," pp. 369-386, in R. Lal, J. Kimble, R. Follett, and B. Stewart (eds.), Soil Processes and the Carbon Cycle. Boca Raton, FL: CRC Lewis Publishers.

Jepma, C. 1997. "Reduced-Impact Logging in Indonesia," Joint Implementation Quarterly 3:3(2).

Kats, G., A. Rosenfeld, T. McIntosh, and S. McGaraghan. 1996. "Energy Efficiency as a Commodity: The Emergence of an Efficiency Secondary Market for Savings in Commercial Buildings," Proceedings of the 1996 ACEEE Summer Study, Vol. 5, pp. 111-122. American Council for an Energy-Efficient Economy, Washington, D.C.

Lal, R., J. Kimble, and R. Follett. 1997. "Knowledge Gaps and Researchable Priorities," pp. 595-604 in R. Lal, J. Kimble, R. Follett, and B. Stewart (eds.), Soil Processes and the Carbon Cycle. Boca Raton, FL: CRC Lewis Publishers. 
Lal, R., J. Kimble, R. Follett, and B. Stewart (eds.). 1998. Soil Processes and the Carbon Cycle. Boca Raton, FL: CRC Lewis Publishers.

Lashof, D. 1998. "Additionality Under the Clean Development Mechanism," unpub. New York: Natural Resources Defense Council.

MacDicken, K. 1997. "Project Specific Monitoring and Verification: State of the Art and Challenges," Mitigation and Adaptation Strategies for Global Change, 2(2-3):191-202.

MacDicken, K. 1998. A Guide to Monitoring Carbon Storage in Forestry and Agroforestry Projects. Arlington, VA: Winrock International Institute for Agricultural Development.

Makundi, W. 1997. "Global Climate Change Mitigation and Sustainable Forest Management: The Challenge of Monitoring and Verification," Mitigation and Adaptation Strategies for Global Change, 2(2-3): 133-155.

Marland, G., B. Schlamadinger, and L. Canella. 1997. "Forest Management for Mitigation of $\mathrm{CO}_{2}$ Emissions: How Much Mitigation and Who Gets the Credits?" Mitigation and Adaptation Strategies for Global Change, 2(2-3): 303-318.

McLain, H. 1998. "Global Carbon Impacts of Using Forest Harvest Residues for District Heating in Vermont," Proceedings of the 1998 ACEEE Summer Study, Vol. 9, pp. 105-117. American Council for an Energy-Efficient Economy, Washington, D.C.

Meier, A. and B. Solomon. 1995. "The EPA's Protocols for Verifying Savings from Utility EnergyConservation Programs," Energy: The International Journal 20(2);105-115 (1995).

Michael, A. 1992. The Difficulty in Defining Sustainability. Report No. 106. Washington, D.C.: Resources for the Future.

Michaelowa, A. 1998. "Joint Implementation - the Baseline Issue: Economic and Political Aspects," Global Environmental Change 8(1): 81-92 (1998).

O'Riordan, T. 1988. "The Politics of Sustainability," in Sustainable Energy Management Principles and Practice, ed. R. Turner. Boulder: Westview Press.

Parton, W., D. Ojima, and D. Schimel. 1995. "Models to Evaluate Soil Organic Matter Storage and Dynamics," pp. 421-448, in M. Carter and B. Stewart (eds.), Structure and Organic Matter Storage in Agricultural Soils. New York: Lewis Publishers. 
Paul, E., K. Paustian, E. Elliot, and C. Cole (eds.). 1997. Soil Organic Matter in Temperate Agroecosystems: Long-term Experiments in North America. Boca Raton, FL: CRC Lewis Publishers.

Perlack, R., J. Ranney and M. Russell. 1991. Biomass Energy Development in Yunnan Province, China. ORNL/TM-11791. Oak Ridge, TN: Oak Ridge National Laboratory.

Pinard, M. and F. Putz. 1996. "Retaining forest biomass by reducing logging damage," Biotropica 28:278-295.

Pinard, M. and F. Putz. 1997. "Monitoring Carbon Sequestration Benefits Associated With a ReducedImpact Logging Project in Malaysia," Mitigation and Adaptation Strategies for Global Change, 2(2-3):203-215.

Pinard, M., F. Putz, J. Tay and T. Sullivan. 1995. "Creating timber harvesting guidelines for a reduced-impact logging project in Malaysia," Journal of Forestry 93:41-45.

Prahl, R. and J. Schlegel. 1993. "Evaluating Market Transformation," in the Proceedings of the 1993 International Energy Program Evaluation Conference. pp, 469-477. Chicago, IL: National Energy Program Evaluation Conference.

Programme for Belize. 1997. "Rio Bravo Carbon Sequestration Pilot Project, Operating Protocols, Introduction," Programme for Belize.

Ravindranath, H. and D. Hall. 1995. Biomass, Energy, and Environment: A Developing Country Perspective from India. Oxford, UK: Oxford University Press.

Ravindranath, N. H. and P. R. Bhat. 1997. "Monitoring of Carbon Abatement in Forestry Projects-Case Study of Western Ghat Project," Mitigation. and Adaptation Strategies for Global Change, 2(2-3):217-230.

Ridge, R., D. Violette, D. Dohrman, and K. Randazzo, Quality Assurance Guidelines for Statistical, Engineering, and Self-Report Methods for Estimating DSM Program Impacts, CADMAC Study ID 2001M. Revised May 1997. Berkeley, CA: Pacific Consulting Services.

Rosenfeld, A., H. Akbari, J. Romm, and M. Pomerantz. 1998. "Cool Communities: Strategies for Heat Island Mitigation and Smog Reduction," Energy and Buildings 28:51-62.

Russell, M., D. Jantzen and Z. Shen. 1992. Electricity from Biomass: Two Potential Chinese Projects. Knoxville, TN: Energy, Environment, and Resources Center, University of Tennessee. 
Sanchez-Azofeifa, G. and C. Quesada-Mateo. 1995 "Deforestation, Carbon Dynamics, and Sustainable Mitigation Measures in Costa Rica: The Puerto Viego de Sarapiqui Case Study," Interciencia 20(6): 396-400.

Sanchez-Azofeifa, G., D. Skole, and W. Chomentowski. 1997. "Sampling Global Deforestation Databases: The Role of Persistence," Mitigation and Adaptation Strategies for Global Change, 2(2-3):177-189.

Sathaye, J. A. and S. Meyers. 1995. Greenhouse Gas Mitigation Assessment: A Guidebook. Dordrecht, Holland: Kluwer Academic Publishers.

Schlamadinger, B. and G. Marland. 1996. "The Role of Forest and Bioenergy Strategies in the Global Carbon Cycle," Biomass and Bioenergy 10:275-300.

Schlegel, J., R. Prahl and J. Raab. 1997. "Next Steps for Evaluation of Market Transformation Initiatives: An Update to the NARUC Guidebook," Ch. 4 in J. Schlegel, M. Goldberg, J. Raab, R. Prahl, M. Keneipp, and D. Violette, eds., Evaluating Energy-Efficiency Programs in a Restructured Industry Environment: A Handbook for PUC Staff. Washington, D.C.: National Association of Regulatory Utility Commissioners.

Schroeder, P., S. Brown, J. Mo, R. Birdsey and C. Cieszewski. 1997. "Biomass Estimation for Temperate Broadleaf Forests of the United States Using Inventory Data," Science 43(3):424434.

SGS International Certification Services Ltd. (SGS). 1998. Protected Areas Project: Assessment of Project Design, and Schedule of Emission Reductions Units. Oxford, UK: SGS International Certification Services Ltd.

Skole, D. and C. Tucker. 1993. "Tropical Deforestation and Habitat Fragmentation in the Amazon: Satellite Data from 1978 to 1988," Science 260:1905-1910.

Skole, D., C. Justice, J. Townshend, and A. Janetos. 1997. "A Land Cover Change Monitoring Program: Strategy for an International Effort, "Mitigation and Adaptation Strategies for Global Change, 2(2-3):157-175.

Slater, P. 1980. Remote Sensing: Optics and Optical Systems. Reading, MA: Addison-Wesley Publishing Co., Inc.

Smith, P., D. Powlson, J. Smith, and E. Elliott (eds.). 1997. "Evaluation and Comparison of Soil Organic Matter Models," Geoderma 81:1-225. 
Stone, T., I. Brown, and G. Woodwell. 1991. "Estimation by Remote Sensing of Deforestation in Central Rondonia, Brazil," Forest Ecology and Management 38(3-4): 291-304.

Subsidiary Body for Scientific and Technological Advice (SBSTA). 1997. "Report of the Subsidiary Body for Scientific and Technological Advice on the Work of Its Fifth Session, Bonn, 25-28 February 1997. Annex III. Uniform Reporting Format: Activities Implemented Jointly Under the Pilot Phase." Framework Convention on Climate Change, United Nations.

Swain, P. and S. Davis. 1978. Remote Sensing: The Quantitative Approach. New York: McGraw Hill Book Co.

Swisher, J. 1992. "Cost and Performance of $\mathrm{CO}_{2}$ Storage in Forestry Projects," Biomass and Bioenergy 1(6): $317-328$.

Swisher, J. 1994. "Forestry and Biomass Energy Projects: Bottom-Up Comparisons of $\mathrm{CO}_{2}$ Storage and Costs," Biomass and Bioenergy 6(5): 359-368.

Swisher, J. 1996. "Facts and Myths on Joint Implementation in the Framework Convention on Climate Change," presented at the Air and Waste Management Association Conference. Boulder, CO: Econergy International Corp.

Swisher, J. 1998. "Project Baselines and Additionality in the Clean Development Mechanism," presented at The Aspen Global Forum, Aspen, CO.

Swisher, J. and F. Renner. 1996. "Carbon Offsets from Biomass Energy Projects," Proceedings of the Seventh National Bioenergy Conference. Muscle Shoals, AL: Tennessee Valley Authority.

Texas Higher Education Coordinating Board, General Services Commission/State Energy Conservation Office, and the Texas Energy Coordination Council. 1998. "Texas Energy Performance Based Contracts: Guidelines and Approval Process for Institutions of Higher Education and State Agencies," Austin, Texas: State Energy Conservation Office.

Trexler, M. and L. Kosloff. 1998. "The 1997 Kyoto Protocol: What Does It Mean for Project-Based Climate Change Mitigation?" Mitigation and Adaptation Strategies for Global Change, 3:158.

Trexler, M., Haugen, C., and Loewen, L., 1992. "Global Warming Mitigation Through Forestry Options in the Tropics," in: R. Sampson and D. Hair, eds., Forests and Global Change, Volume 1: Opportunities for Increasing Forest Cover 73. Washington, D.C.: American Forests.

UNEP. 1992. Convention on Biodiversity, Nairobi, United Nations Environmental Program. 
UNEP/WMO Information Unit on Climate Change. 1992. United Nations Framework Convention on Climate Change. UNEP/WMO Information Unit on Climate Change, Geneva, Switzerland.

UNFCCC. 1997. "Kyoto Protocol to the United Nations Framework Convention of Climate Change," FCCC/CP/1997/L.7/Add.1, Dec. 10, 1997.

UNFCCC. 1998a. "Methodological Issues: Issues Related to Land-Use Change and Forestry," FCCC/SBSTA/1998/INF.1, May 18, 1998. At UNFCCC Web site (under CC:INFO Products): http://www.unfccc.de/ccinfo.

UNFCCC. 1998b. "Non-paper on Principles, Modalities, Rules and Guidelines for an International Emissions Trading Regime," FCCC/SB/1998/MISC.1/Add.1/Rev.1. At UNFCCC Web site (under CC:INFO Products): http://www.unfccc.de/ccinfo.

UNFCCC. 1998c. "Review of the Implementation of Commitments and of Other Provisions of the Convention. Activities Implemented Jointly: Review of Progress Under the Pilot Phase (Decision 5/CP.1)," FCCC/CP/1998/INF.3, Oct. 28, 1998. At UNFCCC Web site (under CC:INFO Products): http://www.unfccc.de/ccinfo.

U.S. Agency for International Development (USAID). 1996. Strategies for Financing Energy Efficiency. Business Focus Series. Washington, D.C.: U.S. Agency for International Development.

U.S. Department of Energy (USDOE). 1994. "Sector-Specific Issues and Reporting Methodologies Supporting the General Guidelines for the Voluntary Reporting of Greenhouse Gases Under Section 1605(b) of the Energy Policy Act of 1992." DOE/PO-0028, Volumes 2 and 3. Washington, D.C.: U.S. Department of Energy.

U.S. Department of Energy (USDOE). 1994a. "General Guidelines for the Voluntary Reporting of Greenhouse Gases Under Section 1605(b) of the Energy Policy Act of 1992." DOE/PO-0028, Volume 1, Washington, D.C.: U.S. Department of Energy.

U.S. Department of Energy (USDOE). 1994b. "Sector-Specific Issues and Reporting Methodologies Supporting the General Guidelines for the Voluntary Reporting of Greenhouse Gases Under Section 1605(b) of the Energy Policy Act of 1992." DOE/PO-0028, Volumes 2 and 3 Washington, D.C.: U.S. Department of Energy.

U.S. General Accounting Office (USGAO). 1998. "Climate Change: Basic Issues in Considering a Credit for Early Action Program." Washington, D.C.: U.S. General Accounting Office. 
U.S. Initiative on Joint Implementation (USIJI). 1995. "Guidelines for a USIJI Project Proposal." Washington, D.C.: U.S. Initiative on Joint Implementation.

U.S. Initiative on Joint Implementation (USIJI). 1998. "USIJI Uniform Reporting Document for Noel Kempff Mercado Climate Action Project Washington, D.C.: U.S. Initiative on Joint Implementation.

University of Edinburgh. 1998. "Provisional Guidelines and Standards." See Web site: http://www.ed.ac.uk/ ebfr11/ecor.

Vine, E. 1994. “The Human Dimension of Program Evaluation," Energy - The International Journal, 19(2):165-178.

Vine, E. and J. Sathaye. 1997. The Monitoring, Evaluation, Reporting, and Verification of Climate Change Mitigation Projects: Discussion of Issues and Methodologies and Review of Existing Protocols and Guidelines. LBNL-40316. Berkeley, CA: Lawrence Berkeley National Laboratory. This report can be downloaded via the World Wide Web: http:/ / eetd.lbl.gov/EA/ccm/MonitoringMitigation.pdf.

Vine, E. and J. Sathaye. 1999. Guidelines for the Monitoring, Evaluation, Reporting, Verification, and Certification of Energy-Efficiency Projects for Climate Change Mitigation. LBNL-41543. Berkeley, CA: Lawrence Berkeley National Laboratory.

Violette, D., S. Ragland, and F. Stern. 1998. Evaluating Greenhouse Gas Mitigation through DSM Projects: Lessons Learned from DSM Evaluation in the United States. Boulder, CO: Hagler Bailly Consulting, Inc.

Watson, R., M. Zinyowera, and R. Moss. 1996. Technologies, Policies and Measures for Mitigating Climate Change. IPCC Technical Paper 1. International Panel on Climate Change.

Watt, E., J. Sathaye, O. de Buen, O. Masera, I. Gelil, N. Ravindranath, D. Zhou, J. Li, and D. Intaraprvich. 1995. The Institutional Needs of Joint Implementation Projects, LBL-36453. Berkeley, CA: Lawrence Berkeley National Laboratory.

Wilkie, D. and J. Finn. 1996. Remote Sensing Imagery for Natural Resources Monitoring: A Guide for First-Time Users. New York, NY: Columbia University.

Winjum, J., S. Brown, and B. Schlamadinger. 1998. "Forest Harvests and Wood Products: Sources and Sinks of Atmospheric Carbon Dioxide," Science 44(2):272-284. 
World Bank 1989. Checklist of Potential Issues for an Environmental Assessment, Operating Manual: Section OD 4.00 - Annex A2. Washington, D.C.: World Bank.

World Bank 1994a. Greenhouse Gas Abatement Investment Project Monitoring \& Evaluation Guidelines. Washington, D.C.: World Bank.

World Bank 1994b. Incorporating Social Assessment and Participation Into Biodiversity Conservation Projects. Washington, D.C.: World Bank.

World Bank 1997. Guidelines for Climate Change Global Overlays, Global Environment Division. Washington, D.C.: World Bank. 
This page is intentionally left blank. 


\section{APPENDIX A \\ ESTIMATION REPORTING FORM: FORESTRY PROJECTS}

The purpose of the Estimation Reporting Form is to ensure the standardized collection of data on estimated impacts from forestry projects. There are four main sections in this form.

In Section A (Project Description), the reporter provides the following information: the title of the project, contact information on the principal project developer, and a brief description of the project. If multiple participants are involved in the project, then these people should be listed.

In Section B (Changes in Carbon Stock), the reporter provides information on the estimated baseline, estimated gross changes in the carbon stock due to the project, and estimated net changes in the carbon stock. The reporter describes how free riders, positive project spillover, project leakage, and market transformation were estimated. In the last part of Section $B$, the reporter provides information on the measurement and operational uncertainties affecting the project (including a description of a contingency plan).

In Section C (Environmental Impacts), the reporter indicates, via a checklist, the types of environmental impacts that could be affected by the project, the types of mitigation activities that could be conducted, and consistency of the project with environmental laws and, if applicable, environmental impact statements.

In Section D (Socioeconomic Impacts), the reporter indicates, via a checklist, the types of socioeconomic impacts that could be affected by the project, and the types of mitigation activities that could be conducted. 


\section{A. PROJECT DESCRIPTION}

A1. Title of project:

A2. Principal project developer and contact:

\begin{tabular}{|l|l|}
\hline \multicolumn{1}{|c|}{ Item } & Please fill in if applicable \\
\hline \hline Name of principal project developer 1 : & \\
\hline Name of project developer (English): & \\
\hline Mailing address: & \\
\hline Telephone: & \\
\hline Fax: & \\
\hline Contact person for this project: & \\
\hline Mailing address: & \\
\hline Telephone: & \\
\hline Fax: & \\
\hline Email: & \\
\hline
\end{tabular}

1 If multiple participants are involved in the project, then they need to assign one of the participants as the "principal project developer" to complete this form. Other participants are not allowed to report on the impacts of this specific project, to avoid multiple reporting.

\section{A3. Other participants}

List other participants:

\section{A4. Project Description}

Briefly describe the project: 


\section{B. CHANGES IN CARBON STOCK}

\section{B1. Estimated Carbon Stock in Baseline [At Time of Project Registration]}

For all years of the project ( 1 to $n$ ), estimate the carbon stock (1) for the unadjusted baseline (without free riders), (2) for free riders, and (3) for the baseline (adjusted for free riders). Provide a separate table for each carbon pool and a total for all of the pools. Indicate the level of precision for each value.

\begin{tabular}{|l|l|l|l|l|l|l|}
\hline Estimated & $\begin{array}{c}\text { Unadjusted } \\
\text { Baseline } \\
\text { Carbon } \\
\text { (1) }\end{array}$ & $\begin{array}{c}\text { Level of } \\
\text { Precision }^{\mathbf{a}}\end{array}$ & $\begin{array}{c}\text { Carbon } \\
\text { from } \\
\text { Free } \\
\text { Riders } \\
\text { (2) }\end{array}$ & $\begin{array}{c}\text { Level of } \\
\text { Precision }^{\mathbf{a}}\end{array}$ & $\begin{array}{c}\text { Without- } \\
\text { Project } \\
\text { Baseline } \\
\text { Carbon } \\
\text { (3=1-2) }\end{array}$ & $\begin{array}{c}\text { Level of } \\
\text { Precision }^{\mathbf{a}}\end{array}$ \\
\hline $\begin{array}{l}\text { Carbon stock } \\
(\mathrm{tC})-\text { Year 1 }\end{array}$ & & & & & & \\
\hline$\cdot$ & & & & & & \\
\hline $\begin{array}{l}\text { Carbon stock } \\
(\mathrm{tC})-\text { Year } \mathrm{n}^{\mathbf{b}}\end{array}$ & & & & & & \\
\hline
\end{tabular}

a Indicate the level of precision used for project values: use either (1) standard deviation around the mean value, or (2) general level of precision (e.g., low, medium, high) - if more information is available, additional levels of precision can be used.

b The "nth" year is the last year of the project monitoring period.

\section{B2. Estimated Gross Changes in Carbon from Project [At Time of Project Registration]}

For all years of the project ( 1 to $n$ ), estimate (1) the carbon stock for the unadjusted project, (2) carbon loss due to project leakage, (3) carbon gains from project spillover, (4) carbon gains from market transformation, and (5) carbon stock for the with-project scenario (after adjustment). Provide a separate table for each carbon pool and a total for all of the pools. Indicate the level of precision for each value. ${ }^{\mathrm{a}}$

\begin{tabular}{|l|l|l|c|c|c|}
\hline \multicolumn{1}{|c|}{ Estimated } & $\begin{array}{c}\text { Unadjusted } \\
\text { With-project } \\
\text { Carbon } \\
(\mathbf{1})\end{array}$ & $\begin{array}{c}\text { Carbon from } \\
\text { Project } \\
\text { Leakage } \\
\text { (2) }\end{array}$ & $\begin{array}{c}\text { Carbon } \\
\text { from } \\
\text { Positive } \\
\text { Project } \\
\text { Spillover } \\
\text { (3) }\end{array}$ & $\begin{array}{c}\text { Carbon from } \\
\text { Market } \\
\text { Transformation } \\
\text { (4) }\end{array}$ & $\begin{array}{c}\text { With-Project } \\
\text { Carbon } \\
(5=(\mathbf{1}+3+4)-2)\end{array}$ \\
\hline $\begin{array}{l}\text { Carbon stock } \\
(\mathrm{tC}) \text {-Year 1 }\end{array}$ & & & & & \\
\hline$\cdot$ & & & & & \\
\hline
\end{tabular}

${ }^{a}$ Indicate the level of precision used for project values: use either (1) standard deviation around the mean value, or (2) general level of precision (e.g., low, medium, high) - if more information is available, additional levels of precision can be used.

b The "nth" year is the last year of the project monitoring period. 


\section{B3. Estimated Net Changes in Carbon Stock [At Time of Project Registration]}

For all years of the project ( 1 to $n$ ), calculate the net change in carbon stock by subtracting withproject carbon (taken from Table B2) from without-project (baseline) carbon (taken from Table B1). Provide a separate table for each carbon pool and a total for all of the pools. Indicate the level of precision for each value.

\begin{tabular}{|c|c|c|c|c|c|c|}
\hline Estimated & $\begin{array}{l}\text { Without- } \\
\text { Project } \\
\text { Baseline } \\
\text { Carbon } \\
\text { (1) }\end{array}$ & $\begin{array}{c}\text { Level of } \\
\text { Precision }^{a}\end{array}$ & $\begin{array}{l}\text { With- } \\
\text { Project } \\
\text { Carbon } \\
\text { (2) }\end{array}$ & $\begin{array}{c}\text { Level of } \\
\text { Precision }^{\mathrm{a}}\end{array}$ & $\begin{array}{c}\text { Net } \\
\text { Change in } \\
\text { Carbon Stock } \\
(3=1-2)\end{array}$ & $\begin{array}{l}\text { Level of } \\
\text { Precision }^{\mathrm{a}}\end{array}$ \\
\hline $\begin{array}{l}\text { Carbon stock } \\
\text { (tC) - Year } 1\end{array}$ & & & & & & \\
\hline : & & & & & & \\
\hline $\begin{array}{l}\text { Carbon stock } \\
(\mathfrak{t C})-\text { Year } n^{b}\end{array}$ & & & & & & \\
\hline
\end{tabular}

a Indicate the level of precision used for project values: use either (1) standard deviation around the mean value, or (2) general level of precision (e.g., low, medium, high) - if more information is available, additional levels of precision can be used.

$\mathrm{b}$ The "nth" year is the last year of the project monitoring period.

B4. Free Riders

B4.1. Describe how free ridership was estimated:

B5. Positive Project Spillover and Project Leakage

B5.1. Describe how positive project spillover and project leakage were identified and estimated, and discusses options within the project to minimize leakage or account for spillover: 


\section{B6. Market Transformation}

B6.1. Describe how market transformation was estimated:-

\section{B7. Uncertainty}

B7.1. Identify and discuss key measurement and operational uncertainties that may affect estimates of carbon stock:

Measurement Uncertainties:

Operational Uncertainties:

B7.2. Describe the project's contingency plan that identifies potential project uncertainties and discusses the contingencies provided within the project estimates to manage the uncertainties.

Contingency plan:

B7.3. Assess the possibility of local or regional political and economic instability in the short-term (5 years or less) and how this may affect project performance.

Political and economic instabilities: 


\section{ENVIRONMENTAL IMPACTS}

C1. Indicate whether the project will have one or more environmental impacts and, where appropriate, describe the type of impact.

\begin{tabular}{|c|c|c|}
\hline & \multicolumn{2}{|r|}{ Potential Environmental Impacts } \\
\hline & Impact Category & Comments \\
\hline 口 & Agrochemicals & Application and disposal of pesticides and fertilizers \\
\hline$\overline{\mathrm{a}}$ & Biological diversity & $\begin{array}{l}\text { Endangered plants and animal species, critical habitats, and } \\
\text { protected areas }\end{array}$ \\
\hline 口 & $\begin{array}{l}\text { Coastal and marine resources } \\
\text { management }\end{array}$ & Coral reefs, mangroves, and wetlands \\
\hline $\bar{a}$ & Dams and reservoirs* & Implementation and operation \\
\hline $\bar{\square}$ & $\begin{array}{l}\text { International treaties and } \\
\text { agreements on environment } \\
\text { and natural resources }\end{array}$ & $\begin{array}{l}\text { Status and application of current and pending treaties and } \\
\text { agreements, including notification requirements }\end{array}$ \\
\hline $\bar{\square}$ & International waterways & Quality or quantity of water flows \\
\hline $\bar{\square}$ & Natural hazards & Measures to address earthquakes, floods, volcanic activity, etc. \\
\hline$\square$ & Soil conservation & Protection and management \\
\hline 口 & Sustainable land use & Multiple use management and non-declining yields \\
\hline $\bar{a}$ & Tropical forests & Protection and management \\
\hline$\vec{a}$ & Water quality & Protection and enhancement \\
\hline $\bar{a}$ & Watersheds & Protection and management \\
\hline$\vec{\square}$ & Wetlands & $\begin{array}{l}\text { Protection and management (e.g., estuaries, lakes, mangroves, } \\
\text { marshes and swamps) }\end{array}$ \\
\hline 口 & Wildlands & Protection and management \\
\hline $\bar{\square}$ & $\begin{array}{l}\text { Wildlife and habitat protection } \\
\text { or enhancement }\end{array}$ & Protection and enhancement \\
\hline
\end{tabular}

*Without project

C2. Identify any proposed mitigation activities.

Mitigation activities: 
C3. Indicate whether an environmental impact statement (EIS) has been filed and that the response to the checklist of environmental impacts is consistent with the EIS.

\begin{tabular}{|c|l|}
\hline$\square$ & EIS filed \\
\hline$\square$ & EIS not filed \\
\hline & \\
\hline$\square$ & Checklist consistent with EIS \\
\hline$\square$ & Checklist not consistent with EIS. Explain reasons: \\
& \\
\hline
\end{tabular}

C4. Indicate whether any environmental laws apply to these impacts and that the response to the checklist of environmental impacts is consistent with the environmental laws.

\begin{tabular}{|c|l|}
\hline & Applicable environmental laws \\
\hline & Checklist consistent with environmental laws \\
\hline$\square$ & Checklist not consistent with environmental laws. Explain reasons: \\
& \\
\hline
\end{tabular}




\section{SOCIOECONOMIC IMPACTS}

D1. Indicate whether the project will have one or more socioeconomic impacts and, where appropriate, describe the type of impact.

\begin{tabular}{|c|c|c|c|}
\hline$\square$ & $\begin{array}{l}\text { Concerns of local communities and } \\
\text { indigenous peoples regarding all } \\
\text { project operations }\end{array}$ & $\square$ & Land settlement \\
\hline 口 & $\begin{array}{l}\text { Cultural properties (archeological sites, } \\
\text { historic monuments, and historic } \\
\text { settlements) }\end{array}$ & $\square$ & $\begin{array}{l}\text { Legal and customary land and resource use } \\
\text { rights of local communities and indigenous } \\
\text { peoples }\end{array}$ \\
\hline$\overline{0}$ & Distribution of income and of wealth & D & $\begin{array}{l}\text { Long-term income opportunities for local } \\
\text { populations (e.g., jobs) }\end{array}$ \\
\hline $\bar{\square}$ & Employment rights & D & Maintaining and fostering local cultures \\
\hline $\bar{a}$ & Gender equity & $\bar{D}$ & Public participation and capacity building \\
\hline$\square$ & Human rights & Q & Quality of life (local or regional) \\
\hline$\square$ & $\begin{array}{l}\text { Induced development and other } \\
\text { sociocultural aspects (secondary } \\
\text { growth of settlements and } \\
\text { infrastructure) }\end{array}$ & $\square$ & Tenure and land use rights \\
\hline$\square$ & Involuntary resettlement & 口 & $\begin{array}{l}\text { Tribal peoples (measures to address the rights } \\
\text { of tribal peoples, including traditional land } \\
\text { and water rights) }\end{array}$ \\
\hline
\end{tabular}

D2. Identify any proposed mitigation activities.

Mitigation activities: 


\section{APPENDIX B}

\section{MONITORING AND EVALUATION REPORTING FORM: FORESTRY PROJECTS}

The purpose of the Monitoring and Evaluation Reporting Form is to ensure the standardized collection of data on measured impacts from forestry projects. There are four main sections in this form.

In Section A (Project Description), the reporter provides the following information: the title of the project, contact information on the principal project developer, and a brief description of the project. If multiple participants are involved in the project, then these people should be listed. Much of this information will be identical to the information contained in the Estimation Reporting Form (Appendix A) and, therefore, the relevant fields are"shaded to indicate to the evaluator that this information may not need to be collected again.

In Section B (Changes in Carbon Stock), the reporter first provides information on the estimated baseline, estimated gross changes in the carbon stock due to the project, and estimated net changes in the carbon stock (primarily drawn from the project proposal, or the Estimation Reporting Form in Appendix A; these sections are shaded). The reporter then provides information on a re-estimated baseline, measured gross changes in the carbon stock due to the project, and measured net changes in the carbon stock. A comparison of the estimated and measured impacts provides information on the performance and effectiveness of the project. The reporter provides information on the data collection and analysis methods used for calculating changes in carbon stock. The reporter also shows how methodological issues were addressed for each method by responding to quality assurance guidelines. The reporter describes how free riders, positive project spillover, project leakage, and market transformation were measured, and compares these calculations with those estimated at the start of the project. If there are differences or discrepancies, the reporter needs to explain the inconsistencies. In the last part of Section B, the reporter provides information on the measurement and operational uncertainties affecting the project (including a description of a contingency plan).

In Section C (Environmental Impacts), the reporter indicates, via a checklist, the types of environmental impacts affected by the project, the types of mitigation activities conducted, and consistency of the project with environmental laws and, if applicable, environmental impact statements.

In Section D (Socioeconomic Impacts), the reporter indicates, via a checklist, the types of socioeconomic impacts affected by the project, and the types of mitigation activities conducted. 


\section{A. PROJECT DESCRIPTION}

\section{[Same as Reponted in Estimation Reporting Form]}

A1. Title of project:

A2. Principal project developer and contact:

\begin{tabular}{|c|c|}
\hline$\because \quad \because \quad \because \quad$ Item & Pleasefill in if applicable \\
\hline Name of principal project developex & 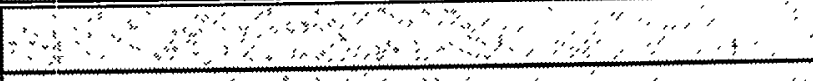 \\
\hline (h) & 8 \\
\hline$\therefore \quad 3$ & \\
\hline Telephone: & 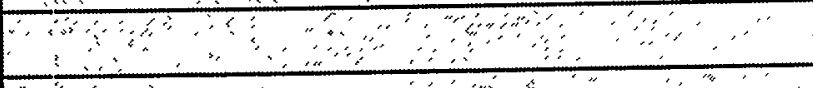 \\
\hline Eax: & $\therefore$ \\
\hline Contact person for thisproject & 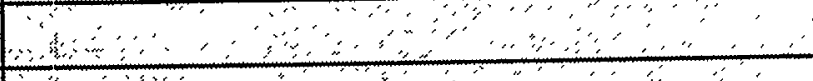 \\
\hline $\begin{aligned} \text { Mailing address: } \\
\end{aligned}$ & 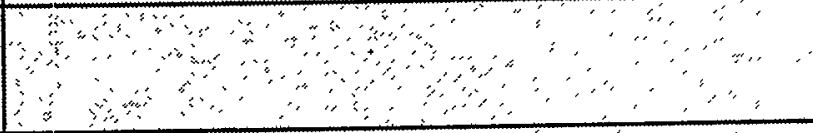 \\
\hline Telephone: & (a) \\
\hline Fax & $6 y^{2}$ \\
\hline & \\
\hline
\end{tabular}

If multiple participants are involved in the project, thien they need to assign one of the participants as the "principal project developer" to complete this form. Other participants are not allowed to report on the impacts of this specific project, to avoid multiple reporting.

\section{A3, Other participants}

List other participants:

A4. Project Description

Briefly describe the project 


\section{B. CHANGES IN CARBON STOCK}

\section{B1. Estimated Carbon Stock in Baseline [At Time of Project Registration]}

For all years of the project (1 to n) estimate the carbon stock (1) for the unadjusted baseline (without free riders), (2) for free riders, and (3) for the baseline (adjusted for free riders). Provide a separate table for each carbon pool and a total for all of the pools, Indicate the level of precision for each value.

\begin{tabular}{|c|c|c|c|c|c|c|}
\hline Estimated & $\begin{array}{l}\text { Unadjusted } \\
\text { Baseline } \\
\text { Carbon } \\
\text { (1) }\end{array}$ & $\begin{array}{l}\text { Level of } \\
\text { Precision } \\
\end{array}$ & $\begin{array}{l}\text { Carbon } \\
\text { from } \\
\text { Free } \\
\text { Riders } \\
\text { (2) }\end{array}$ & $\begin{array}{l}\text { Level of } \\
\text { Precisiona }\end{array}$ & $\begin{array}{l}\text { Without-Project } \\
\text { Baseline Carbon } \\
\quad(3=1-2) \\
\quad\end{array}$ & Level of \\
\hline $\begin{array}{l}\text { Carbon stock } \\
\text { (tC)-Year } 1\end{array}$ & 3 & & & & $\because \cdots$ & ... \\
\hline $\begin{array}{llll} & \ddots & & \\
\cdots & & \ddots & \\
\ddots & & \ddots\end{array}$ & $\because \quad \therefore \quad \therefore 4$ & & & & $\because \because \quad \because \quad \therefore$ & $\cdots$ \\
\hline $\begin{array}{l}\text { Carbon stock }(\mathbf{t C}) \\
-Y e a r \mathbf{n}^{\mathbf{b}}\end{array}$ & & & & & 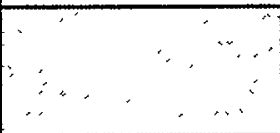 & \\
\hline
\end{tabular}

a Indicate the level of precision used for project values: use either (1) standard deviation around the mean value, or (2) general level of precision (e.g; low, medium, high) - if more information is available, additional levels of precision can be used.

$\mathrm{b}$ The "nth" year is the last year of the project monitoring period.

\section{B2. Estimated Gross Changes in Carbon from Project [At Time of Project Registration]}

For all year's of the project (1, to n), estimate (1) the carbon'stock for the unadjusted project, (2) carbon loss due to project leakage, (3) carbon gains from project spillover, (4) carbon gains from market transformation, and (5) carbon stôck for the with-project scenario (after adjustment). Provide a separate table for each carbon pool and a total for all of the pools. Indicate the levele of precision for each value. ${ }^{a}$

\begin{tabular}{|c|c|c|c|c|c|}
\hline Estimated & $\begin{array}{l}\text { Unadjusted } \\
\text { With-Project } \\
\text { Carbon } \\
\text { (1) }\end{array}$ & $\begin{array}{c}\text { Carbon from } \\
\text { Project } \\
\text { Leakage }\end{array}$ & $\begin{array}{l}\text { Carbon from } \\
\text { Positive } \\
\text { Project } \\
\text { Spillover } \\
\text { (3) }\end{array}$ & $\begin{array}{l}\text { Carbon from } \\
\text { Market } \\
\text { Transformation } \\
\text { (4) }\end{array}$ & $\begin{array}{l}\text { With-Project Carbon } \\
(5=(1+3+4)-2)\end{array}$ \\
\hline $\begin{array}{l}\text { Carbon stock' } \\
\text { (tC) - Year } 1\end{array}$ & & & 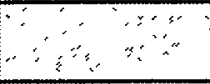 & $\therefore \quad \cdots$ & $\because$ \\
\hline : & & & & & \\
\hline $\begin{array}{l}\text { Carbon stock } \\
\text { (tC)-Year } \mathrm{n}^{\mathrm{b}}\end{array}$ & & & & & \\
\hline
\end{tabular}

a Indicate the level of precision used for project values: use either (1) standard deviation around the mean value, or (2) general level of precision (e.g., low medium, high) - if more information is available, additional levels of precision can be used:

$\mathrm{b}$ The "nth" year is the last year of the project monitoring period. 


\section{B3. Estimated Net Changes in Carbon Stock [At Timé of Project Registration]}

For all years of the project ( 1 to $n$ ), calculate the net change in carbon stock by subtracting with-project carbon (taken from Table B2) from without project baseline carbon (taken from Table B1), Provide a separate table for each carbon pool and a total for sill of the pools. Indicate the level of precision for each value.

\begin{tabular}{|c|c|c|c|c|c|c|}
\hline $\begin{array}{l}\ddots \text { Estimated } \\
\therefore \\
\because \cdots\end{array}$ & $\begin{array}{l}\text { Without- } \\
\text { Project } \\
\text { Baseline } \\
\text { Carbon } \\
\text { (i) }\end{array}$ & Pevel of & $\begin{array}{l}\text { With } \\
\text { Project } \\
\text { Carbon } \\
\text { (2) }\end{array}$ & $\begin{array}{l}\text { Level of } \\
\text { Precisiona }\end{array}$ & $\begin{array}{l}\text { Net } \\
\text { Change in } \\
\text { Carbon Stock } \\
(3=1-2)\end{array}$ & $\begin{array}{c}\text { Level of } \\
\text { Precisiona }\end{array}$ \\
\hline $\begin{array}{l}\text { Carbonstock } \\
\text { (tC)-Year } 1\end{array}$ & $\therefore \quad \therefore$ & $\begin{array}{r}3 \\
\therefore \\
\vdots\end{array}$ & & 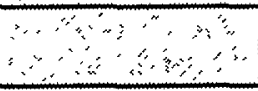 & $\begin{array}{l}\because \\
\cdots\end{array}$ & $\because \vdots$ \\
\hline $\begin{array}{l}0 \\
\therefore\end{array}$ & & & & & & $\therefore$ \\
\hline $\begin{array}{l}\text { Carbon stock } \\
\text { (tC)-Year in }\end{array}$ & & & & & 93 & 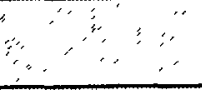 \\
\hline
\end{tabular}

a Indicate the level of precision used for project values: use either (1) standard deviation around the mean value, or (2) general level of precision (e.g., low, meditun, high) - if more information is available, additional levels of precision can be used:

b The "nth" year is the last year of the project monitoring period.

\section{B4. Re-estimated Carbon Stock in Baseline [During IProject Implementation]}

For all years of the project ( 1 to $n)$, re-estimate the carbon stock (1) for the unadjusted baseline use (without free riders), (2) for free riders, and (3) for the baseline (adjusted for free riders). Provide a separate table for each carbon pool and a total for all of the pools. Indicate the level of precision for each value.

\begin{tabular}{|l|l|l|l|l|l|l|}
\hline Re-estimated & $\begin{array}{c}\text { Unadjusted } \\
\text { Baseline } \\
\text { Carbon } \\
(1)\end{array}$ & $\begin{array}{c}\text { Level of } \\
\text { Precision }^{\mathbf{a}}\end{array}$ & $\begin{array}{c}\text { Carbon } \\
\text { from } \\
\text { Free } \\
\text { Riders } \\
\text { (2) }\end{array}$ & $\begin{array}{c}\text { Level of } \\
\text { Precision }\end{array}$ & $\begin{array}{c}\text { Without-Project } \\
\text { Baseline } \\
\text { Carbon } \\
(3=1-2)\end{array}$ & $\begin{array}{c}\text { Level of } \\
\text { Precisiona }\end{array}$ \\
\hline $\begin{array}{l}\text { Carbon stock } \\
(\mathrm{t} C)-\text { Year } 1\end{array}$ & & & & & & \\
\hline. & & & & & & \\
\hline $\begin{array}{l}\text { Carbon stock } \\
(\mathrm{tC})-\text { Year } \mathbf{n}^{\mathbf{b}}\end{array}$ & & & & & & \\
\hline
\end{tabular}

a Indicate the level of precision used for project values: use either (1) standard deviation around the mean value, or (2) general level of precision (e.g., low, medium, high) - if more information is available, additional levels of precision can be used.

$b$ The "nth" year is the last year of the project monitoring period. 


\section{B5. Measured Gross Changes in Carbon from Project [During Project Implementation]}

For all years of the project ( 1 to $n$ ), measure (1) the carbon stock for the unadjusted project, (2) carbon loss due to project leakage, (3) carbon gains from project spillover, (4) carbon gains from market transformation, and (5) carbon stock for the with-project scenario (after adjustment). Provide a separate table for each carbon pool and a total for all of the pools. Indicate the level of precision for each value. ${ }^{a}$

\begin{tabular}{|l|l|l|c|l|l|}
\hline \multicolumn{1}{|c|}{ Measured } & $\begin{array}{c}\text { Unadjusted } \\
\text { With-Project } \\
\text { Carbon } \\
\text { (1) }\end{array}$ & $\begin{array}{c}\text { Carbon from } \\
\text { Project } \\
\text { Leakage } \\
\text { (2) }\end{array}$ & $\begin{array}{c}\text { Carbon } \\
\text { from } \\
\text { Positive } \\
\text { Project } \\
\text { Spillover } \\
\text { (3) }\end{array}$ & $\begin{array}{c}\text { Carbon from } \\
\text { Market } \\
\text { Transformation } \\
\text { (4) }\end{array}$ & $\begin{array}{c}\text { With-Project } \\
\text { Carbon } \\
(5=(1+3+4)-2)\end{array}$ \\
\hline $\begin{array}{l}\text { Carbon stock } \\
(t C) \text {-Year 1 }\end{array}$ & & & & & \\
\hline$\cdot$ \\
\hline
\end{tabular}

a Indicate the level of precision used for project values: use either (1) standard deviation around the mean value, or (2) general level of precision (e.g., low, medium, high) - if more information is available, additional levels of precision can be used.

$\mathrm{b}$ The "nth" year is the last year of the project monitoring period.

\section{B6. Measured Net Changes in Carbon Stock [During Project Implementation]}

For all years of the project ( 1 to $n)$, calculate the net change in carbon stock by subtracting with-project carbon (taken from Table B5) from without-project baseline carbon (taken from Table B4). Provide a separate table for each carbon pool and a total for all of the pools. Indicate the level of precision for each value.

\begin{tabular}{|c|c|c|c|c|c|c|}
\hline Measured & $\begin{array}{l}\text { Without- } \\
\text { Project } \\
\text { Baseline } \\
\text { Carbon } \\
\text { (1) }\end{array}$ & $\begin{array}{l}\text { Level of } \\
\text { Precision }^{\mathrm{a}}\end{array}$ & $\begin{array}{l}\text { With- } \\
\text { Project } \\
\text { Carbon } \\
\text { (2) }\end{array}$ & $\begin{array}{l}\text { Level of } \\
\text { Precision }^{\mathrm{a}}\end{array}$ & $\begin{array}{c}\text { Net } \\
\text { Change in } \\
\text { Carbon Stock } \\
(3=1-2)\end{array}$ & $\begin{array}{l}\text { Level of } \\
\text { Precision }^{\mathrm{a}}\end{array}$ \\
\hline $\begin{array}{l}\text { Carbon stock } \\
\text { (tC) - Year } 1\end{array}$ & & & & & & $\cdot$ \\
\hline • & & & & & & \\
\hline $\begin{array}{l}\text { Carbon stock } \\
\text { (tC) - Year } \mathrm{n}^{\mathrm{b}}\end{array}$ & & & & & & \\
\hline
\end{tabular}

a Indicate the level of precision used for project values: use either (1) standard deviation around the mean value, or (2) general level of precision (e.g., low, medium, high) - if more information is available, additional levels of precision can be used.

$\mathrm{b}$ The "nth" year is the last year of the project monitoring period. 
B7. Data Collection and Analysis Methods

B7.1. Check one or more of the following data collection and analysis methods used for calculating changes in carbon stock:

\begin{tabular}{|c|l|}
\hline$\square$ & Modeling \\
\hline$\square$ & Remote sensing \\
\hline$\square$ & Field/site measurements \\
\hline
\end{tabular}

\section{B8. Quality Assurance Guidelines}

The Quality Assurance Guidelines (QAG) request evaluators to explain how basic methodological issues are addressed in the measurements and calculations of carbon stock. A separate sheet for each data collection and analysis method needs to be provided.

\begin{tabular}{|c|l|}
\hline Table QAG-1 & Quality assurance guidelines for modeling \\
\hline \hline Calibration & $\begin{array}{l}\text { 1. Describe how the models were calibrated to observed data. } \\
\text { 2. Describe the criteria used to judge whether the model was appropriately calibrated. } \\
\text { 3. Describe the input values that were changed to bring the simulation into calibration } \\
\text { and give the reasons why a value was changed. }\end{array}$ \\
\hline Data & $\begin{array}{l}\text { 1. Describe the data that were collected to support the analysis. } \\
\text { 2. Describe the source(s) and method(s) of collecting these data. }\end{array}$ \\
\hline Weather & Describe how the weather data was chosen for the simulation. \\
\hline Variance & Describe how confidence intervals were derived. \\
\hline
\end{tabular}

\begin{tabular}{|c|c|}
\hline Table QAG-2 & Quality assurance guidelines for remote sensing and field/site measurement \\
\hline Sampling & $\begin{array}{l}\text { 1. If a sample was used, describe the sample design (e.g., was a random sample used? } \\
\text { proportional sample? cluster sample? stratified sample?). } \\
\text { 2. Describe any procedures used to determine the size of the samples in order to } \\
\text { achieve a specific level of precision at a given level of confidence. } \\
\text { 3. If a stratified sample was used, describe how the strata were defined and how the } \\
\text { allocation to strata was determined. }\end{array}$ \\
\hline Data & See Table QAG-1. \\
\hline $\begin{array}{l}\text { Specification } \\
\text { and error }\end{array}$ & $\begin{array}{l}\text { Describe any substantial errors in measuring important variables and how these errors } \\
\text { were minimized. }\end{array}$ \\
\hline Outliers & $\begin{array}{l}\text { If outliers were identified, describe how they were identified, how many there were, } \\
\text { and how they were handled. }\end{array}$ \\
\hline Missing data & Describe how missing data were handled. \\
\hline $\begin{array}{l}\text { Comparison } \\
\text { group }\end{array}$ & $\begin{array}{l}\text { 1. If a comparison group was not used to estimate changes in carbon stock, describe } \\
\text { what was done to control for the effects of background variables (e.g., deforestation) } \\
\text { that may account for any increase or decrease in addition to the project itself. } \\
\text { 2. If a comparison group was used to estimate gross or net changes in carbon stock, } \\
\text { describe how the group was defined. }\end{array}$ \\
\hline $\begin{array}{c}\text { Measurement } \\
\text { duration }\end{array}$ & Describe the measurement periods. \\
\hline Variance & See Table QAG-1. \\
\hline
\end{tabular}




\section{B9. Free Riders}

B9.1. Describe how free ridership was evaluated, compare to estimated free ridership, and explain inconsistencies:

B10. Positive Project Spillover and Project Leakage

B10.1. Describe how positive project spillover and project leakage were evaluated, compare to estimated spillover and leakage, and explain inconsistencies. Where applicable, assess how effective options have been to minimize leakage or to account for spillover.

\section{B11. Market Transformation}

B11.1. Which of the following indicators were used to describe how the market has been transformed, or that the changes in carbon stock resulting from the project are expected to persist? [Check all that may apply]

\begin{tabular}{|c|l|}
\hline$\square$ & Changes in government standards or regulations \\
\hline$\square$ & Physical changes in production or distribution practices that are not easily undone \\
\hline$\square$ & Institutional changes in standard practice \\
\hline$\square$ & New market entrants \\
\hline$\square$ & Profitable market entities continue the market transformation \\
\hline$\square$ & Key market barriers removed or reduced \\
\hline
\end{tabular}

B11.2. Which of the following methods were used to evaluate market transformation? [Check all that may apply]

\begin{tabular}{|l|l|}
\hline$\square$ & Surveys \\
\hline$\square$ & Sales tracking \\
\hline$\square$ & Multivariate statistical models \\
\hline$\square$ & Modeling of market processes \\
\hline$\square$ & Econometric studies \\
\hline$\square$ & Process evaluations \\
\hline
\end{tabular}


B11.3. Compare measured changes from market transformation to estimated changes from market transformation, and explain inconsistencies:

\section{B12. Uncertainty}

B12.1. Identify and discuss key measurement and operational uncertainties affecting estimates of carbon stock:

Measurement Uncertainties:

Operational Uncertainties:

B12.2. Describe the project's contingency plan that identifies potential project uncertainties and discusses the contingencies provided within the project estimates to manage the uncertainties.

Contingency plan:

B12.3. Assess the possibility of local or regional political and economic instability in the short-term (5 years or less) and how this may affect project performance.

Political and economic instabilities: 


\section{ENVIRONMENTAL IMPACTS}

C1. Identify and check whether the project will have one or more environmental impacts and, where appropriate, describe the type of impact. If there are differences or discrepancies with the information in the Monitoring and Evaluation Reporting Form, explain the inconsistencies.

\begin{tabular}{|c|c|c|}
\hline & \multicolumn{2}{|r|}{ Potential Environmental Impacts } \\
\hline & Impact Category & Comments \\
\hline ב & Agrochemicals & Application and disposal of pesticides and fertilizers \\
\hline$\square$ & Biological diversity & $\begin{array}{l}\text { Endangered plants and animal species, critical habitats, and } \\
\text { protected areas }\end{array}$ \\
\hline $\bar{\square}$ & $\begin{array}{l}\text { Coastal and marine resources } \\
\text { management }\end{array}$ & Coral reefs, mangroves, and wetlands \\
\hline $\bar{a}$ & Dams and reservoirs* & Implementation and operation \\
\hline $\bar{a}$ & $\begin{array}{l}\text { International treaties and } \\
\text { agreements on environment } \\
\text { and natural resources }\end{array}$ & $\begin{array}{l}\text { Status and application of current and pending treaties and } \\
\text { agreements, including notification requirements }\end{array}$ \\
\hline $\bar{\square}$ & International waterways & Quality or quantity of water flows \\
\hline 口 & Natural hazards & Measures to address earthquakes, floods, volcanic activity, etc. \\
\hline 口 & Soil conservation & Protection and management \\
\hline 口 & Sustainable land use & Multiple use management and non-declining yields \\
\hline$\overline{0}$ & Tropical forests & Protection and management \\
\hline $\mathrm{Q}$ & Water quality & Protection and enhancement \\
\hline$\square$ & Watersheds & Protection and management \\
\hline$\square$ & Wetlands & $\begin{array}{l}\text { Protection and management (e.g., estuaries, lakes, mangroves, } \\
\text { marshes and swamps) }\end{array}$ \\
\hline [ & Wildlands & Protection and management \\
\hline$\vec{\square}$ & $\begin{array}{l}\text { Wildlife and habitat protection } \\
\text { or enhancement }\end{array}$ & Protection and enhancement \\
\hline
\end{tabular}

*Without project

C2. Identify any proposed mitigation activities.

Mitigation activities: 


\section{SOCIOECONOMIC IMPACTS}

D1. Indicate whether the project will have one or more socioeconomic impacts and, where appropriate, describe the type of impact. If there are differences or discrepancies with the information in the Estimation Reporting Form, explain the inconsistencies.

\begin{tabular}{|c|c|c|c|}
\hline$\square$ & $\begin{array}{l}\text { Concerns of local communities and } \\
\text { indigenous peoples regarding all } \\
\text { project operations }\end{array}$ & {[} & Land settlement \\
\hline$\square$ & $\begin{array}{l}\text { Cultural properties (archeological sites, } \\
\text { historic monuments, and historic } \\
\text { settlements) }\end{array}$ & [] & $\begin{array}{l}\text { Legal and customary land and resource use } \\
\text { rights of local communities and indigenous } \\
\text { peoples }\end{array}$ \\
\hline$\square$ & Distribution of income and of wealth & $\square$ & $\begin{array}{l}\text { Long-term income opportunities for local } \\
\text { populations (e.g., jobs) }\end{array}$ \\
\hline ㅁ & Employment rights & 口 & Maintaining and fostering local cultures \\
\hline $\bar{Q}$ & Gender equity & $\square$ & Public participation and capacity building \\
\hline $\bar{\square}$ & Human rights & $\bar{\square}$ & Quality of life (local or regional) \\
\hline D & $\begin{array}{l}\text { Induced development and other } \\
\text { sociocultural aspects (secondary } \\
\text { growth of settlements and } \\
\text { infrastructure) }\end{array}$ & $\bar{\square}$ & Tenure and land use rights \\
\hline$\square$ & Involuntary resettlement & $\square$ & $\begin{array}{l}\text { Tribal peoples (measures to address the rights } \\
\text { of tribal peoples, including traditional land } \\
\text { and water rights) }\end{array}$ \\
\hline
\end{tabular}

D2. Identify any proposed mitigation activities.

Mitigation activities: 


\section{APPENDIX C}

\section{VERIFICATION REPORTING FORM: FORESTRY PROJECTS}

The Verification Reporting Form is to be used for verifying the measured changes in carbon stock of forestry projects as reported in the Monitoring and Evaluation Form (Appendix B). There are four main sections in this form.

Verification refers to establishing whether the measured changes in carbon stock actually occurred, similar to an accounting audit performed by an objective, certified party. External (third-party) verification processes need to be put in place and not rely on internal verification or audits. As part of the verification exercise, an overall assessment of the quality and completeness of each of the GHG impact estimates needs to be made by completing the Verification Reporting Form, similar to the Monitoring and Evaluation Reporting Form. For forestry projects, verifying baseline and post-project conditions may involve research studies, surveys, or other assessments (see Section 6), as well as requesting documentation on key aspects of the project. At a minimum, the verifier should ask the following general questions:

\begin{tabular}{|c|l|}
\hline & Are the monitoring and evaluation methods well documented and reproducible? \\
\hline$\square$ & Have the results been checked against other methods? \\
\hline$\square$ & $\begin{array}{l}\text { Have the results been compared for reasonableness with outside or independently published } \\
\text { estimates? }\end{array}$ \\
\hline$\square$ & $\begin{array}{l}\text { Are there any environmental or socioeconomic impacts that need to be evaluated in more } \\
\text { detail? }\end{array}$ \\
\hline
\end{tabular}

In Section A (Project Description), the verifier provides the following information: the title of the project, contact information on the principal project developer, and a brief description of the project. If multiple participants are involved in the project, then these people should be listed. Much of this information will be identical to the information contained in the Monitoring and Evaluation Reporting Form (Appendix B) and, therefore, the relevant fields are shaded.

In Section B (Changes in Carbon Stock), the verifier first provides information on the re-estimated baseline, measured gross changes in the carbon stock due to the project, and measured net changes in the carbon stock (primarily drawn from the Monitoring and Evaluation Reporting Form in Appendix B; these, sections are shaded). The verifier then provides information on a verified baseline, verified gross changes 
in the carbon stock due to the project, and verified net changes in the carbon stock. A comparison of the measured and verified impacts provides information on the performance and effectiveness of the project. If additional data collection and analysis was conducted, the verifier provides information on the data collection and analysis methods used for verifying changes in carbon stock.

The verifier also needs to indicate whether key methodological issues were addressed for each method by responding to quality assurance guidelines. The verifier describes how free riders, positive project spillover, project leakage, and market transformation were verified, and compares these calculations with those measured during project implementation. If there are differences or discrepancies, the verifier needs to explain the inconsistencies. In the last part of Section B, the verifier provides information on the measurement and operational uncertainties affecting the project (including a description of a contingency plan). If there are differences or discrepancies with the information in the Monitoring and Evaluation Reporting Form, the verifier needs to explain the inconsistencies.

In Section C (Environmental Impacts), the verifier indicates, via a checklist, the types of environmental impacts affected by the project, the types of mitigation activities conducted, and consistency of the project with environmental laws and, if applicable, environmental impact statements. If there are differences or discrepancies with the information in the Monitoring and Evaluation Reporting Form, the verifier needs to explain the inconsistencies.

In Section D (Socioeconomic Impacts), the verifier indicates, via a checklist, the types of socioeconomic impacts affected by the project, and the types of mitigation activities conducted. If there are differences or discrepancies with the information in the Monitoring and Evaluation Reporting Form, the verifier needs to explain the inconsistencies. 


\section{A. PROJECT DESCRIP̈TION}

[Same as Reported in Monitoring and Evaluation Reporting Form]

\section{A1. Title of project:}

A2. Principal project developer and contact

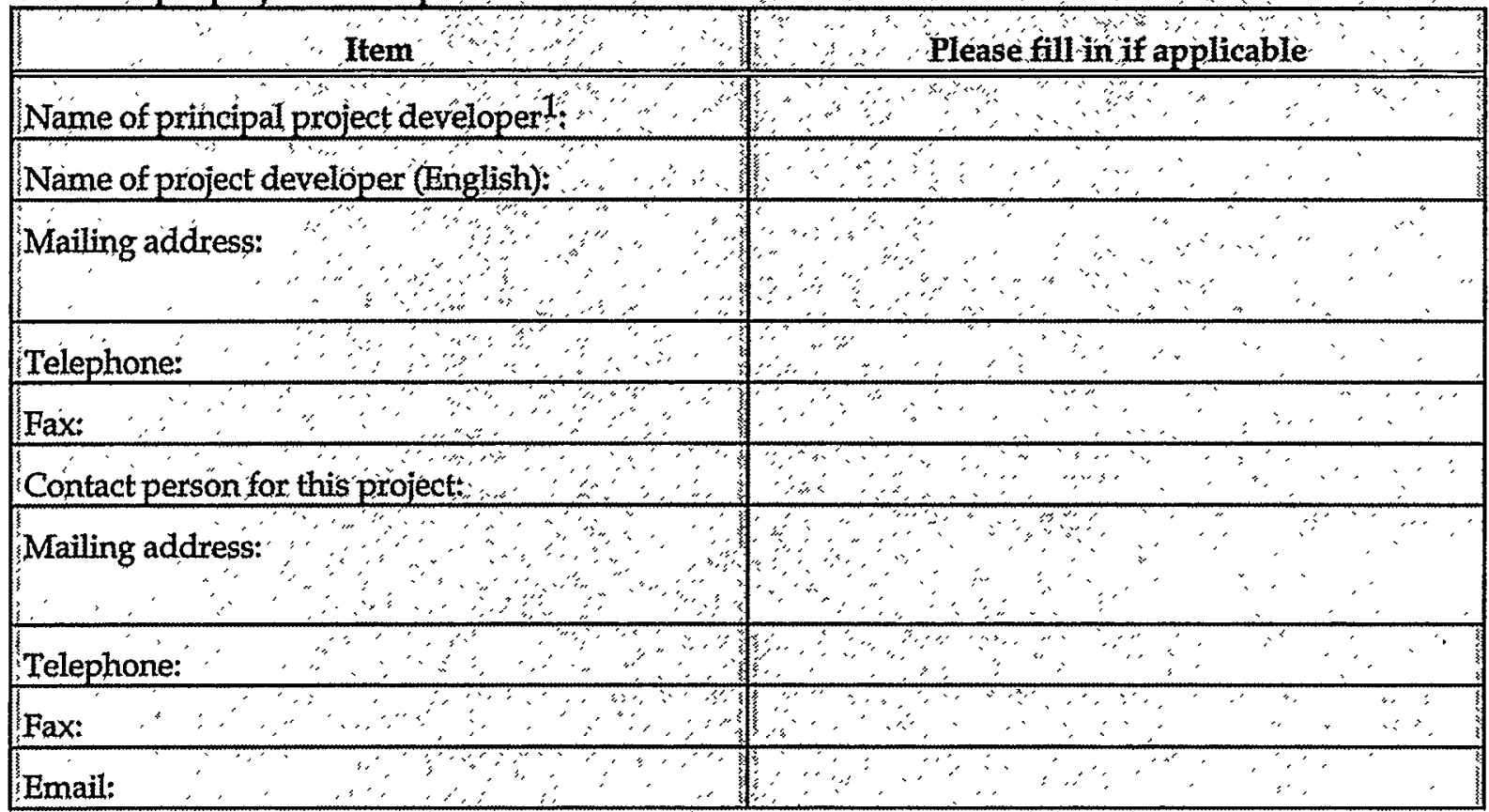

IIf multiple participants are involved in the project, then they need to assign one of the participants as the "principal' project developer" to complete this form. Other participants are not allowed to report on the impacts of this specific project, to avoid multiple reporting.

\section{A3. Other participants}

List other participants:

\section{A4. Project Description}

Briefly describe the project: 


\section{B. CHANGES IN CARBON STOCK}

B1. Re-estimated Carbon Stock in Baseline ISame as Reported in Section B4 in Monitoring and Evâliation Reporting Form 1

For all years of the project ( 1 to m), ine-stimate the carbon stock (1) for the unadjusted baseline (without free riders), (2) for free riders, and (3) for the baselirie (adjusted for free riders). Provide a separate table for each carbon pool and total for all of the pools. In dicate the level of prectsion for each value.

\begin{tabular}{|c|c|c|c|c|c|c|}
\hline Re-estimated & $\begin{array}{l}\text { Unadjusted } \\
\text { Baseline } \\
\text { Carbon } \\
\text { (1) }\end{array}$ & $\begin{array}{c}\text { Level of } \\
\text { Precisiona }\end{array}$ & $\begin{array}{l}\text { Carbon } \\
\text { from } \\
\text { Free } \\
\text { Riders } \\
\text { (2) }\end{array}$ & $\begin{array}{c}\text { Level of } \\
\text { Precision } \\
\end{array}$ & $\begin{array}{c}\text { Without-project } \\
\text { Baseline } \\
\text { Carbon } \\
(3=1-2)\end{array}$ & $\begin{array}{l}\text { Level of } \\
\text { Precision } \\
\end{array}$ \\
\hline $\begin{array}{l}\text { Carbon stock } \\
\text { (tc)-Year } 1\end{array}$ & $\because$\begin{tabular}{c}
3 \\
\hdashline
\end{tabular} & 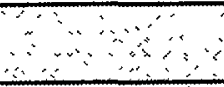 & & & 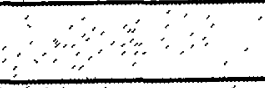 & \\
\hline & $\begin{array}{l}\therefore: 3 \\
\vdots \because \cdots \\
\because\end{array}$ & & & & & \\
\hline arbon stock & & & & & & \\
\hline
\end{tabular}

andicate the level of precision used for project values use either (1) standard deviation around the mean value, or (2) general level of precision (e.g.tow, medium, high) - if more information is available, additional levels of precision can be used:

b The "nith" year is the last year of the project monitoring period

B2. Measured Gross Changes in Carbon from Project Isame as Reported in Section B5 in Monitoring and Evaluation Reporting Form 1

For all years of the project (1 ton), measure (1) the carbon stock for the unadjusted project, (2) carbon loss due to project leakage (3) carbon gains from project spillover (4) carbon gains from market transformation, and (5) carbon stock for the with-project scenario (after adjustment). Provide a separate table for each carbon pool and a total for all of the pools. Indicate the level of precision for each value a

\begin{tabular}{|c|c|c|c|c|c|}
\hline \begin{tabular}{l} 
Measured \\
M \\
\hdashline
\end{tabular} & $\begin{array}{l}\text { Unadjusted } \\
\text { With-Project } \\
\text { Carbon } \\
\text { (1) }\end{array}$ & $\begin{array}{l}\text { Catbon from } \\
\text { Project } \\
\text { Leakage }\end{array}$ & $\begin{array}{l}\text { Carbon } \\
\text { from } \\
\text { Positive } \\
\text { Project } \\
\text { Spillover } \\
\text { (a) }\end{array}$ & $\begin{array}{l}\text { Carbon from } \\
\text { Market } \\
\text { Transformation } \\
\text { (4) }\end{array}$ & $\begin{array}{l}\text { With-Project } \\
(5=(1+3+4)-2) \\
\text { Carbon }\end{array}$ \\
\hline $\begin{array}{l}\text { Carbon stock } \\
(\mathrm{tC})-\text { Year } 1 \text { " }\end{array}$ & & $\therefore$ & , & 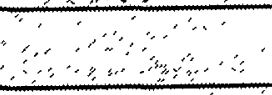 & \\
\hline & & & & & \\
\hline $\begin{array}{l}\text { Carbon stock } \\
\text { (tC)-Year } n^{b}\end{array}$ & & & & & \\
\hline
\end{tabular}

andicate the level of precision used for project valuest use either (1) standard deviation around the mean value, or (2) general level of precision (e,g, low medium, high) - if more information is available, additional levels of precision can be ùsed.

b $\mathrm{The}^{\text {" }} \mathrm{n \textrm {h }}$ " year is the last year of the project monitoning period. 


\section{B3. Measured Net Changes in Carbon Stock ISame as Reported in Section B6 in Monitoring and}

Evaluation Reporting Form?

For all years of the project ( 1 to $n$ ), calculate the net change in carbon stock by subtracting with-project carbon (taken from Table B5) from without-project baseline carbon (taken from Table B4). Provide a separate table for each carbon pool and a total for all of the pools. Indicate the level of precision for each value.

\begin{tabular}{|c|c|c|c|c|c|c|}
\hline Measured & $\begin{array}{l}\text { Without- } \\
\text { Project } \\
\text { Baseline } \\
\text { Carbon } \\
\therefore(1)\end{array}$ & $\begin{array}{l}\text { Levelót } \\
\text { Precisiona }\end{array}$ & $\begin{array}{l}\text { With } \\
\text { Project } \\
\text { Carbon } \\
\text { (2) }\end{array}$ & $\begin{array}{l}\text { Level of } \\
\text { Precisiona }\end{array}$ & $\begin{array}{l}\text { Net } \\
\text { Change in } \\
\text { Carbon Stock } \\
(3=1-2)\end{array}$ & $\begin{array}{l}\text { Level of } \\
\text { Precisiona }\end{array}$ \\
\hline $\begin{array}{l}\text { Carbon stock } \\
\text { (tC) - Year } 1\end{array}$ & $\because \cdots$ & & $\therefore \therefore \therefore$ & $\because, \quad, \cdots$ & $\therefore ;$ & $\therefore$ \\
\hline , & & & & & $\begin{array}{l}\because \cdots, \cdots \\
\ddots, \quad \therefore \\
\therefore,\end{array}$ & \\
\hline $\begin{array}{l}\text { Carbon stock } \\
\text { (tC) - Year i b }\end{array}$ & & & 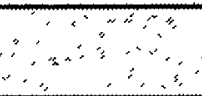 & 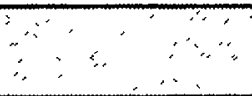 & 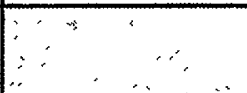 & "., \\
\hline
\end{tabular}

a Indicate the level of precision used for project values: use either (1) standard deviation around the mean value, or (2) general level of precision (e.g, low, medium, high) - if more information is available, additional levels of precision can be used.

b The "nth" year is the last year of the project monitoring period.

\section{B4. Verified Carbon Stock in Baseline (to be completed by verifier)}

For all years of the project ( 1 to $n$ ), verify the carbon stock (1) for the unadjusted baseline use (without free riders), (2) for free riders, and (3) for the baseline (adjusted for free riders). Baseline results may be different than those reported in the Monitoring and Evaluation Reporting Form. Provide a separate table for each carbon pool and a total for all of the pools. Indicate the level of precision for each value. If there are no changes to what has been reported, use the values in Table B1 above.

\begin{tabular}{|l|c|c|c|c|c|c|}
\hline Verified & $\begin{array}{c}\text { Unadjusted } \\
\text { Baseline } \\
\text { Carbon } \\
(\mathbf{1})\end{array}$ & $\begin{array}{c}\text { Level of } \\
\text { Precision }\end{array}$ & $\begin{array}{c}\text { Carbon } \\
\text { from } \\
\text { Free } \\
\text { Riders } \\
\text { (2) }\end{array}$ & $\begin{array}{c}\text { Level of } \\
\text { Precision }^{\text {a }}\end{array}$ & $\begin{array}{c}\text { Without-Project } \\
\text { Baseline } \\
\text { Carbon } \\
\text { (3=1-2) }\end{array}$ & $\begin{array}{c}\text { Level of } \\
\text { Precision }^{\text {a }}\end{array}$ \\
\hline $\begin{array}{l}\text { Carbon stock } \\
\text { (tC)-Year 1 }\end{array}$ & & & & & & \\
\hline$\cdot$ \\
\hline
\end{tabular}

a Indicate the level of precision used for project values: use either (1) standard deviation around the mean value, or (2) general level of precision (e.g., low, medium, high) - if more information is available, additional levels of precision can be used.

b The "nth" year is the last year of the project monitoring period. 


\section{B5. Verified Gross Changes in Carbon from Project (to be completed by verifier)}

For all years of the project ( 1 to $n)$, measure (1) the carbon stock for the unadjusted project, (2) carbon loss due to project leakage, (3) carbon gains from project spillover, (4) carbon gains from market transformation, and (5) carbon stock for the with-project scenario (after adjustment). Monitored results may be different than those reported in the Monitoring and Evaluation Reporting Form. Provide a separate table for each carbon pool and a total for: all of the pools. Indicate the level of precision for each value. ${ }^{a}$ If there are no changes to what has been reported, use the values in Table B2 above.

\begin{tabular}{|l|c|c|c|c|c|}
\hline \multicolumn{1}{|c|}{ Verified } & $\begin{array}{c}\text { Unadjusted } \\
\text { With -Project } \\
\text { Carbon } \\
(1)\end{array}$ & $\begin{array}{c}\text { Carbon from } \\
\text { Project } \\
\text { Leakage } \\
\text { (2) }\end{array}$ & $\begin{array}{c}\text { Carbon } \\
\text { from } \\
\text { Positive } \\
\text { Project } \\
\text { Spillover } \\
\text { (3) }\end{array}$ & $\begin{array}{c}\text { Carbon from } \\
\text { Market } \\
\text { Transformation } \\
(4)\end{array}$ & $\begin{array}{c}\text { With-Project } \\
\text { Carbon } \\
(5=(1+3+4)-2)\end{array}$ \\
\hline $\begin{array}{l}\text { Carbon stock } \\
(\mathrm{tC})-\text { Year } 1\end{array}$ & & & & & \\
\hline$\cdot$ & & & & & \\
\hline
\end{tabular}

a Indicate the level of precision used for project values: use either (1) standard deviation around the mean value, or (2) general level of precision (e.g., low, medium, high) - if more information is available, additional levels of precision can be used.

$b$ The "nth" year is the last year of the project monitoring period.

\section{B6. Verified Net Changes in Carbon Stock (to be completed by verifier)}

For all years of the project ( 1 to $\mathrm{n}$ ), calculate the net change in carbon stock by subtracting with-project carbon (taken from Table B5) from without-project baseline carbon (taken from Table B4). Provide a separate table for each carbon pool and a total for all of the pools. Indicate the level of precision for each value. ${ }^{a}$ If there are no changes to what has been reported, use the values in Table B3 above.

\begin{tabular}{|l|l|l|l|l|l|l|}
\hline Verified & $\begin{array}{c}\text { Without- } \\
\text { Project } \\
\text { Baseline } \\
\text { Carbon } \\
\text { (1) }\end{array}$ & $\begin{array}{c}\text { Level of } \\
\text { Precision }^{\mathbf{a}}\end{array}$ & $\begin{array}{c}\text { With } \\
\text { Project } \\
\text { Carbon } \\
\text { (2) }\end{array}$ & $\begin{array}{c}\text { Level of } \\
\text { Precision }^{\mathbf{a}}\end{array}$ & $\begin{array}{c}\text { Net } \\
\text { Change in } \\
\text { Carbon Stock } \\
\text { (3=1-2) }\end{array}$ & $\begin{array}{c}\text { Level of } \\
\text { Precision }^{\mathbf{a}}\end{array}$ \\
\hline $\begin{array}{l}\text { Carbon stock } \\
(\mathrm{tC})-\text { Year 1 }\end{array}$ & & & & & & \\
\hline$\cdot$ & & & & & & \\
\hline $\begin{array}{l}\text { Carbon stock } \\
\text { (tC) - Year } \mathbf{n}^{\mathbf{b}}\end{array}$ & & & & & & \\
\hline
\end{tabular}

a Indicate the level of precision used for project values: use either (1) standard deviation around the mean value, or (2) general level of precision (e.g., low, medium, high) - if more information is available, additional levels of precision can be used.

$b$ The "nth" year is the last year of the project monitoring period. 
B7. Data Collection and Analysis Methods [Only to be completed by verifier if additional data collection and analysis were conducted as part of verification]

B7.1. Check one or more of the following data collection and analysis methods used for calculating changes in carbon stock:

\begin{tabular}{|c|l|}
\hline$\square$ & Modeling \\
\hline$D$ & Remote sensing \\
\hline$D$ & Field/site measurements \\
\hline
\end{tabular}

B8. Quality Assurance Guidelines (to be completed by verifier)

The Quality Assurance Guidelines (QAG) request evaluators to explain how basic methodological issues are addressed in the measurements and calculations of carbon stock. A separate sheet for each data collection and analysis method needs to be provided. Check the box to indicate that these issues were addressed. If not addressed, or if there were problems, discuss on a separate sheet for each table.

\begin{tabular}{|c|c|l|}
\hline Table QAG-1 & Quality assurance guidelines for modeling \\
\hline \hline Calibration & $\square$ & $\begin{array}{l}\text { 1. Was there a description of how the models were calibrated to observed data? } \\
\text { 2. Was there a description of the criteria used to calibrate the model? } \\
\text { 3. Was there a description of the input values changed to bring the simulation } \\
\text { into calibration? And were reasons given for why a value was changed? }\end{array}$ \\
\hline Data & $\square$ & $\begin{array}{l}\text { 1. Was there a description of the data collection process that supported the } \\
\text { analysis? }\end{array}$ \\
\hline Weather & $\square$ & 2. Was there a description of the source(s) and method(s) of collecting these data? \\
\hline Variance & $\square$ & Was there a description on how the weather data was chosen for the simulation? \\
\hline
\end{tabular}




\begin{tabular}{|c|c|l|l|}
\hline Table QAG-2 & Quality assurance guidelines for remote sensing and field/site measurement \\
\hline \hline Sampling & $\square$ & $\begin{array}{l}\text { 1. If a sample was used, was there a description of the sample design (e.g., was a } \\
\text { random sample used? proportional sample? cluster sample? stratified } \\
\text { sample?)? } \\
\text { 2. Was there a description of the procedures used to determine the size of the } \\
\text { samples in order to achieve a specific level of precision at a given level of } \\
\text { confidence? }\end{array}$ \\
\hline $\begin{array}{c}\text { 3. If a stratified sample was used, was there a description of how the strata were } \\
\text { defined and the allocation to strata? }\end{array}$ \\
\hline $\begin{array}{c}\text { Specification } \\
\text { and error }\end{array}$ & $\square$ & \begin{tabular}{l} 
See Table QAG-1. \\
\hline Outliers \\
there a description of the process used to minimize these errors?
\end{tabular} \\
\hline Missing data & $\square$ & $\begin{array}{l}\text { Was there a description of how outliers were identified, how many there were, } \\
\text { and how they were handled? }\end{array}$ \\
\hline $\begin{array}{c}\text { Comparison } \\
\text { group }\end{array}$ & $\square$ & $\begin{array}{l}\text { Was there a description of how missing data were handled? } \\
\text { 1.If a comparison group was not used to estimate gross or net changes in carbon } \\
\text { stock, was there a description of what was done to control for the effects that } \\
\text { may account for any increase or decrease in addition to the project itself? }\end{array}$ \\
\hline $\begin{array}{c}\text { Measurement } \\
\text { duration }\end{array}$ & $\square$ & $\begin{array}{l}\text { Was there a description of the measurement periods? } \\
\text { there a descron group was used to estimate changes in carbon stock, was }\end{array}$ \\
\hline Variance & $\square$ & See Table QAG-1. \\
\hline
\end{tabular}

B9. Free Riders [to be completed by verifier]

B9.1. Describe how free ridership was evaluated, compare to measured free ridership, and explain inconsistencies:

B10. Positive Project Spillover and Project Leakage [to be completed by verifier ]

B10.1. Describe how positive project spillover and project leakage were identified and evaluated, compare to measured spillover and leakage, explain inconsistencies, and assess the effectiveness of options within the project to minimize leakage or account for spillover: 
B11. Market Transformation [Only to be completed by verifier if additional data collection and analysis were conducted as part of verification]

B11.1. Which of the following indicators were used to describe how the market has been transformed, or that the changes in carbon stock resulting from the project are expected to persist? [Check all that may apply]

\begin{tabular}{|c|l|}
\hline$\square$ & Changes in government standards or regulations \\
\hline$\square$ & Physical changes in production or distribution practices that are not easily undone \\
\hline$\square$ & Institutional changes in standard practice \\
\hline$\square$ & New market entrants \\
\hline$\square$ & Profitable market entities continue the market transformation \\
\hline$\square$ & Key market barriers removed or reduced \\
\hline
\end{tabular}

B11.2. Which of the following methods were used to evaluate market transformation? [Check all that may apply]

\begin{tabular}{|c|l|}
\hline$\square$ & Surveys \\
\hline$\square$ & Sales tracking \\
\hline$\square$ & Multivariate statistical models \\
\hline$\square$ & Modeling of market processes \\
\hline$\square$ & Econometric studies \\
\hline$\square$ & Process evaluations \\
\hline
\end{tabular}

B11.3. Compare verified changes from market transformation to measured changes from market transformation, and explain inconsistencies:

B12. Uncertainty [to be completed by verifier ]

B12.1. Identify and discuss key measurement and operational uncertainties affecting estimates of carbon stock. If there are differences or discrepancies with the information in the Monitoring and Evaluation Reporting Form, explain the inconsistencies.

Measurement Uncertainties:

Operational Uncertainties: 
B12.2. Describe the project's contingency plan that identifies potential project uncertainties and discusses the contingencies provided. within the project estimates to manage the uncertainties.

Contingency plan:

B12.3. Assess the possibility of local or regional political and economic instability in the shortterm (5 years or less) and how this may affect project performance.

Political and economic instabilities: 


\section{ENVIRONMENTAL IMPACTS}

C1. Identify and check whether the project will have one or more environmental impacts and, where appropriate, describe the type of impact. [to be completed by verifier ]. If there are differences or discrepancies with the information in the Monitoring and Evaluation Reporting Form, explain the inconsistencies. [to be completed by verifier]

\begin{tabular}{|c|c|c|}
\hline & \multicolumn{2}{|r|}{ Potential Environmental Impacts } \\
\hline & Impact Category & Comments \\
\hline 口 & Agrochemicals & Application and disposal of pesticides and fertilizers \\
\hline$\overline{0}$ & Biological diversity & $\begin{array}{l}\text { Endangered plants and animal species, critical habitats, and } \\
\text { protected areas }\end{array}$ \\
\hline$\overline{0}$ & $\begin{array}{l}\text { Coastal and marine resources } \\
\text { management }\end{array}$ & Coral reefs, mangroves, and wetlands \\
\hline 口 & Dams and reservoirs* & Implementation and operation \\
\hline $\bar{\square}$ & $\begin{array}{l}\text { International treaties and } \\
\text { agreements on environment } \\
\text { and natural resources }\end{array}$ & $\begin{array}{l}\text { Status and application of current and pending treaties and } \\
\text { agreements, including notification requirements }\end{array}$ \\
\hline$\overline{0}$ & International waterways & Quality or quantity of water flows \\
\hline $\bar{\square}$ & Natural hazards & Measures to address earthquakes, floods, volcanic activity, etc. \\
\hline $\bar{\square}$ & Soil conservation & Protection and management \\
\hline $\bar{\square}$ & Sustainable land use & Multiple use management and non-declining yields \\
\hline $\bar{\square}$ & Tropical forests & Protection and management \\
\hline $\bar{\square}$ & Water quality & Protection and enhancement \\
\hline$\underline{\square}$ & Watersheds & Protection and management \\
\hline $\bar{\square}$ & Wetlands & $\begin{array}{l}\text { Protection and management (e.g., estuaries, lakes, mangroves, } \\
\text { marshes and swamps) }\end{array}$ \\
\hline a & Wildlands & Protection and management \\
\hline$\square$ & $\begin{array}{l}\text { Wildlife and habitat protection } \\
\text { or enhancement }\end{array}$ & Protection and enhancement \\
\hline
\end{tabular}

*Without project

C2. Identify any proposed mitigation. [to be completed by verifier ]

Mitigation activities: 
C3. Indicate whether an environmental impact statement (EIS) has been filed and that the response to the checklist of environmental impacts is consistent with the EIS. [to be completed by verifier ]

\begin{tabular}{|c|l|}
\hline$\square$ & EIS filed \\
\hline$\square$ & EIS not filed \\
\hline & \\
\hline$\square$ & Checklist consistent with EIS \\
\hline$\square$ & Checklist not consistent with EIS. Explain reasons: \\
& \\
\hline
\end{tabular}

C4. Indicate whether any environmental laws apply to these impacts and that the response to the checklist of environmental impacts is consistent with the environmental laws. [to be completed by verifier ]

\begin{tabular}{|c|l|}
\hline & Applicable environmental laws \\
\hline$\square$ & Checklist consistent with environmental laws \\
\hline$\square$ & Checklist not consistent with environmental laws. Explain reasons: \\
& \\
\hline
\end{tabular}




\section{SOCIOECONOMIC IMPACTS}

D1. Identify and check whether the project will have one or more socioeconomic impacts and, where appropriate, describe the type of impact. If there are differences or discrepancies with the information in the Monitoring and Evaluation Reporting Form, explain the inconsistencies. [to be completed by verifier ]

\begin{tabular}{|c|c|c|c|}
\hline 口 & $\begin{array}{l}\text { Concerns of local communities and } \\
\text { indigenous peoples regarding all } \\
\text { project operations }\end{array}$ & $\square$ & Land settlement \\
\hline$\square$ & $\begin{array}{l}\text { Cultural properties (archeological sites, } \\
\text { historic monuments, and historic } \\
\text { settlements) }\end{array}$ & $\square$ & $\begin{array}{l}\text { Legal and customary land and resource use } \\
\text { rights of local communities and indigenous } \\
\text { peoples }\end{array}$ \\
\hline$\square$ & Distribution of income and of wealth & $\square$ & $\begin{array}{l}\text { Long-term income opportunities for local } \\
\text { populations (e.g., jobs) }\end{array}$ \\
\hline 므 & Employment rights & 口 & Maintaining and fostering local cultures \\
\hline 므 & Gender equity & 口 & Public participation and capacity building \\
\hline Q & Human rights & $\square$ & Quality of life (local or regional) \\
\hline$\square$ & $\begin{array}{l}\text { Induced development and other } \\
\text { sociocultural aspects (secondary } \\
\text { growth of settlements and } \\
\text { infrastructure) }\end{array}$ & $\square$ & Tenure and land use rights \\
\hline 口 & Involuntary resettlement & $\square$ & $\begin{array}{l}\text { Tribal peoples (measures to address the rights } \\
\text { of tribal peoples, including traditional land } \\
\text { and water rights) }\end{array}$ \\
\hline
\end{tabular}

D2. Identify any proposed mitigation activities. [to be completed by verifier ]

Mitigation activities: 